
CONSTANT PROPORTION PORTFOLIO INSURANCE IN DEFINED-CONTRIBUTION PENSION PLAN MANAGEMENT

A THESIS SUBMITTED TO

THE GRADUATE SCHOOL OF APPLIED MATHEMATICS

$\mathrm{OF}$

MIDDLE EAST TECHNICAL UNIVERSITY

BY

BÜŞRA ZEYNEP TEMOÇİN

IN PARTIAL FULFILLMENT OF THE REQUIREMENTS

FOR

THE DEGREE OF DOCTOR OF PHILOSOPHY

IN

FINANCIAL MATHEMATICS

DECEMBER 2015 

Approval of the thesis:

\section{CONSTANT PROPORTION PORTFOLIO INSURANCE IN DEFINED-CONTRIBUTION PENSION PLAN MANAGEMENT}

submitted by BÜŞRA ZEYNEP TEMOÇİN in partial fulfillment of the requirements for the degree of Doctor of Philosophy in Department of Financial Mathematics, Middle East Technical University by,

Prof. Dr. Bülent Karasözen

Director, Graduate School of Applied Mathematics

Assoc. Prof. Dr. Ali Devin Sezer

Head of Department, Financial Mathematics

Assoc. Prof. Dr. A. Sevtap Selçuk-Kestel

Supervisor, Institute of Applied Mathematics, METU

Prof. Dr. Ralf Korn

Co-supervisor, Department of Mathematics, TU Kaiserslautern, Germany

\section{Examining Committee Members:}

Assoc. Prof. Dr. Ömür Uğur

Institute of Applied Mathematics, METU

Assoc. Prof. Dr. A. Sevtap Selçuk-Kestel

Institute of Applied Mathematics, METU

Assoc. Dr. Yeliz Yolcu Okur

Institute of Applied Mathematics, METU

Assist. Prof. Dr. Şule Şahin

Department of Actuarial Science, Hacettepe University

Assist. Prof. Dr. Özge Sezgin Alp

Department of Insurance and Risk Management, Başkent University

Date: 

I hereby declare that all information in this document has been obtained and presented in accordance with academic rules and ethical conduct. I also declare that, as required by these rules and conduct, I have fully cited and referenced all material and results that are not original to this work.

Name, Last Name: BÜŞRA ZEYNEP TEMOÇİN

Signature 


\begin{abstract}
CONSTANT PROPORTION PORTFOLIO INSURANCE IN

DEFINED-CONTRIBUTION PENSION PLAN MANAGEMENT
\end{abstract}

\author{
Temoçin, Büşra Zeynep \\ Ph.D., Department of Financial Mathematics \\ Supervisor : : Assoc. Prof. Dr. A. Sevtap Selçuk-Kestel \\ Co-Supervisor : Prof. Dr. Ralf Korn
}

December 2015, 94 pages

In this thesis, various portfolio insurance strategies are designed and proposed for portfolio management of defined-contribution type pension plans. These type of plans consist of consecutive and defined premium payments which are invested in financial markets and lead to a benefit that will be collected at the retirement. Since the beneficiary faces all of the financial risk throughout the plan, a capital protection mechanism is needed in such retirement systems. The main contribution of the present research is to formulate this problem using different portfolio insurance methods with the aim of providing a minimum guarantee on the portfolio value under the assumption of stochastic floor processes. More specifically, various versions of Constant Proportion Portfolio Insurance (CPPI) method with distinctive floor processes are developed in different markets and with certain trading constraints. Modifying the classical dynamics of CPPI for the pension fund framework, the portfolio efficiencies of these newly introduced strategies are analyzed in continuous- and discrete-time trading markets.

In a market with continuous-time trading, two distinctive CPPI strategies are introduced. With the aim of eliminating the discontinuities resulting from the contribution payments, a replication strategy is carried out and a continuous-time environment is achieved. Through a detailed sensitivity analysis and terminal wealth distributions illustrated by Monte Carlo simulations, portfolio performances are studied. To ensure that there is no bias in the comparison, optimal CPPI-multiplier for each guarantee framework is obtained via using a classical stochastic control approach. Showing that 
critical risks (such as cash-lock risk and gap-risk) can arise once one steps outside of continuous-time environment, the need of modeling in a more realistic market with discrete-time trading is addressed.

Considering the problem in a discrete-time trading setting, additional path-dependent CPPI strategies are proposed imposing certain trading constraints. In these strategies, the floor processes are designed to vary randomly based on the performance of the portfolio with the aim of capturing cash-lock and gap risks. In addition to sensitivity analysis conducted, risk analysis is carried out via computing the local risk measures; cash-lock probability, expected shortfall (ESF) and shortfall probability. Portfolio performances of these proposed strategies are then discussed through calibration of risk measures.

Keywords: CPPI, DC pension plans, Stochastic optimal control, Portfolio insurance, Risk measures 


\title{
$\ddot{O} \mathbf{z}$
}

\section{BELIRLENMIŞ KATKI PAYI ESASLI EMEKLILIK PLANLARININ SABİT ORANLI PORTFÖY SIGGORTASI METODU İLE YÖNETIMI}

\author{
Temoçin, Büşra Zeynep \\ Doktora, Finansal Matematik Bölümü \\ Tez Yöneticisi : Doç. Dr. A. Sevtap Selçuk-Kestel \\ Ortak Tez Yöneticisi : Prof. Dr. Ralf Korn
}

Aralık 2015, 94 sayfa

Bu tezde, belirlenmiş katkı payı esaslı emeklilik sistemlerinde porftöy yönetimi problemi için çeşitli pörtfoy sigortası stratejileri önerilmiştir. Bu tip sistemlerde, emeklilik anında kazanılmış olan tazminat miktarı portföy performansına bağlıdır ve düzenli yapılan prim ödemeleri ile artar. Prim miktarlarının stokastik dinamiğe sahip olduğu varsayımı altında problem, portföye minimum garanti atamak amacıyla farklı portföy sigortası metotları ile modellenmiştir. Özel olarak, Sabit Oranlı Portföy Sigortası (SOPS) metodunun çeşitli versiyonları farklı garanti süreçleri ve alım-satım işlemi kısıtları altında önerilmiştir. SOPS metodunun klasik dinamikleri, emeklilik sistemi çerçevesinde değiştirilerek bu yeni tanıtılmış stratejiler için portföy verimliliği analiz edilmiştir. Öncelikle, önerilen iki yeni SOPS stratejisi dinamik tahsisatın mümkün olduğu sürekli-zaman alım-satımı varsayımı altında çalışılmıştır. Daha sonra portföy verimlilikleri duyarlılık analizi ve Monte Carlo simulasyonları ile elde edilmiş tazminat dağılımları kullanılarak karşılaştırılmıştır. Karşılaştırmada bir yanlılık olmaması amaciyla, optimal kontrol problemi çözülmüş ve önerilen garanti süreçleri için SOPSçarpanı bulunmuştur. Sürekli-zaman varsayımından çıkıldığı anda kritik risklerin ortaya çıktığı gösterilmiş ve kesikli-zaman alım-satımı ile modellenmiş daha gerçekçi bir markette problem ele alınmıştır.

Kesikli-zaman alım-satımı çerçevesinde, yol-bağımlı SOPS stratejileri alım-satım kısıtları dayatılarak önerilmiştir. Bu stratejilerdeki garanti süreçleri, nakit-hapsi ve açık verme risklerine karşı korunma sağlamaları amacıyla, portföyün performansına bağlı olarak 
rassal biçimde değişecek şekilde tasarlanmıştır. Yapılan duyarlılık analizine ek olarak, lokal ve global risk ölçüleri olan nakit-hapsi olasılığı, beklenen açık miktarı ve açık verme olasılığı hesaplanmıştır. Bu risk ölçülerinin kalibrasyonuna dayanılarak, önerilen stratejilerin portföy performansları değerlendirilmiştir.

Anahtar Kelimeler: SOPS, Belirlenmiş Katkı esaslı emeklilik sistemleri, Stokastik optimal kontrol, Portföy sigortası, Risk ölçüleri 
To My Family 


\section{ACKNOWLEDGMENTS}

I would like to express my great appreciation to my thesis supervisor Assoc. Prof. Dr. A. Sevtap Selcuk-Kestel for her valuable advices, guidance and encouragement during the development of this thesis. Her unwavering positive attitude and support helped me bring this work to fruition.

I would also like to express my deepest gratitude to my co-supervisor Prof. Dr. Ralf Korn. His willingness to support and his invaluable guidance has brightened my path. It has been a privilege and a great experience to work with him. I am also grateful for the financial support he provided during my research visit at Fraunhofer ITWM.

I would also like to thank my defense committee members Assoc. Prof. Dr. Ömür Uğur, Assoc. Prof. Dr. Yeliz Yolcu Okur, Assist. Prof. Dr. Şule Şahin and Assist. Prof. Dr. Özge Sezgin Alp for their insightful comments and suggestions.

I am thankful to the members of Fraunhofer Institute for Industrial Mathematics for their hospitality during my Kaiserslautern research visits. I would specially like to thank Roman Horsky for his useful advices.

My special thanks go to Assoc. Prof. Dr. Ömür Uğur and Assoc. Prof. Dr. Yeliz Yolcu Okur for their insightful suggestions during my thesis committee meetings and to Assoc. Prof. Dr. Azize Hayfavi for her theoretical support and always illuminating conversations.

My gratitude is extended to the members of Institute of Applied Mathematics, especially to Prof. Dr. Gerhard-Wilhelm Weber for his always supporting approach and kindness, and my sincere friends for providing an excellent working environment.

I gratefully acknowledge the partial financial support of The Scientific and Technological Research Council of Turkey (TÜBİTAK) under the scholarship program 2214-A.

Finally, I eternally grateful for my mother Gülten, my father Fahrettin, my brother Semih and my husband Ufuk for their unconditional love and support. All my accomplishments are thanks to their love and I dedicate this dissertation to them. 


\section{TABLE OF CONTENTS}

ABSTRACT ........................... vii

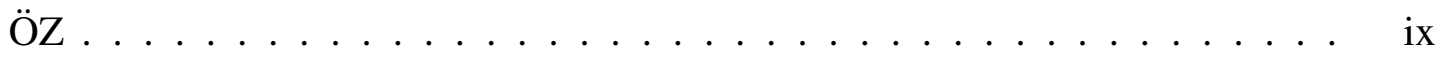

ACKNOWLEDGMENTS . . . . . . . . . . . . . . . . . Xiii

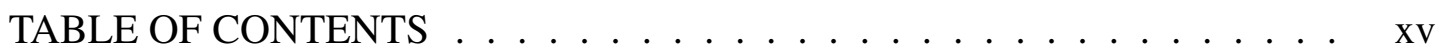

LIST OF FIGURES . . . . . . . . . . . . . . . . . . . . Xix

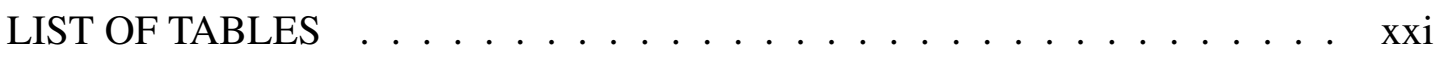

CHAPTERS

$1 \quad$ Introduction $\ldots \ldots \ldots \ldots \ldots$

$1.1 \quad$ Motivation and Literature Review . . . . . . . . . . . 1

1.2 Aim of the Thesis ............. 3

$1.3 \quad$ Plan of the thesis . . . . . . . . . . . 4

2 Preliminaries $\ldots \ldots \ldots \ldots \ldots$

$2.1 \quad$ Pension Plans $\ldots \ldots \ldots \ldots \ldots$

2.1.1 Portfolio Insurance in DC Pension Plans . . . . . 8

2.2 Constant Proportion Portfolio Insurance . . . . . . . . 9

2.2.1 Classical CPPI . . . . . . . . . 10

2.2.2 Cash-lock risk . . . . . . . . . . . 12

$2.2 .3 \quad$ Gap risk . . . . . . . . . . . . 13 
3 CPPI in Pension Plans under Continuous-Time Trading . . . . . . . 15

$3.1 \quad$ The market model . . . . . . . . . . . . . . 15

3.2 Defined-Contribution modelling . . . . . . . . . 16

3.3 Replicating Portfolio . . . . . . . . . . . . . 16

3.4 Different Guarantee Types in the classical CPPI Framework . 20

3.4.1 Deterministic (Net present value) floor . . . . . 20

3.4.2 Random floor . . . . . . . . . . . . 22

3.5 Optimal Control Problem .............. 25

3.5.1 Verification of the solution ........ 26

3.6 Risk Measures and Comparison of Strategies . . . . . . . 28

3.6.1 Cash-lock Risk . . . . . . . . . . . 29

3.6.2 Gap Risk . . . . . . . . . . . . . . 30

$3.7 \quad$ Numerical Results . . . . . . . . . . . . . . . 31

4 CPPI in Pension Plans under Discrete-Time Trading . . . . . . . . . . 39

4.1 The market model . . . . . . . . . . . . 39

4.2 Defined-Contribution modelling . . . . . . . . . 39

$4.3 \quad$ CPPI under Discrete-Time Trading . . . . . . . . . 39

4.3.1 Various CPPI strategies under Discrete-Time Trading 41

4.3.1.1 CPPI with NPV floor $\ldots \ldots \ldots 4$

4.3.1.2 CPPI with random-growth floor . . . 43

4.3.1.3 CPPI strategies with variable floors . . 45

$4.4 \quad$ Risk Measures and Comparison of Strategies . . . . . . . . 48

4.4.1 Cash-lock Risk . . . . . . . . . . . . 48 
4.4.1.1 Cash-lock Risk for NPV floor CPPI . . 49

4.4.1.2 Cash-lock Risk for random floor CPPI 55

4.4.2 Gap Risk .............. 59

4.4.2.1 Gap risk for NPV floor CPPI . . . 60

4.4.2.2 Gap Risk for Random floor CPPI . . . 68

$4.5 \quad$ Numerical Results . . . . . . . . . . . 73

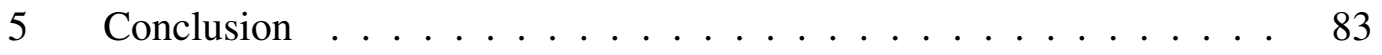

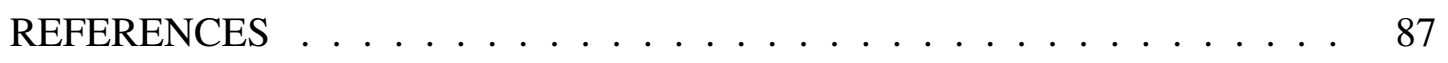

APPENDICES

A Fenton-Wilkinson Approximation Method. . . . . . . . . . 91

CURRICULUM VITAE ........................ 93 


\section{LIST OF FIGURES}

Figure 3.1 Cash-locked portfolios with different floors . . . . . . . . . 30

Figure 3.2 CPPI with NPV floor for $\eta=2 \ldots \ldots \ldots \ldots$

Figure 3.3 CPPI with random floor for $\eta=2 \ldots \ldots \ldots$

Figure 3.4 CPPI with NPV floor for $c=0.8 \ldots \ldots \ldots \ldots$

Figure 3.5 CPPI with random floor for $c=0.8 \ldots \ldots \ldots \ldots$

Figure 3.6 Evolution of the floors when market goes down . . . . . . . . 37

Figure 3.7 Terminal wealth densities of CPPI porfolios under certain parameter values ............................ 38

Figure 4.1 A trajectory for the parameters under a certain parameter set . . . 71

Figure 4.2 Local cash-lock probabilities for a given trajectory . . . . . . . . . 72

Figure 4.3 Local shortfall probabilities for a given trajectory . . . . . . . . . 72

Figure 4.4 Local expected shortfall values for a given trajectory . . . . . . 73

Figure 4.5 A trajectory for $m=1 \ldots \ldots \ldots \ldots$

Figure 4.6 A trajectory for $m=3 \ldots \ldots \ldots \ldots$

Figure 4.7 A trajectory for $m=6 \ldots \ldots \ldots \ldots$

Figure 4.8 Terminal wealth densities for the parameters under a certain parameter set ...................... 81 


\section{LIST OF TABLES}

Table 3.1 Assumed values for parameters under continuous-time trading setting 31

Table 3.2 Distributional properties of CPPI portfolio with random and NPV

floor under certain parameter values . . . . . . . . . . . . . 36

Table 4.1 Assumed values for the parameters under discrete-time trading model 74

Table 4.2 Distributional properties of CPPI portfolio with various path-dependent

floors under certain parameter values . . . . . . . . . . . 75

Table 4.3 Coefficients of variation of CPPI portfolio with various path-dependent

floors under certain parameter values . . . . . . . . . . 76 


\section{CHAPTER 1}

\section{Introduction}

\subsection{Motivation and Literature Review}

Defined-contribution type pension funds can be considered as a form of savings where external contribution payments constitute the principal amount of the portfolio wealth. These are saving plans in which a certain amount of money is regularly set aside by the plan participant. These payments then are invested in financial markets and accumulate to a benefit which is collected with the returns at retirement. Being a part of the mandatory pension system, they are the main source to finance retirement in many countries and are becoming more common in other countries where the participation is still on a voluntary basis. As a result of this rapid growth, pension systems have become a popular subject for researchers in recent years. Although pension systems are created to increase financial life quality by providing income after retirement, there are many risks associated with these systems. The uncertainty linked to the retirement income and the fact that the pension participant/beneficiary is directly exposed to the financial risk of the plan portfolio, raise the importance of pension fund modelling. Especially, a downside-protection against market conditions has become a prominent need in this context. With the aim of developing the mathematical theory for these kind of protection schemes, the present thesis is devoted to study and design a set portfolio insurance strategies in defined contribution (DC) type pension funds.

Pension plans include many stochastic components which are set to be deterministic for simplicity in practice. However, the uncertainty in these components is not predictable and therefore cannot be captured by deterministic approaches. Especially, the risk on the future benefits of a defined-contribution pension fund is more significant as savings are solely dependent on market movements. For a general overview on the development in the pension funds modelling, see [23]. Towards reducing the impact of this market/investment risk, several protection methods have been introduced in the literature from different aspects of pension modeling. Booth and Yakoubov [15] were among the first to study the management of investment risk for defined-contribution pension schemes. Their work provided preferable allocation decisions based on performance analysis. Boulier et al. [18] also studied defined-contribution plans where a guarantee is given on the benefits. In his work, contribution rate was assumed to be continuous and deterministic whereas interest rate was modeled stochastically by Vasicek model. The guarantee was then defined as a function of the contribution and 
interest rate. The optimal portfolio was found by formulating and solving Merton's portfolio problem with the objective function being the difference between the terminal wealth and the guarantee. Battocchio and Menoncin [7] solved the portfolio problem maximizing the expected utility of terminal wealth in a complete financial market for DC pension funds with stochastic interest rate. A detailed study on the classical stochastic optimal control problem under stochastic interest rates is presented by Korn and Kraft [37]. The authors solve the maximization problem of the utility of terminal by proving a verification theorem in the absence of usual Lipschitz assumptions. Cairns et al. [20, 21] presented studies on asset-allocation strategies for DC plans in the presence of salary and interest rate risk. Introducing a new form of terminal utility function which uses final salary as a numeraire, they made performance comparisons of the optimal strategy with other reference strategies. Their results suggested that the optimal strategy enhances the welfare of beneficiaries more than the other strategies.

A popular example for downside protection strategies in the literature is Constant Proportion Portfolio Insurance (CPPI). The CPPI is a dynamic portfolio insurance strategy that aims to protect the investor against adverse market movements by guaranteeing an initially specified fixed amount of money at the end of the investment horizon [10]. The methodology is firstly introduced by Perold and Sharpe [41] for fixed-income instruments, and later by Black and Jones [11] for equity instruments. For a detailed detailed dissertation on the subject, see [33]. With the main objective of providing a floor to the value of savings, the optimal control problem is formulated in a different way in CPPI framework. Instead of a classical maximization of expected utility of the terminal wealth, the difference between the assumed floor and the portfolio value is maximized as the objective function. Trading is done continuously and the guarantee/floor is assumed to be constant in the classical CPPI.

While providing a simple and tractable setting for portfolio insurance, the continuous rebalancing assumption of classical CPPI fails to suggest a realistic perspective. This strict assumption avoids most of the risks which are critical for long-term investments and are present in real financial markets. The two major problem that arise in practice for CPPI portfolios are the so-called cash-lock phenomenon and gap-risk. The cash-lock is the situation when the portfolio wealth ends up fully invested in the riskfree asset without the chance to recover. Balder and Mahayni [5] computed cash-lock probabilities for certain portfolio insurance strategies including classical CPPI under continuous-time, and presented the performance comparison results.

The other prominent risk which threatens a CPPI portfolio is the gap-risk. This is the probability of portfolio value falling below the floor level and failing to guarantee the desired amount at maturity. This risk is measured by Expected Shortfall (ESF) which is computed based on the shortfall probabilities. Balder et al. [4] studied the problem under a discrete-time trading assumption and presented risk measures used to quantify the gap-risk for a CPPI with fixed-growth floor. The literature also includes hedging strategies with artificial assets to model jumps and price gap-risk. In [46], Tankov introduces the so-called exotic gap options to hedge against gap events, or jumps in a Lévy-type framework.

Other threatening situations occur in cases of major increases or decreases in the mar- 
ket. In the case of a market rise, the floor might become insignificant comparing to the portfolio value. Since this eventuality may create a high potential loss and prevent from taking advantage of the market rise, a modification is needed in the floor. The main problem here is that although portfolio value increases significantly, the potential loss also accelerates as long as floor remains low. Similarly, in the case of a rapid market decrease, the portfolio value might approach to floor. This would prevent the participation in future rises and limit the potential gain. Certain mechanisms to cope with these problems were given in [19] under-discrete time trading assuming a floor that grows at a constant rate. These mechanisms are designed to automatically manipulate the floor once these situations emerge. For an alternative approach of variable floors, see the paper of Ameur and Prigent [2].

The literature on application of CPPI in defined-contribution pension fund management is limited due to the discontinuous and complicated structure of pension systems especially in the presence of imposed stochastic dynamics. Therefore, this thesis is mainly focused to present, study and develop the applications of CPPI in definedcontribution pension plans and to investigate the above-mentioned risks under both continuous- and discrete-time trading. The main novelty of the thesis compared to existing literature, comes from the introduction of various floor processes with different characteristics. Unlike the classical CPPI where the investor selects a certain fixed floor which he/she does not want the portfolio value fall under, the floor processes proposed have stochastic dynamics with path-dependent structures. Applying this kind of a portfolio insurance strategy to pension funds raises further investment risks since the horizon is usually much longer than a typical financial investment. Towards the management of these risks, another contribution of the present thesis is the analysis of the cash-lock and gap-risk through computation of risk measures and proposal of appropriate hedging strategies.

\subsection{Aim of the Thesis}

In this thesis, various portfolio insurance strategies are designed and proposed for defined-contribution pension funds from a theoretical and technical point of view. The main aim is to provide a minimum guarantee on the terminal wealth that the beneficiary collects at the retirement. More specifically, various guarantee concepts for the CPPI are proposed under both continuous- and discrete-trading assumptions imposing trading restrictions. Therefore, the problem is considered in both complete and incomplete markets having path dependent or independent structures. Since in a DC pension plan the wealth is enhanced by consecutive payments, which is assumed to be stochastic for all cases, the problem itself contains discrete dynamics. Therefore the problem is considered in two different markets with continuous- and discrete-time trading assumptions.

The steps of the research carried out is summarized as follows: First, two CPPI strategies are introduced under continuous-time trading having different random dynamics. Two distinctive floor/guarantee processes are defined where the main assumption is that the guarantee at retirement will be equal to summation of the time value of con- 
tribution payments made by the plan participant. The labor income is modeled as stochastic process and contributions assumed to be a proportion of this income. The discontinuity coming from the incoming contribution payments is eliminated via pricing and short-selling the claim of future premiums. This way, the incoming payments are treated as if they were already a part of the portfolio. In the newly constructed continuous environment, the floor processes are defined as; net present value (NPV) floor being time zero value of the future payments claim and random floor being the time value of past and future payments. To ensure that there is no bias in the comparison, the optimal CPPI-multiplier is obtained for each guarantee framework via using a classical stochastic control approach. Through terminal wealth distributions and sensitivity analyses, performances of both strategies are compared portfolio efficiencies are discussed.

To further analyze the risks that are avoided under continuous-trading and to study the appropriate hedging methods, the same problem is handled in a more realistic setting with discrete-time trading, as a second step. Redefining the NPV and random floors in a way that they preserve their discrete structure and considering a new path-dependent set of floors, cash-lock and gap-risks are addressed and the relevant risk measures are computed. Previously defined floors are modified to current framework and other path-dependent variable floor CPPIs are given. Starting with the initial contribution, the random floor, in this case is, enhanced with each payment made at the fixed dates. Specific variable CPPI strategies such as constrained CPPI, Ratchet CPPI and Margin CPPI with Ratchet effect are studied. Here, constrained CPPI involves a strict constraint on the exposure to limit excessive borrowing whereas ratchet floor decreases the risk of overgrowing cushion. Margin effect, lastly, minimizes the cash-lock risk by decreasing the floor at a minimum level. Since the framework considered does not have enough initial margin to decrease the floor without manipulating the end guarantee, a modification is suggested in the mechanism. With a detailed sensitivity analysis the effectiveness of each strategy is discussed and comparisons are made. Risks of the proposed CPPIs are analyzed and quantified through risk measures and sensitivity analyses.

Contributions of the present thesis are many-fold in the aspects of DC pension plans and CPPI scheme. These are can be specified as;

- application of CPPI in DC plans

- introduction of new CPPI strategies with floors having stochastic dynamics in a continuous-time trading market

- design of path-dependent CPPI strategies in a discrete-time trading environment and computation of risk measures.

\subsection{Plan of the thesis}

In the next chapter, general information on the pension plans is presented. A brief summary on different types of pension funds is given with an emphasis on defined- 
contribution (DC) plans and application of portfolio insurance in these systems is discussed. In Chapter 2, an overview of the classical CPPI methodology is given. The continuous dynamics of the strategy are presented and prominent risks associated with a CPPI strategy is addressed. Chapter 3 presents the adaptation of the classical CPPI for DC pension systems. The replication of the claim of future payable contributions is given along with the newly introduced guarantee types. Optimal control problem is then formulated for these CPPI strategies and the solution is obtained via dynamic programming. To measure the effect of model parameters on the terminal wealth for each strategy a sensitivity analysis is given in the numerical results section. Moreover, portfolio efficiency comparison is presented based on terminal wealth distributions. Lastly, cash-lock phenomenon and gap-risks are illustrated with a numerical example and the need for a discrete-time trading modeling is discussed. In Chapter 4, CPPI under discrete-time trading and various CPPI strategies are given. Comparison of strategies based on the computed risk measures is presented in Section 4.4 and numerical results are given in Section 4.5. Finally, Chapter 5 summarizes the work carried in the thesis with a discussion on future research ideas. 


\section{CHAPTER 2}

\section{Preliminaries}

\subsection{Pension Plans}

Pension funds have become an important subject of research in recent years. Since the life expectancy have increased in the last decades, ensuring an acceptable level of financial-life quality at later ages has become a major economic issue and a need to construct a pension system that maintains economic efficiency with a low risk has emerged.

Pension funds are savings systems, where cash inflows -in the form of contributions or benefits based on the pension type- enter into the wealth dynamics of the fund. We can divide them in two works keeping a collective perspective, where the modelling is handled from the point of view of the pension issuer by collecting all of the pensioners' accounts into one pool. Among many others, some prominent studies for these kind of systems are present in [16, 17, 21, 40]. In the individual perspective, pension account of each plan participant is treated separately. We concentrate on the latter case approaching from the pensioner's point of view. Among many others, some papers on DC pension fund management are [15, 34, 35, 39]. Stochastic optimal control problems in the context of DC funds are presented in [13, 26, 28]. Detailed information and a general overview of the economic issues related to pension funds can be found in [3, 12, 23]. Essentially, the pension plans with individual perspective are categorized into two types as follows:

- Defined-benefit (DB) plans, where a specific benefit that will be payable at retirement is identified in advance. The contributions are then determined in order to guarantee that the fund stays in balance. In these systems, the financial risks are beared by the sponsor of the plan.

- Defined-contribution (DC) plans, where the contributions are defined and the benefit is random being dependent on the performance of the pension fund/ portfolio. The contribution amount typically is either a percentage of an participant's labor income or a specific amount. In this case, the financial risks are charged to the plan participants.

Although defined-benefit plans have been more common in the past due to their safe 
structure from the participant's standpoint, in the last decades most of the plans have been designed based on defined contributions. In this thesis, defined-contribution type plans are considered. The management of this type of funds consists of two phases: accumulation phase and decumulation phase. In the decumulation phase, the problem of distributing the accumulated funds after retirement is considered. Among many others, some papers dealing with the decumulation phase funds are [1, 8, 14, 22]. The literature on pension fund management for accumulation phase is based on models where the contributions are collected in the account of the participant during the working life and benefit is paid at retirement. The aim is to study pre-retirement fund evolution reducing the risk charged to the participant. Since in DC plans the benefits are not determined and therefore the participant is directly exposed to the risk, a very important issue is to provide a minimum guarantee for the fund. This minimum guarantee is a lower bound for the wealth payable to the participants in retirement, so it provides a downside protection against the investment risk. Another important issue to take into consideration when working on DC-type pension funds is that these systems can be constrained, by law, to evolve above a certain level, which is the so called solvency level. The minimum guarantee and the solvency level restrictions result in a portfolio allocation where a substantial part of the wealth is invested in the riskless asset. This is, on the other hand, not desirable for long-term as it will suppress the potential gains from a possible market increase. Although the guarantee would be met under the given solvency conditions, the benefit at the retirement would be at its minimum with a return on the risk-free interest rate level. Therefore, new plans should be designed which protect the participant from downside risk by guaranteeing an amount while making it possible to benefit from climbing markets. In [20] optimal portfolio problem is solved under continuous-time trading for DC pension funds under stochastic interest rate and salary assumptions and in the absence of a guarantee scheme. Similarly, in [7] Battocchio and Menoncin work in the same setting with a further assumption of stochastic inflation rate and give explicit closed form solutions for the optimal portfolio. For discrete-time trading, the same problem is solved in [29, 30] by dynamic programming principle and backward induction assuming constant salary.

Another problem emerging in portfolio protection/insurance is the determination of guarantee amount that will be paid at the retirement. Here, it should be noted that the fund wealth is composed of the contribution payments (or premiums) made by the participant and return of the portfolio constituted from these payments. Therefore, it is also very critical to take into account the stochasticity from the payments which also put another randomness on the benefit.

To respond this need, the main aim here is to design a protected portfolio scheme for DC pension funds which takes into account the randomness yielding from the contribution amounts and also able to guarantee at least the accumulated amount of wealth.

\subsubsection{Portfolio Insurance in DC Pension Plans}

Plans providing a protection scheme at retirement are introduced in [18] in a continuoustime trading market with stochastic interest rate and assuming a deterministic contribution process. In this setup, the market consists of the riskless asset, a risky asset and 
a rolling-horizon bond. The plan guarantees a minimal annuity and pays a deterministic minimum stream of benefits from the retirement until the death date which also assumed to be deterministic. The maximization problem of the expected power utility from the terminal wealth is solved. In [24] the problem is handled under stochastic interest rate and contribution flow where the difference between the final wealth and the minimum guarantee is paid to the participant at retirement, and the rest is collected by the manager. A more general setting is presented in [25] with volatility also having stochastic dynamics. The optimal portfolio problem is solved from the manager's perspective via martingale methods. In the discrete-time trading framework, [42] considers the optimization problem where the fund is protected by a deterministic minimum guarantee. The participant makes a single lump-sum deposit at the beginning and the difference between the solvency level and the wealth is invested in the riskless asset.

\subsection{Constant Proportion Portfolio Insurance}

Portfolio insurance methods are designed to enable the investor to limit downside risk while allowing some participation in upside markets. These methods protect a given percentage of the initial capital by providing a guarantee at maturity. This is a desirable feature mostly in falling markets and for investments with long horizons. Two prominent portfolio insurance methods in literature are the Option Based Portfolio Insurance (OBPI) and the Constant Proportion Portfolio Insurance (CPPI). In the present thesis, the latter is studied. A CPPI is a popular dynamic portfolio insurance strategy which aims to protect the investor against adverse market movements by guaranteeing at least an initially specified (typically) fixed amount of money at the retirement date. The method is firstly introduced for fixed-income securities by Perold and Sharpe in [41] and later extended for equities by Black and Jones with a borrowing limit assumption [11]. Further developed in [10], the standard method which is called classical CPPI promises a floor value for the wealth at each time and uses a simplified strategy to allocate assets dynamically over time. The instant allocation is made based on the difference between the portfolio value and the floor. This introduced difference process is called the cushion and is denoted by $C$. The cushion process hence is defined as the difference between the current portfolio value $V$ and the floor which is denoted by $Y$. The investor starts by setting a guarantee level as to the lowest acceptable value for the portfolio. Then, she computes the cushion and determines the amount allocated to the risky asset by multiplying the cushion with a predetermined multiplier. Both the floor and the multiplier are exogenous inputs to the model representing investor's risk tolerance. The total amount allocated into the risky asset is known as the exposure. The remaining funds are invested in the risk-free asset.

A higher multiplier value allows the investor to participate more in the stock market representing a low risk averseness. This would make it possible to take advantage of an increase in the market. However, it would also mean that the portfolio will approach the floor faster in case of a sustained decrease in stock prices. Since the exposure is a function of the cushion, it approaches to zero when cushion also approaches to zero. This prevents portfolio value from falling below the floor process. Portfolio value will fall below the floor only in the case where there is a sudden sharp drop in the market before the investor has an opportunity to trade. 
An important point to note is that the floor process $Y$ must be hedgeable and the explicit form of the corresponding hedging strategy should be computable. Otherwise, corresponding allocation would be unknown and the portfolio insurance would fail. Before explaining the classical CPPI method, some basic definitions are given next.

Definition 2.1. A self-financing portfolio is a portfolio with no inflow or withdrawal of money. In other words, the purchase of a new portfolio must be financed solely by selling assets already in the portfolio.

A common assumption in finance according to the following definition is that the market is free of arbitrage.

Definition 2.2. An arbitrage possibility is a self-financing portfolio $h$ such that initial value of the portfolio is zero, that is $V^{h}(0)=0$, but

$$
V^{h}(T) \geq 0 \text { and } P\left(V^{h}(T)>0\right)>0
$$

with probability one. We say that the market is arbitrage-free if there are no arbitrage possibilities.

Lastly, the replicating (hedging) portfolio is defined as it will be used in the next sections.

Definition 2.3. A contingent claim $X$ can be replicated or equivalently is hedgeable, if there exists a self-financing portfolio $h$ such that

$$
V^{h}(T)=X .
$$

Here, $h$ is called the replicating (hedging) portfolio.

\subsubsection{Classical CPPI}

The CPPI method, as described in [10], manages a portfolio dynamically so that it evolves above a floor $Y(t)$ at any time $t$. The value of the floor process represents dynamically insured amount at each time. The market considered is a Black-Scholes market with two assets; a money market account $B$ and a stock (or a stock index) $S$ whose price dynamics are given by

$$
d B(t)=r B(t) d t
$$

and

$$
\frac{d S(t)}{S(t)}=\mu_{S} d t+\sigma_{S} d W(t), S(0)=S_{0} .
$$

Here, $W$ is a Brownian motion defined on the complete probability space $(\Omega, \mathbb{F}, \mathbb{P})$ endowed with the filtration $\left\{\mathbb{F}_{t}\right\}_{t \in[0, T]}$. The parameters $\mu_{s}$ and $\sigma_{s}$ are real constants with $\sigma_{s}>0$, and the risk-free rate $r$ is also assumed to be constant. The floor which serves as a lower bound for the portfolio is assumed to grow with the risk-free rate, having the following dynamics 


$$
d Y(t)=r Y(t) d t
$$

The initial floor $Y(0)$ is clearly less than the initial portfolio value which is denoted by $V(0)$. According to the strategy, the desire of the investor is to have at least a portfolio value of $V(0)$ at the retirement, that is, she does not want to have any capital losses. As a risk-free asset is present in the market, in which she can invest the floor completely, to achieve this goal she would only need an initial capital of $Y(0)=$ $V(0) e^{-r T}$ at time $t=0$. Therefore, the investor can risk the excess amount $V(0)-Y(0)$ without any probability of not meeting the final payoff. This excess amount is called the cushion value and is denoted by $C(0)$ at time $t=0$. Since in the classical CPPI, continuous trading is possible, she can react the market movements immediately. With the possibility of moving the funds from risky asset to risk-free asset instantly, the investor participate in the stock market in accordance with her risk averseness. The cushion is defined as

$$
C(t)=V(t)-Y(t)
$$

and the exposure, which is the amount invested in risky asset, is given as $e(t)=m C(t)$ at any time $t$. Different values of $m$ changes the nature of the portfolio immensely and the interesting scenario arises when $m \gg 1$, that is, when the risk profile is less risk averse. In this case, as a result of leverage effect, the portfolio becomes more prone to market movements and although it is bounded below by the floor, the portfolio might crash through the guarantee level in case of a sudden drop. In the discrete-time trading case, which will be discussed in the next sections, investor cannot trade instantly and faces a much higher risk of the portfolio falling under the floor before the next trading time. Considering their dynamics given in (2.4) and (2.3), it is obvious that $B$ and $Y$ has the following relation

$$
\frac{d B(t)}{B(t)}=\frac{d Y(t)}{Y(t)}
$$

Lemma 2.1 ([[10]). The cushion process in classical CPPI is the unique solution of the following $S D E$

$$
d C(t)=C(t)\left(\left(m\left(\mu_{S}-r\right)+r\right) d t+m \sigma_{S} d W(t)\right)
$$

and is given by

$$
C(t)=C(0) e^{\left(r-\frac{1}{2} m^{2} \sigma_{S}^{2}\right) t+m\left(\mu_{S}-r\right) t+m \sigma_{S} W(t)}
$$

where $C(0)=V(0)-Y(0)$.

Proof. The change in the value of a self-financing portfolio derives from the change of asset values and amounts invested in them. This relation is given by 


$$
d V(t)=e(t) \frac{d S(t)}{S(t)}+(V(t)-e(t)) \frac{d B(t)}{B(t)}
$$

By the definition of $C,(2.8)$ and $(2.5)$, the dynamics of the cushion are obtained as follows

$$
\begin{aligned}
d C(t) & =d(V(t)-Y(t)) \\
& =e(t) \frac{d S(t)}{S(t)}+(V(t)-e(t)) \frac{d B(t)}{B(t)}-d Y(t) \\
& =e(t) \frac{d S(t)}{S(t)}+(V(t)-e(t)-Y(t)) \frac{d B(t)}{B(t)} \\
& =m C(t) \frac{d S(t)}{S(t)}+C(t)(1-m) \frac{d B(t)}{B(t)} \\
& =C(t)\left(\left(m\left(\mu_{S}-r\right)+r\right) d t+m \sigma_{S} d W(t)\right) .
\end{aligned}
$$

By Itô formula the solution of the above SDE is simply found as

$$
C(t)=C(0) e^{\left(r-\frac{1}{2} m^{2} \sigma_{S}^{2}\right) t+m\left(\mu_{S}-r\right) t+m \sigma_{S} W(t)},
$$

which proves the existence. For the proof of uniqueness of the solution, see [36].

There are some distinctive risks associated with a CPPI strategy which do not exist for other investment schemes. The most prominent ones are the cash-lock risk and the gap-risk which are discussed below. In following chapters these risks will be studied under different market assumptions.

\subsubsection{Cash-lock risk}

One of the most important risks that arises for a CPPI portfolio manager in a discretetime trading market is the so-called cash-lock phenomenon, i.e. the effect that due to losses only the lower bound for the guarantees can be realized via riskless investment from a particular time onwards. This is the situation when the portfolio wealth ends up fully invested in the risk-free asset without the chance to recover. Since a cashlocked position prevents any participation a rising market, it is considered as a crucial risk for investments with long horizons. Once the exposure drops to zero it stays there until the end of the investment period. In continuous-time, however, this risk is not a major concern as dynamic trading is possible and investor can quickly shift the funds as the cushion approaches to zero. Therefore, this risk is mostly studied in markets with discrete-time trading, which will also be considered in this thesis. However, in a framework where floor interference is possible, this problem can be prevented by adjusting the floor downwards according to market conditions. 


\subsubsection{Gap risk}

Gap-risk is another major risk that a portfolio manager faces while managing a CPPI portfolio. It is essentially the probability of portfolio value crashing through the floor, that is, going below the floor resulting in a negative gap. This situation arises when the wealth is heavily invested in stocks and the fund manager does not have enough time to rebalance the portfolio in the case of a sudden market drop. Since this might cause failure in meeting the guaranteed amount at the end of the plan, it is crucial to quantify and hedge this "gap risk".

The risks explained above will be illustrated and analyzed in the following chapters in detail for different market assumptions. For quantitative analysis purposes, associated risk measures will be computed and calibrations will be presented. Moreover, mechanisms for hedging these risks will be introduced. 


\section{CHAPTER 3}

\section{CPPI in Pension Plans under Continuous-Time Trading}

Considering a defined-contribution plan, in this section our aim is to attain a guarantee on the pension fund under continuous-time trading. With this aim, two different floor processes are introduced having deterministic and stochastic dynamics. The time horizon for the fund management is assumed to be $[0, T]$ where time $t=0$ is the entrance date to the plan and $T$ is the date of retirement. We consider regularly made contribution payments (i.e. monthly/yearly) which are defined as proportions of the contributor's labor income. Furthermore, this income is defined to be a stochastic process reflecting the risks of financial market. These CPPI strategies are the special cases of classical CPPI given in Chapter 2.2 which are introduced into DC pension plan management. In the next sections, the market setting is described along with the two proposed floor processes.

\subsection{The market model}

To keep the setting simple, a continuous-time securities market is considered including a money market account $B$ and a stock (or a stock index) $S$ with price dynamics given by

$$
\begin{gathered}
d B(t)=r B(t) d t \\
\frac{d S(t)}{S(t)}=\mu_{S} d t+\sigma_{S} d W(t), S(0)=S_{0} .
\end{gathered}
$$

Here, $W$ is a Brownian motion defined on the complete probability space $(\Omega, \mathbb{F}, \mathbb{P})$ endowed with the filtration $\left\{\mathbb{F}_{t}\right\}_{t \in[0, T]}$; and $\mu_{s}, \sigma_{s}$ are real constants with $\sigma_{s}>0$, where the interest rate $r$ is assumed to be constant.

An important feature of our Black-Scholes market setting is that it is complete, that is, sufficiently integrable $\mathcal{F}_{t}$-measurable random variables can be replicated by suitable self-financing trading strategies. In a complete market there exists a unique equivalent martingale measure $\mathbb{Q}$ under which the unique price of a contingent claim can be calculated as an expectation [44]. Incompleteness arises in a market when the sources of randomness are more than the number of assets available. 


\subsection{Defined-Contribution modelling}

We assume that each beneficiary contributes a constant proportion, $\gamma$, of his/her labor income at fixed time instants $t_{i} \in[0, T]$ and the pension plan involves an ongoing stream of contribution payments. The realistic modeling of labor income can be very difficult as there are many stochastic factors such as disability, mortality and economic or political crises. Therefore, to be able to reflect this randomness, we suppose that the labor income $L(t)$ is a stochastic process satisfying the following stochastic differential equation

$$
\frac{d L(t)}{L(t)}=\mu_{L} d t+\sigma_{L} d W(t), L(0)=L_{0}
$$

where $\mu_{L}$ and $\sigma_{L}$ are assumed to be real constants. The labor income at time $t$ is thus given as

$$
L(t)=L(0) e^{\left(\mu_{L}-\sigma_{L}^{2} / 2\right) t+\sigma_{L} W(t)}
$$

assuming $t_{0}=0$ and $t_{n}=T$. Under this setting, each contribution $\gamma\left(t_{i}\right)$ has the form

$$
\gamma\left(t_{i}\right)=\gamma L\left(t_{i}\right)
$$

with the dynamics

$$
d \gamma(t)=\gamma d L(t)
$$

given that $t \in\left(t_{i}, t_{i+1}\right)$ for $i=0,1,2 \ldots, n$.

It is important to note that thanks to market completeness, the future contributions given by (3.5) can be fully hedged. Hence, a replicating portfolio exists for the stream of future contribution payments. This stream can be viewed as a claim and a unique price can be assigned under the risk-neutral measure. While handling the portfolio allocation, this replication will be used in different ways. This section describes the specific CPPI strategies with the introduced floors.

\subsection{Replicating Portfolio}

In order to price the claim of future contributions, the measure should be changed from the real-world probability measure $\mathbb{P}$ to the unique risk-neutral measure $\mathbb{Q}$. By Girsanov's theorem [44], the risk-neutral dynamics of $L(t)$ is given by 


$$
\frac{d L(t)}{L(t)}=\left(\mu_{L}-\sigma_{L} \theta\right) d t+\sigma_{L} d \widetilde{W}(t)
$$

where

$$
\theta=\frac{\mu_{s}-r}{\sigma_{S}}
$$

is the market price of risk and $\widetilde{W}$ is the Brownian motion under $\mathbb{Q}$.

Let $Z(t)$ denote the time- $t$ price of the stream of future contributions payable between time $t$ and $T$. Then, the price is defined as the summation of discounted future payments and is given by

$$
Z(t):=\mathbb{E}^{\mathbb{Q}}\left[\sum_{i: t_{i} \geq t} e^{-r\left(t_{i}-t\right)} \gamma\left(t_{i}\right) \mid \mathcal{F}_{t}\right]
$$

We thus in particular also include the possible contribution exactly at time $t$.

Proposition 3.1. The time-t price of the claim of future contributions is given by

$$
Z(t)=\gamma L(t) g(t)
$$

where $g(t)=\sum_{i: t_{i} \geq t} e^{\left(\mu_{L}-r-\theta \sigma_{L}\right)\left(t_{i}-t\right)}$ for $t \in[0, T]$ and $i=0,1,2 \ldots, n$..

Proof. By Itô's formula, the solution of the SDE given in 3.6 is given by

$$
L\left(t_{i}\right)=L(t) e^{\left(\mu_{L}-\sigma_{L} \theta-\sigma_{L}^{2} / 2\right)\left(t_{i}-t\right)+\sigma_{L}\left(\widetilde{W}\left(t_{i}\right)-\widetilde{W}(t)\right)}
$$

at any time $t_{i}>t$. Substituting (3.9) in 3.7),

$$
\begin{aligned}
Z(t) & =\mathbb{E}^{\mathbb{Q}}\left[\sum_{i: t_{i} \geq t} e^{-r\left(t_{i}-t\right)} \gamma\left(t_{i}\right) \mid \mathcal{F}_{t}\right] \\
& =\gamma \mathbb{E}^{\mathbb{Q}}\left[\sum_{i: t_{i} \geq t} e^{-r\left(t_{i}-t\right)} L(t) e^{\left(\mu_{L}-\sigma_{L} \theta-\sigma_{L}^{2} / 2\right)\left(t_{i}-t\right)+\sigma_{L}\left(\widetilde{W}\left(t_{i}\right)-\widetilde{W}(t)\right)} \mid \mathcal{F}_{t}\right] .
\end{aligned}
$$

Since $L(t)$ is $\mathcal{F}_{t}$-measurable, it follows that 


$$
\begin{aligned}
Z(t) & =\gamma L(t) \mathbb{E}^{\mathbb{Q}}\left[\sum_{i: t_{i} \geq t} e^{\left(\mu_{L}-r-\sigma_{L} \theta-\sigma_{L}^{2} / 2\right)\left(t_{i}-t\right)+\sigma_{L}\left(\widetilde{W}\left(t_{i}\right)-\widetilde{W}(t)\right)}\right] \\
& =\gamma L(t) \sum_{i: t_{i} \geq t} e^{\left(\mu_{L}-r-\sigma_{L} \theta-\sigma_{L}^{2} / 2\right)\left(t_{i}-t\right)} \mathbb{E}^{\mathbb{Q}}\left[e^{\sigma_{L}\left(\widetilde{W}\left(t_{i}\right)-\widetilde{W}(t)\right)}\right] .
\end{aligned}
$$

The last expectation is the moment generating function of $\mathcal{N}\left(0, t_{i}-t\right)$, thus

$$
\mathbb{E}^{\mathbb{Q}}\left[e^{\sigma_{L}\left(\widetilde{W}\left(t_{i}\right)-\widetilde{W}(t)\right)}\right]=e^{\frac{1}{2} \sigma_{L}^{2}\left(t_{i}-t\right)}
$$

Substituting this last relation into definition of $Z(t)$, it holds

$$
\begin{aligned}
Z(t) & =\gamma L(t) \sum_{i: t_{i} \geq t} e^{\left(\mu_{L}-r-\sigma_{L} \theta-\sigma_{L}^{2} / 2\right)\left(t_{i}-t\right)} e^{\frac{1}{2} \sigma_{L}^{2}\left(t_{i}-t\right)} \\
& =\gamma L(t) \sum_{i: t_{i} \geq t} e^{\left(\mu_{L}-r-\sigma_{L} \theta\right)\left(t_{i}-t\right)}
\end{aligned}
$$

Using the notation

$$
g(t)=\sum_{i: t_{i} \geq t} e^{\left(\mu_{L}-r-\sigma_{L} \theta\right)\left(t_{i}-t\right)}
$$

it is concluded that

$$
Z(t)=\gamma L(t) g(t)
$$

this proves the proposition.

Hence, by Proposition 3.1, the exact value of the claim $Z(t)$ is known and it can be hedged using the assets in the market. One can then short-sell this claim at time zero and collect its value $Z(0)$. This way, instead of waiting for the contributions to come in, the price can be directly invested into the pension plan. The replicating portfolio is then neutralized by the incoming future payments and the future payments are be considered as if they were already a part of the assets in the portfolio. Thus, following this strategy makes the wealth process independent from the future inflows and introduces a continuous setting by eliminating the discontinuity coming from the payments.

To obtain the explicit form of the replicating portfolio, first the dynamics of $Z(t)$ should be examined. By (3.7), the risk-neutral dynamics of $Z(t)$ between discontinuity points $t_{i}(i=0,1,2, \ldots, n)$ is given as 


$$
\frac{d Z(t)}{Z(t)}=r d t+\sigma_{L} d \widetilde{W}(t)
$$

whereas under $\mathbb{P}$ it satisfies

$$
\frac{d Z(t)}{Z(t)}=\left(r+\sigma_{L} \theta\right) d t+\sigma_{L} d W(t)
$$

Again, these dynamics only hold for $t \in\left(t_{i}, t_{i+1}\right)$. At payment times, on the other hand, the differential does not exist and the process evolution is given by

$$
Z\left(t_{i}^{+}\right)=Z\left(t_{i}\right)-\gamma\left(t_{i}\right)
$$

for $i=0,1,2, \ldots, n$. Hence, $Z(t)$ has discontinuous dynamics at times $t_{i}$.

To prove that $Z$ is hedgeable, the relevant replicating portfolio should be identified. For this, a self-financing trading strategy $\varphi=\left(\varphi_{B}, \varphi_{S}, \varphi_{Z}\right)$ is considered where $\varphi_{B}, \varphi_{S}$ and $\varphi_{Z}$ denote the number of units held from the respective asset with $\varphi_{Z}=-1$. Assuming that $\bar{\varphi}=\left(\varphi_{B}, \varphi_{S}\right)$ is a hedging strategy for the $Z$, the following holds

$$
\begin{aligned}
d V^{\varphi}(t) & =\varphi_{B}(t) d B(t)+\varphi_{S}(t) d S(t)-d Z(t) \\
& =\left(\varphi_{B} r B+\varphi_{S} S \mu_{S}-Z\left(r+\sigma_{L} \theta\right)\right) d t+\left(\varphi_{S} S \sigma_{S}-Z \sigma_{L}\right) d W
\end{aligned}
$$

Equating the diffusion terms and the drift terms to zero, the numbers of assets are obtained as

$$
\varphi_{S}(t)=\frac{Z}{S} \frac{\sigma_{L}}{\sigma_{S}} \text { and } \varphi_{B}(t)=\frac{Z}{B}\left(1-\frac{\sigma_{L}}{\sigma_{S}}\right)
$$

Note in particular that due to the form of $\varphi_{B}(t)$ the pair $\bar{\varphi}=\left(\varphi_{B}, \varphi_{S}\right)$ is indeed selffinancing.

By short-selling the replicating portfolio $\bar{\varphi}$ the beneficiary collects the amount

$$
Z(0)=\gamma L(0) g(0)
$$

at time $t=0$ which is the initial value of the pension portfolio. This of course is significantly higher than just the initial premium of $\gamma(0)=\gamma L(0)$. However, it can be indeed argued that the future contributions to the fund might be at risk due to a possible unemployment of the contributor. One can then at least value and replicate the future payments that are ensured by the working contract of the contributor. As the future contributions are now neutralized by the payment inflow to the replicating portfolio, 
the (personal) wealth process of the beneficiary invested into the fund stays continuous also over the contribution payment times.

\subsection{Different Guarantee Types in the classical CPPI Framework}

In this section, various types of guarantees/floors are introduced on which the CPPI strategies are based. They vary from being based on the actual value of the labor process and updated past guarantees - which are then themselves stochastic processes - to completely specified guarantees that are based on the initial net present value of the premium stream.

\subsubsection{Deterministic (Net present value) floor}

The guarantee in classical CPPI is an initially fixed amount of money $\bar{Y}$ paid at maturity. As a consequence, by arbitrage considerations, the floor level $Y(t)$ at time $t$ that is necessary for this guarantee equals

$$
Y(t)=e^{-r(T-t)} \bar{Y}
$$

with $Y(T)=\bar{Y}$. Note further that - again for arbitrage reasons - it should hold

$$
\bar{Y} \leq V(0) e^{r T}
$$

i.e. $Y(0)<V(0)$. Having fixed the guarantee, one next chooses the investment which is described by the multiplier of the cushion. For this, the cushion process $C(t)$ is introduced as the difference between the actual value of the DC fund and the floor, that is

$$
C(t)=V(t)-Y(t)
$$

as in (2.4). In a CPPI strategy one then always invests a multiple $m C(t)$ (with $m \geq 0$, often $m \gg 1$ ) into the stock and the remaining money into the bond. Note that the investor can now vary both the multiplier $m$ and the guarantee level $\bar{Y}$. Of course, a higher guarantee level will typically decrease the mean of the final value. We will get back to the optimal choice of the multiplier later.

In the current work, a special case of deterministic floor called net present value (NPV) floor is defined by setting the initial floor value equal to the net present value of the future contributions. The floor process is assumed to grow at the risk-free rate $r$. Let $Y(0)$ denote the net present value of the future contributions at time 0 , then $Y(0)$ is 
simply the price of the replicating portfolio of future contributions satisfying $Y(0) \leq$ $V(0)$. The guaranteed amount at time $T$ is thus

$$
\bar{Y}=Y(0) e^{r T}
$$

whereas at any time $t, \bar{Y}=Y(0) e^{r t}$ holds. The following relation is obtained from Proposition 3.1.

$$
Y(0)=c \gamma L(0) g(0)
$$

where $c$ is a constant representing the proportion of the initial wealth that will be guaranteed. If there are no further contributions to the fund then the choice of a multiplier $m$ for the cushion process leads to the following result (see [10]):

Proposition 3.2. Given an initial capital of $V(0)$ and a CPPI multiplier $m \geq 0$, it holds

$$
\begin{aligned}
d C(t) & =C(t)\left(\left(m\left(\mu_{S}-r\right)+r\right) d t+m \sigma_{S} d W(t)\right), \\
V(T) & =\bar{Y}+\left(V(0)-e^{-r T} \bar{Y}\right) e^{\left(r+m\left(\mu_{S}-r\right)-\frac{1}{2} m^{2} \sigma_{S}^{2}\right) T+m \sigma_{S} W(T)}, \\
\mathbb{E}(V(T)) & =\bar{Y}+\left(V(0)-e^{-r T} \bar{Y}\right) e^{\left(r+m\left(\mu_{S}-r\right)\right) T}
\end{aligned}
$$

for $t \in[0, T]$.

Proof. The portfolio value satisfies the following

$$
d V(t)=e(t) \frac{d S(t)}{S(t)}+(V(t)-e(t)) \frac{d B(t)}{B(t)}
$$

Then, by using the definition of $C, Y$ and the relation given above, it follows

$$
\begin{aligned}
d C(t) & =d(V(t)-Y(t)) \\
& =C(t)\left(\left(m\left(\mu_{S}-r\right)+r\right) d t+m \sigma_{S} d W(t)\right) .
\end{aligned}
$$

Moreover, the terminal wealth $V(T)$ is defined as the summation of guarantee at time $T$ and the excess return earned from investing in the initial cushion in stock market. Since the initial cushion is given as

$$
C(0)=\left(V(0)-e^{-r T} \bar{Y}\right) e^{\left(r+m\left(\mu_{S}-r\right)-\frac{1}{2} m^{2} \sigma_{S}^{2}\right) T+m \sigma_{S} W(T)},
$$

it holds that 


$$
V(T)=\bar{Y}+\left(V(0)-e^{-r T} \bar{Y}\right) e^{\left(r+m\left(\mu_{S}-r\right)-\frac{1}{2} m^{2} \sigma_{S}^{2}\right) T+m \sigma_{S} W(T)} .
$$

Computing the expectation of $V(T)$ applying the moment generating function definition of Normal distribution completes the proof.

Wealth dynamics. It is clear that the portfolio value satisfies

$$
d V(t)=e(t) \frac{d S(t)}{S(t)}+(V(t)-e(t)) \frac{d B(t)}{B(t)} .
$$

Using the dynamics of the cushion and the assets, it is found that

$$
\begin{aligned}
d V(t) & =d C(t)+d Y(t) \\
& =C(t)\left(\left(m\left(\mu_{S}-r\right)+r\right) d t+m \sigma_{S} d W(t)\right)+r Y(t) d t \\
& =\left(m\left(\mu_{S}-r\right) C(t)+r V(t)\right)+m C(t) \sigma_{S} d W(t) .
\end{aligned}
$$

Next, the dynamics of the random floor is examined when it is defined based on future contributions.

\subsubsection{Random floor}

The second floor introduced has stochastic dynamics and is called random floor. In this CPPI setting, the aim of the present thesis is to ensure that a fraction of all past and future contributions will be guaranteed until retirement. More precisely, let $\bar{\gamma}\left(t_{i}\right)$ be the guaranteed fraction of the contribution payment at any time $t_{i} \in[0, T]$, i.e.

$$
\bar{\gamma}\left(t_{i}\right)=c \gamma\left(t_{i}\right)
$$

for some real constant $0<c<1$ and $i=0,1,2, \ldots, n$. Then for any time $t$, the payments made in the past will be carried over to present time and the future contributions will be included to the guarantee/floor process after discounting to time $t$. Denoting the floor value at time $t$ by $Y(t)$, the floor process is defined as the summation of time- $t$ values of the contributions $\bar{\gamma}\left(t_{i}\right)$ for $i=0,1,2, \ldots, n$, i.e.

$$
Y(t):=\sum_{i: 0 \leq t_{i}<t} e^{r\left(t-t_{i}\right)} \bar{\gamma}\left(t_{i}\right)+\mathbb{E}^{\mathbb{Q}}\left[\sum_{i: t_{i} \geq t} e^{-r\left(t-t_{i}\right)} \bar{\gamma}\left(t_{i}\right) \mid \mathcal{F}_{t}\right]
$$

Applying Itô's formula to $Y$, the risk neutral dynamics are found as follows

$$
d Y(t)=r Y(t) d t+c \sigma_{L} Z(t) d \widetilde{W}(t)
$$


with $Z(t)$ as given in 3.7$)$. Under the real-world measure $\mathbb{P}, Y(t)$ then satisfies

$$
d Y(t)=\left(r Y(t)+c \sigma_{L} \theta Z(t)\right) d t+c \sigma_{L} Z(t) d W(t)
$$

Similar to what has been done in Section 3.3 , now the aim is to show that this newly defined floor process is hedgeable (or replicable). Otherwise, the CPPI strategy would not work because it would not be possible to mimic its behavior using the assets and therefore, it would be impossible to always evolve above the floor. So, next it is shown that a replication strategy exists for $Y(t)$ which is given in $(3.18)$. We consider a selffinancing hedging strategy $\bar{\pi}=\left(\pi_{B}, \pi_{S}\right)$ where $\pi_{B}$ and $\pi_{S}$ denote the number of units held from the respective asset. Treating $Y$ as a portfolio and choosing $\varphi_{Y}=-1$, it holds

$$
\begin{aligned}
d V^{\pi}(t) & =\pi_{B}(t) d B(t)+\pi_{S}(t) d S(t)-d Y(t) \\
& =\left(\pi_{B} r B+\pi_{S} S \mu_{S}-r Y-c \sigma_{L} \theta Z(t)\right) d t+\left(\pi_{S} S \sigma_{S}-c \sigma_{L} Z\right) d W .
\end{aligned}
$$

Equating the diffusion terms and the drift terms to zero, the replicating portfolio $\bar{\pi}$ is obtained as

$$
\pi_{S}(t)=\frac{Z(t)}{S(t)} \frac{c \sigma_{L}}{\sigma_{S}} \text { and } \pi_{B}(t)=\frac{1}{B(t)}\left(Y(t)-Z(t) \frac{c \sigma_{L}}{\sigma_{S}}\right) .
$$

Wealth dynamics. The portfolio should be allocated in such a way that it is able to mimic the floor while staying always above it. To achieve this, the asset exposure should include the fraction coming from the replicating strategy $\left(\pi_{S}\right)$ and the exposure of CPPI, that is $m C(t)$. The total amount invested in the stock index is therefore given by

$$
e(t):=m C(t)+\Pi_{S}(t) S(t)
$$

where the remaining funds are invested in the bond. According to this allocation, inserting the asset dynamics into (3.16), the CPPI value process is given as

$$
\begin{aligned}
d V(t)=( & \left.C(t)\left(m\left(\mu_{S}-r\right)+r\right)+c Z(t) \frac{\sigma_{L}}{\sigma_{S}}\left(\mu_{S}-r\right)+r Y(t)\right) d t \\
& +\left(m C(t) \sigma_{S}+c Z(t) \sigma_{L}\right) d W(t)
\end{aligned}
$$

with the initial value $V(0)=Z(0)$.

It is required that the portfolio value process always evolves above the guarantee process, i.e.

$$
V(t) \geq Y(t), \quad \forall t \in[0, T]
$$

Then, with the condition $0<c<1$, it holds 


$$
\gamma(0) L(0) g(0)>\bar{\gamma} L(0) g(0)
$$

that is,

$$
V(0)>Y(0)
$$

Therefore, the cushion value at time zero is positive. Using the definition of the cushion (2.4), and the dynamics of $V(t)$ and $Y(t)$ as derived above, the SDE of the cushion is found as follows

$$
d C(t)=C(t)\left(\left(m\left(\mu_{S}-r\right)+r\right) d t+m \sigma_{S} d W(t)\right) .
$$

With this form of the cushion it is particularly obtained:

Proposition 3.3. In case of the random floor $Y(t)$ of the form given in (3.18), following a conventional CPPI strategy leads to

$$
\begin{aligned}
V(T) & =Y(T)+(V(0)-Y(0)) e^{\left(r+m\left(\mu_{S}-r\right)-\frac{1}{2} m^{2} \sigma_{S}^{2}\right) T+m \sigma_{S} W(T)} \\
Y(T) & =\sum_{i: 0 \leq t_{i} \leq T} e^{r\left(T-t_{i}\right)} \bar{\gamma}\left(t_{i}\right) \\
Y(0) & =\bar{\gamma} L(0) \sum_{i: 0 \leq t_{i}} e^{\left(\mu_{L}-r-\theta \sigma_{L}\right) t_{i}} \\
\mathbb{E}(Y(T)) & =\bar{\gamma} L(0) \sum_{i: 0 \leq t_{i} \leq T} e^{r T+\left(\mu_{L}-r\right) t_{i}}=: \bar{Y}_{T} \\
\mathbb{E}(V(T)) & =\bar{Y}_{T}+(V(0)-Y(0)) e^{\left(r+m\left(\mu_{S}-r\right)\right) T}
\end{aligned}
$$

for $i=0,1,2, \ldots, n$.

Proof. By definition (3.18), it is clear that

$$
Y(T)=\sum_{i: 0 \leq t_{i}<T} e^{r\left(T-t_{i}\right)} \bar{\gamma}\left(t_{i}\right)
$$

Taking the expectation of $Y(T)$ using the dynamics given in (3.3) and (3.17) yields

$$
\begin{aligned}
\mathbb{E}(Y(T)) & =\sum_{i: 0 \leq t_{i}<T} e^{r\left(T-t_{i}\right)} \mathbb{E}\left(\bar{\gamma}\left(t_{i}\right)\right) \\
& =\bar{\gamma} L(0) \sum_{i: 0 \leq t_{i} \leq T} e^{r T+\left(\mu_{L}-r\right) t_{i}}
\end{aligned}
$$

The terminal wealth $V(T)$ is guarantee at maturity with the excess return earned from investing in the initial cushion in stock market. Therefore it is found that 


$$
V(T)=Y(T)+(V(0)-Y(0)) e^{\left(r+m\left(\mu_{S}-r\right)-\frac{1}{2} m^{2} \sigma_{S}^{2}\right) T+m \sigma_{S} W(T)}
$$

Computing the expectation of $V(T)$ and using the moment generating function of Normal distribution completes the proof.

Note that the cushion process $C$ has the same dynamics under both floor assumptions. Therefore, the optimal control problem formulated is valid for both cases which will be presented in the next section.

\subsection{Optimal Control Problem}

In this section, the optimal multiplier choice problem is examined by formulating an optimal control problem and using the methodology given in [38]. For more detailed information, the general theory of optimal control in finance is given in [45]. The problem is the optimization of the cushion process over the control variable $m$. Therefore, the objective function is not directly related to the form of the floor, so the solution is valid for both cases given in Section 3.4. As the labor income $L(t)$ does not introduce any additional randomness, a one-dimensional control problem is solved where $C$ is taken as the state variable. The utility function $u(\cdot)$ is assumed to be of constant relative risk aversion type. For the functional $J:[0, T] \times \mathbb{R} \rightarrow \mathbb{R}$, the optimal control problem is formulated as

$$
\begin{gathered}
J(t, C(t))=\max _{m \in \mathcal{A}} \mathbb{E}[u(C(T))], \\
\text { s.t. } J(T, C(T))=u(C(T))
\end{gathered}
$$

with $\mathcal{A}$ being the set of admissible controls $m:[0, T] \rightarrow \mathbb{R}$ i.e. progressively measurable square integrable random variables such that $C(T)$ is almost surely positive. Hence, the problem is stated as

$$
\max _{m \in \mathcal{A}\left(0, C_{0}\right)}\left(J_{t}+C\left(m\left(\mu_{S}-r\right)+r\right) J_{C}+\frac{1}{2} C^{2} m^{2} \sigma_{S}^{2} J_{C C}\right)=0
$$

where it is denoted that $J_{t} \equiv \partial J / \partial t, J_{C} \equiv \partial J / \partial C$ and $J_{C C} \equiv \partial^{2} J / \partial^{2} C$. Differentiating the HJB equation given by (3.33) with respect to $m$ yields

$$
C\left(\mu_{S}-r\right) J_{C}+C^{2} m \sigma_{S}^{2} J_{C C}=0 .
$$

Using (3.34) the HJB equation is reformulated as 


$$
J_{t}-\frac{1}{2} C^{2} m^{2} \sigma_{S}^{2} J_{C C}+C r J_{C}=0
$$

which holds simultaneously with (3.34). Considering the ansatz

$$
J(t, C)= \begin{cases}\frac{C^{1-\eta}}{1-\eta} h(t) & \text { if } \eta>0, \eta \neq 1 \\ \log (C) h(t) & \text { if } \eta=1\end{cases}
$$

for the value function, the candidate for the optimal solution is obtained as follows:

$$
m^{*}=\frac{\mu_{S}-r}{\sigma_{S}^{2} \eta}
$$

Here the parameter $\eta>0$ represents the risk aversion level. Inserting the ansatz and the candidate solution given by (3.37) into (3.35) the ordinary differential equation is obtained

$$
h^{\prime}+\rho h=0
$$

where

$$
\rho=\frac{1}{2} \frac{\left(\mu_{S}-r\right) 2}{\sigma_{S}^{2} \eta}(1-\eta)+r(1-\eta) .
$$

The function $h$ is immediately found as

$$
h(t)=e^{\rho(T-t)} .
$$

As the exponential term of the value function is positive, $J$ is strictly concave. Therefore, $m^{*}$ is a maximizer.

In the next subsection, it is shown that $m^{*}$ is also an optimal solution for the problem (3.32), i.e. the verification theorem is proved.

\subsubsection{Verification of the solution}

To provide the relation between the solution of the PDE and the optimal control problem, the Theorem given in [36] is used. Consider a controlled process with an SDE of the form

$$
d X(t)=\mu(t, X(t), u(t)) d t+\sigma(t, X(t), u(t)) d W(t) .
$$


The notations for the theorem are as follows: for $n, d \in \mathbb{N}$ let $Q:=\left[t_{0}, t_{1}\right) \times \mathbb{R}^{n}$ with $0 \leq t_{0}<t_{1}<\infty, \bar{Q}:=\left[t_{0}, t_{1}\right] \times \mathbb{R}^{n}$ and $U \subset \mathbb{R}^{d}$. Further, let the coefficients of the process 3.40) satisfy Lipschitz and growth conditions for some constant $T$.

Theorem 3.4. Let $G \in C^{1,2}(Q) \cap C(\bar{Q})$ with $|G(t, x)| \leq K\left(1+|x|^{k}\right)$ for some suitable constants $K>0, k \in \mathbb{N}$, be a solution to the Hamilton-Jacobi-Bellman equation:

$$
\begin{gathered}
\sup _{u \in U}\left(A^{u} G(t, x)+L(t, x, u)\right)=0, \quad(t, x) \in Q \\
G(t, x)=\Psi(t, x), \quad(t, x) \in \partial Q
\end{gathered}
$$

Then,

1. $G(t, x) \leq J(t, x ; u)$ for all $(t, x) \in Q$ and $u(\cdot) \in \mathcal{A}(t, x)$.

2. If for all $(t, x) \in Q$ there exists a $u^{*}(\cdot) \in \mathcal{A}(t, x)$ with

$$
u^{*}(s) \in \underset{u \in U}{\arg \max }\left(A^{u} G\left(s, X^{*}(s)\right)+L\left(s, X^{*}(s), u\right)\right)
$$

for all $s \in[t, \tau]$, where $X^{*}(s)$ is the controlled process corresponding to $u^{*}(\cdot)$, then it is obtained

$$
G(t, x)=V(t, x)=J\left(t, x ; u^{*}\right) .
$$

In particular, $u^{*}(t)$ is an optimal control and $G(t, x)$ coincides with the value function.

Proof. It is clear that our HJB equation has the same form as in Theorem 3.4. Therefore, to be able to apply the theorem, as a first step it should be proved that the optimal solution given by (3.37) is admissible. Then, as the second step, the proof of the following inequality should be given

$$
\mathbb{E}\left(\sup _{t \in[0, T]}|J(t, C)|^{n}\right)<\infty \text { holds for real } n \geq 1
$$

Step 1 : To investigate the admissibility of $m^{*}$, the definition from [36] is given next.

Definition 3.1. (Definition 5.15 p. 225, [36]) Let $(\Omega, \mathbb{F}, \mathbb{P})$ endowed with the filtration $\left\{\mathbb{F}_{t}\right\}_{t \in[0, T]}$ be a probability space. A $U$-valued progressively measurable process $u(t), t \in\left[t_{0}, t_{1}\right]$ is an admissible control if for all values $x \in \mathbb{R}^{n}$ the stochastic differential equation (3.40) with initial condition $X\left(t_{0}\right)=x$ possesses a unique solution $\{X(t)\}_{t \in\left[t_{0}, t_{1}\right]}$ and if it holds

$$
\mathbb{E}\left(\int_{t_{0}}^{t_{1}}|u(s)|^{k} d s\right)<\infty
$$


and

$$
\mathbb{E}\left(\|X(\cdot)\|^{k}\right)<\infty
$$

for all $k \in \mathbb{N}$.

As $m^{*}$ is found to be a constant, it is bounded and inequality (3.44) holds. Moreover, the solution of our controlled process given in 3.23 ) is found as

$$
C(t)=C_{0} e^{\left(m\left(\mu_{S}-r\right)+r-\frac{m^{2} \sigma_{S}^{2}}{2}\right) t+m \sigma_{S} W(t)} .
$$

Therefore, uniqueness of the solution is proved as well as the following inequality

$$
\mathbb{E}\left(\|C(t)\|^{k}\right)=C_{0}^{2} e^{2\left(m\left(\mu_{S}-r\right)+r+\frac{m^{2} \sigma_{S}^{2}}{2}\right) t}<\infty
$$

Hence, the control $m^{*}$ is admissible.

Step 2 : By (3.46), it holds

$$
\mathbb{E}\left(\sup _{t \in[0, T]}|J(t, C)|^{n}\right)=\mathbb{E}\left(\sup _{t \in[0, T]}\left|\frac{C^{1-\eta}}{1-\eta} h(t)\right|\right)
$$

with $h(t)$ given as in 3.39 . As $C(t)$ is bounded by (3.46), it is obtained that

$$
\mathbb{E}\left(\sup _{t \in[0, T]}\left|\frac{C^{1-\eta}}{1-\eta} h(t)\right|\right)<\infty
$$

which completes the proof. Therefore, the solution $m^{*}$ is the optimal control for our optimal control problem 3.32.

\subsection{Risk Measures and Comparison of Strategies}

In this section, gap and cash-lock risks are analyzed for the CPPI strategies considered under continuous-time trading. Some of these risks mostly arise under discrete-time trading assumption due to the inability of instant trading. However, they can also occur in a market with continuous-trading when there is a sudden drop in the market. Therefore, their occurrence is first discussed in continuous-time trading setting by computing respective risk measures. After obtaining the risk measures, a numerical example 
is presented and the effectiveness of the CPPI strategies with NPV and random floor are discussed.

\subsubsection{Cash-lock Risk}

As described in Section 2.2.2, cash-lock phenomenon occurs when the total wealth gets locked up invested in the risk-free asset and stays there until the retirement. This means that at some point during the plan, the cushion becomes zero and does not recover until the retirement due to zero asset exposure. This is not possible in continuoustime trading as the portfolio manager will react instantly and prevent the cushion to approach zero. This is also justified by the continuous dynamics of the cushion which is given as a geometric Brownian motion $(g B M)$ for both floors as in (3.23).

Definition 3.2. (Cash-lock probability) For the period $(t, \tau)$, the cash-lock probability $P_{t, \tau}^{C L}$ denotes the probability that the proportion of the risky asset at $\tau$ is equal to zero given that it is equal to $\zeta$ at $t$, i.e.

$$
P_{t, \tau}^{C L}:=P\left(\frac{m C(\tau)}{V(\tau)}=0 \mid \frac{m C(t)}{V(t)}=\zeta\right)
$$

Therefore, such a probability $P_{t, \tau}^{C L}$ is zero for continuous-time CPPI with both NPV and random floors. However, this is only valid for an artificial continuous-time market, that is the probability is non-zero in markets where dynamic trading is not possible. To illustrate the cash-lock phenomenon in a discrete-trading setting that a path is simulated via Monte Carlo simulation where time is discretized according to Euler method. In this simulation, despite the fact that a very fine grid is used for the timeline, the inability of instant trading caused a cash-locked position in a decreasing market generated specifically. Figure 3.1 shows the cash-lock phenomenon which is impossible in continuous-time, but has a positive probability in a discrete-trading setting which is encountered in the implementation due to time discretization. Here, $\eta$ is the risk aversion parameter of the utility function and $c$ is the guarantee rate as defined in (3.17). One can see from the figure that, once the market goes down the portfolio approaches to floor very quickly and cushion gets closer to zero before the investor has time to reallocate the wealth. Therefore, the total wealth gets invested in cash asset/bond and evolves as the floor until retirement yielding no excess gains. This is an important risk for settings with discrete trading and it should hedged by designing complicated CPPI strategies which is able to vary based on the market. This is the second aim of the present study and it is handled in Chapter 4. 

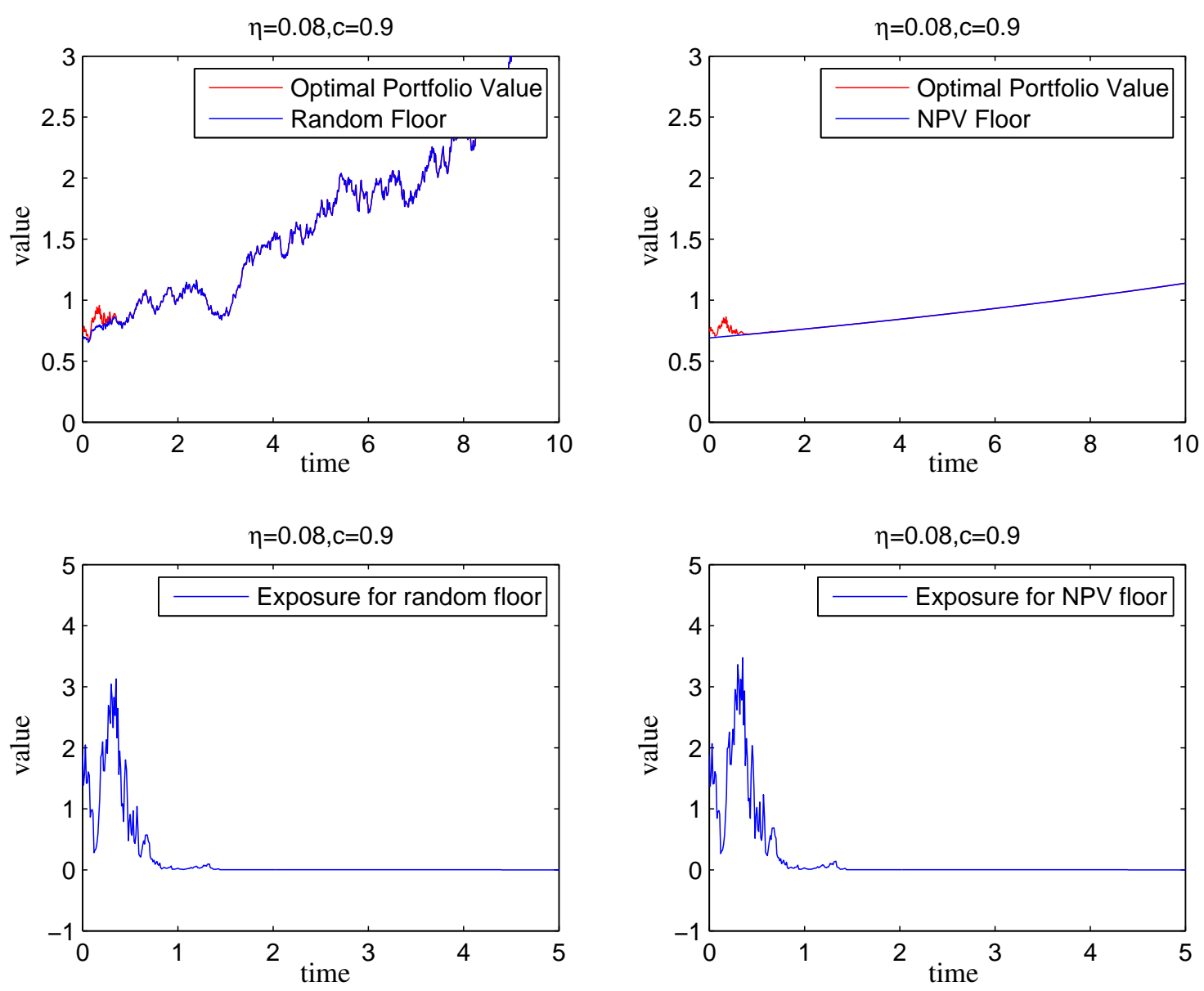

Figure 3.1: Cash-locked portfolios with different floors

\subsubsection{Gap Risk}

Another problem associated with dynamic portfolio insurance strategies such as CPPI is the gap-risk which is described in Section 2.2.2. Gap-risk is the risk of failing to achieve the guarantee at the retirement with probability one. This shortfall probability is caused by the incompleteness of the market due to certain imposed restrictions.

Definition 3.3. (Shortfall Probability) The shortfall probability $P^{S F}$ denotes the probability that the final value of the CPPI strategy is less than the guaranteed amount $Y(T)$, i.e.

$$
P^{S F}:=P(C(T)<0) .
$$

Again, with continuous trading, it is impossible for the cushion to be negative at any time during the investment period. This can also be seen very clearly from the dynamics of the cushion which is given in (3.2) and (3.23) for both floors. Since the cushion is Geometric Brownian motion, it is non-negative. 
Since, these are major risks and are present in real financial markets, they are revisited in Chapter 4 under a discrete trading environment.

\subsection{Numerical Results}

To illustrate the behavior of CPPI portfolios under different floor assumptions presented, some numerical examples are given in this section. The set of input parameters is given in Table 3.1. Except the labor income drift $\mu_{L}$, the parameters are selected arbitrarily as their size have a small effect on the comparison of final wealths. The drift $\mu_{L}$ is specifically set at a value higher than the risk-free rate with the purpose of reflecting realistic income levels. Throughout the section this parameter set is used in numerical results, unless stated otherwise. All numerical calculations are carried out via MATLAB.

Table 3.1: Assumed values for parameters under continuous-time trading setting

\begin{tabular}{lc}
\hline Interest rate, $r$ & 0.05 \\
Stock parameters & \\
$\quad$ Drift, $\mu_{S}$ & 0.12 \\
Volatility, $\sigma_{S}$ & 0.2 \\
Labor income parameters & \\
$\quad$ Drift, $\mu_{L}$ & 0.06 \\
Volatility, $\sigma_{L}$ & 0.09 \\
Guarantee rate, $c$ & 0.8 \\
Risk aversion parameter, $\eta$ & 2 \\
Contribution rate, $\gamma$ & 0.1 \\
\hline
\end{tabular}

Figures 3.2 and 3.3 correspond to the evolution of the optimal portfolios with different floors under varying guarantee rate, $c$. We see that the portfolio becomes closer to the floor as $c$ increases and almost mimics it when $c \rightarrow 1$. This is an anticipated situation as the gains are expected to decrease when a high proportion of the portfolio value is guaranteed. Moreover, the perfect hedging in the random floor case can be clearly observed from Figure 3.3 . 

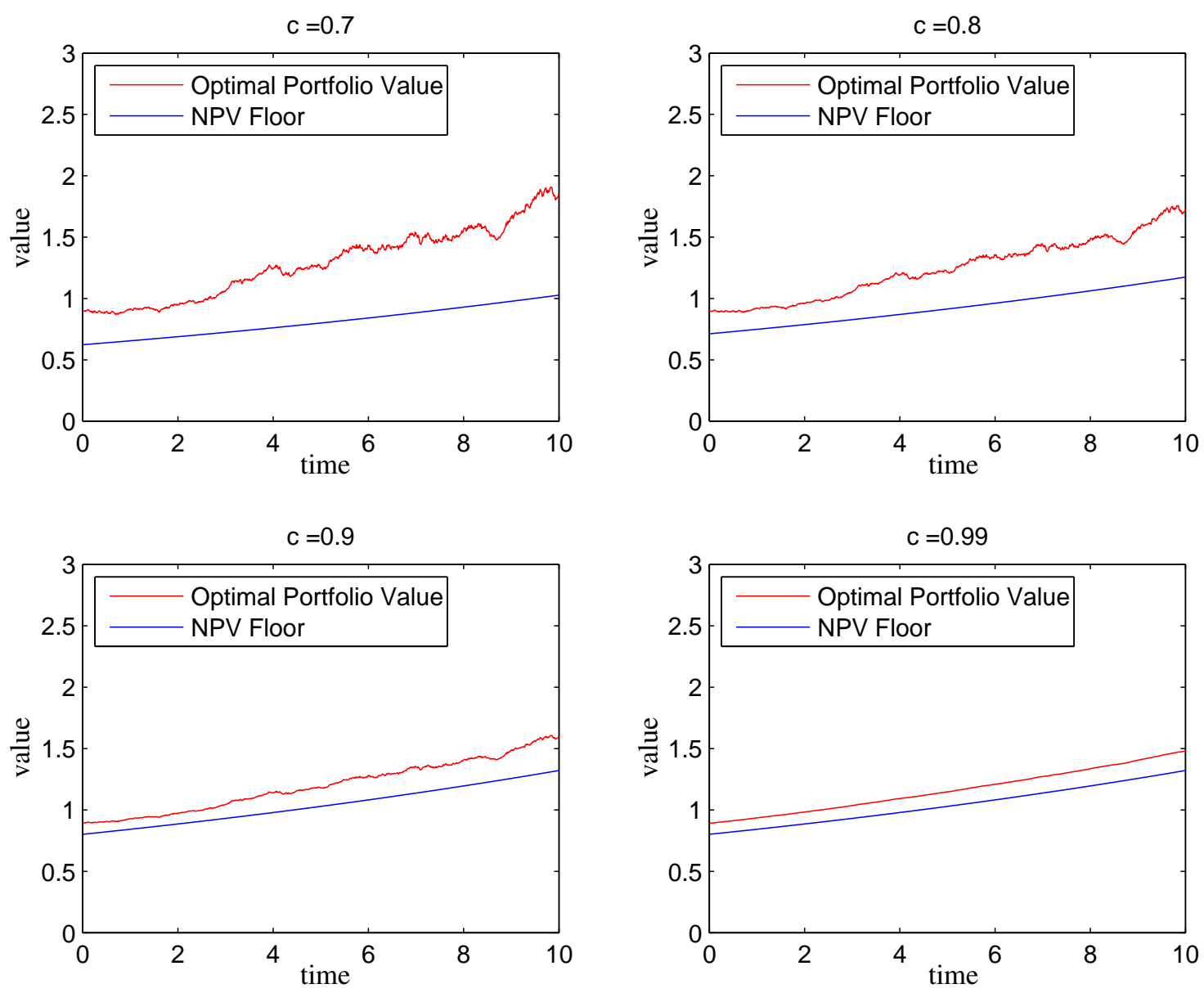

Figure 3.2: CPPI with NPV floor for $\eta=2$

Figures 3.4 and 3.5 show the differing behavior of the portfolio value for varying risk aversion levels. It can be seen from both figures that, for increasing risk aversion the portfolio demonstrates a more robust behavior with decreasing gains. This is not a surprising result as the stock exposure and the parameter $\eta$ are inversely proportional. Moreover, the main comparison between the strategies with two different floors leads us to the fact that the NPV floor CPPI strategy promises lower gains as expected. However, it is important to stress that setting the final guarantee value equal to the net present value of the future payments is still a better option compared to the case where the beneficiary decides about the guarantee amount. The reason is that in the NPV floor CPPI, the randomness in the future labor income is taken into account and the beneficiary most likely will fail to do so.

Generally, the portfolio value for each case evolves above the floor level emphasizing the efficiency of both of the approaches. 

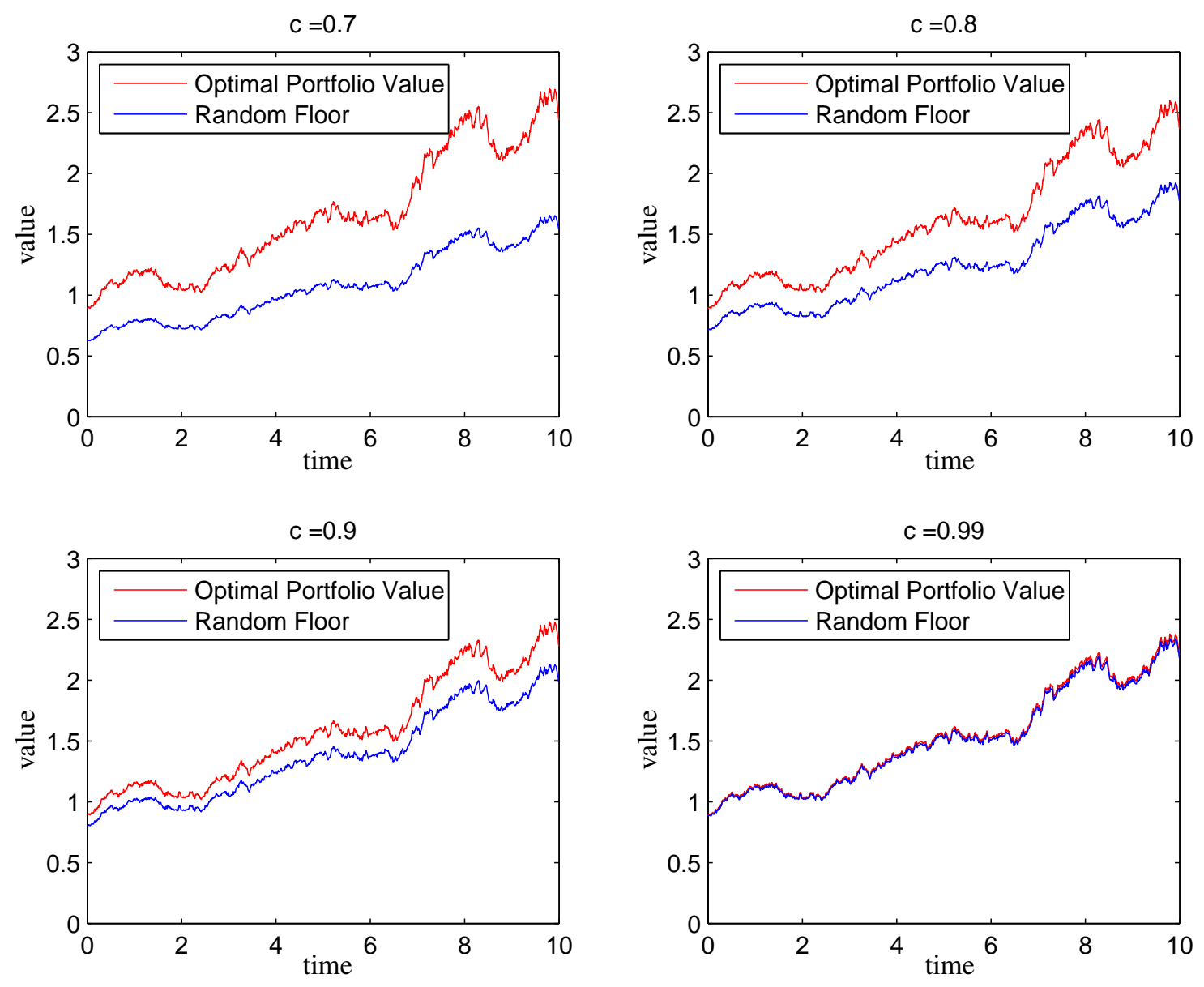

Figure 3.3: CPPI with random floor for $\eta=2$ 

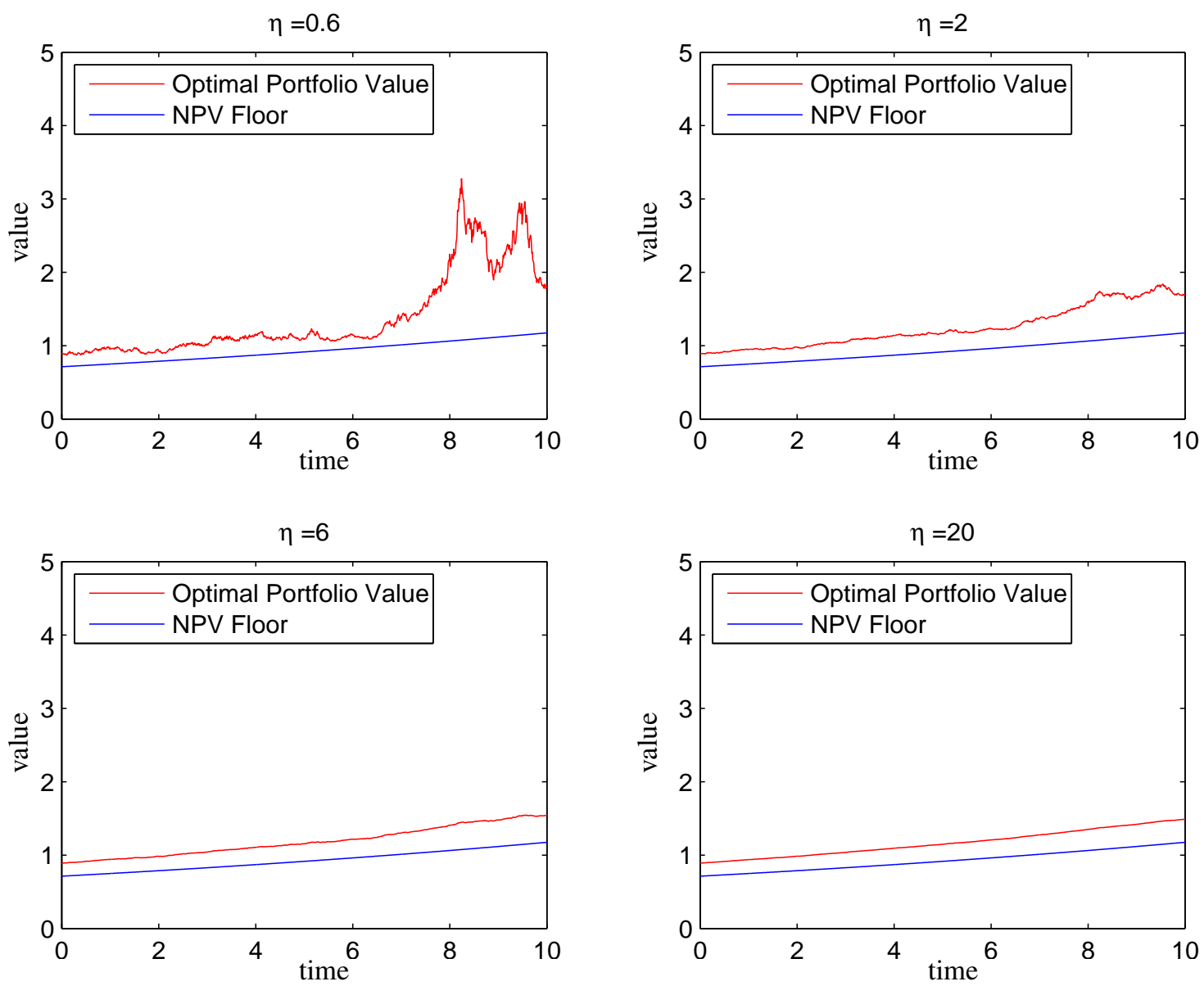

Figure 3.4: CPPI with NPV floor for $c=0.8$ 

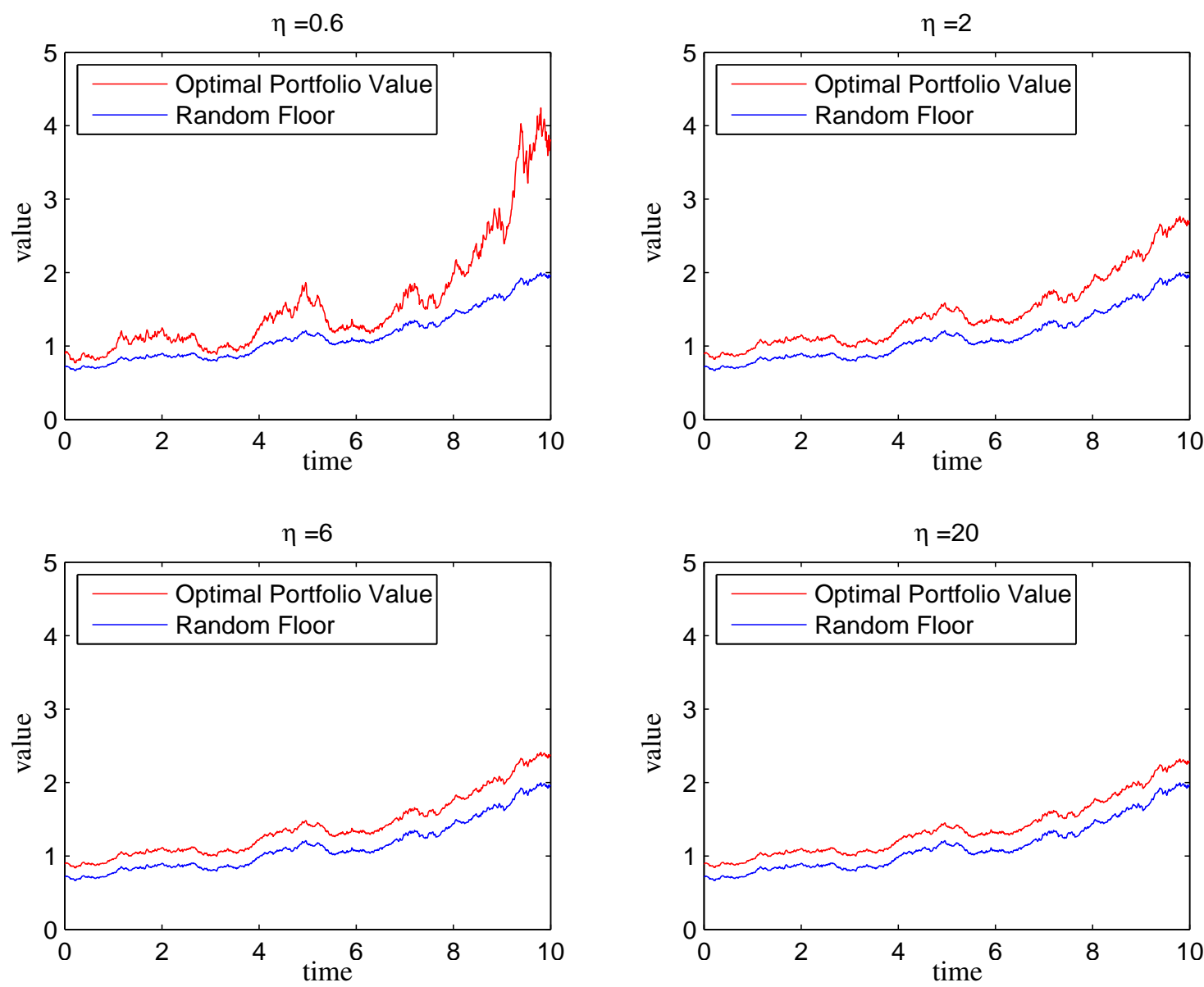

Figure 3.5: CPPI with random floor for $c=0.8$ 
Table 3.2: Distributional properties of CPPI portfolio with random and NPV floor under certain parameter values

\begin{tabular}{lccccccc}
\hline \multirow{3}{*}{ Parameter } & & \multicolumn{3}{c}{ Value } & \multicolumn{2}{c}{ Terminal Wealth (NPV) } & \multicolumn{3}{c}{ Terminal Wealth (Random) } \\
\cline { 2 - 8 } & & $\mathbb{E}\left(V_{T}\right)$ & $\sigma^{2}\left(V_{T}\right)$ & $C V\left(V_{T}\right)$ & $\mathbb{E}\left(V_{T}\right)$ & $\sigma^{2}\left(V_{T}\right)$ & $C V\left(V_{T}\right)$ \\
\hline \multirow{4}{*}{$\sigma_{S}$} & 0.1 & 1.7299 & 0.1054 & 0.1877 & 4.4465 & 0.6211 & 0.1772 \\
& 0.2 & 1.7038 & 0.1047 & 0.1899 & 2.1211 & 0.6074 & 0.3674 \\
$\mu_{S}$ & 0.4 & 1.6508 & 0.0100 & 0.0606 & 1.8710 & 0.2635 & 0.2744 \\
\cline { 2 - 8 } & 0.06 & 1.7033 & 0.0007 & 0.0155 & 1.7599 & 0.1870 & 0.2457 \\
& 0.12 & 1.7281 & 0.1212 & 0.2015 & 2.1764 & 0.7004 & 0.3845 \\
$\sigma_{L}$ & 0.24 & 22.170 & 3789.5 & 2.7767 & 23.389 & 3840.1 & 2.6495 \\
\cline { 2 - 8 } & 0.045 & 1.8587 & 0.1083 & 0.1711 & 2.0732 & 0.2841 & 0.2571 \\
& 0.09 & 1.7230 & 0.1104 & 0.1928 & 2.1696 & 0.6373 & 0.3680 \\
$\mu_{L}$ & 0.18 & 1.4764 & 0.0946 & 0.2083 & 2.4353 & 2.5760 & 0.6591 \\
\hline \multirow{4}{*}{$\eta$} & 0.03 & 1.4554 & 0.0711 & 0.1832 & 1.8098 & 0.4270 & 0.3611 \\
& 0.06 & 1.7240 & 0.1140 & 0.1958 & 2.1712 & 0.6522 & 0.3720 \\
& 0.1 & 2.1470 & 0.1646 & 0.1890 & 2.7045 & 0.9752 & 0.3651 \\
\hline & 0.6 & 3.0874 & 36.008 & 1.9436 & 3.5150 & 39.658 & 1.7916 \\
& 2 & 1.7096 & 0.0949 & 0.1802 & 2.1373 & 0.5829 & 0.3572 \\
$c$ & 6 & 1.5330 & 0.0044 & 0.0433 & 1.9606 & 0.2752 & 0.2676 \\
& 20 & 1.4857 & 0.0003 & 0.0117 & 1.9134 & 0.2261 & 0.2485 \\
\hline & 0.7 & 1.8410 & 0.2573 & 0.2755 & 2.2194 & 0.8544 & 0.4165 \\
& 0.8 & 1.7259 & 0.1121 & 0.1940 & 2.1756 & 0.6512 & 0.3709 \\
& 0.9 & 1.5867 & 0.0247 & 0.0990 & 2.0589 & 0.4598 & 0.3293 \\
& 0.99 & 1.4793 & 0.0002 & 0.0096 & 1.9954 & 0.3492 & 0.2961 \\
\hline & 0.05 & 0.8607 & 0.0264 & 0.1888 & 1.0820 & 0.1583 & 0.3677 \\
& 0.1 & 1.7088 & 0.0933 & 0.1788 & 2.1357 & 0.5752 & 0.3551 \\
& 0.2 & 3.4370 & 0.4169 & 0.1879 & 4.3175 & 2.4601 & 0.3633 \\
\hline
\end{tabular}

Table 3.2 shows the impacts of changing the value of one parameter while holding other parameters at the values in Table 3.1 for sensitivity test. A rise in the stock drift increases the expected terminal wealth for both cases with a substantial rise of the variance. Also as expected, increasing stock volatility decreases the mean of terminal wealth. One important point to notice is that, while labor income volatility directly affects the wealth under random floor assumption, it is almost irrelevant for the NPV floor case. Again, this is not surprising due the fact that the evolution of random floor depends on $\sigma_{L}$ as presented in (3.20). Moreover, for increasing values of $\eta$ i.e. higher levels of risk aversion, mean and variance decreases for both cases. More specifically, for $\eta>2$ there is a sharp decrease in wealth mean and variance. This is the result of holding a very low-risk portfolio due to high risk aversion level. Since investment in risky asset will be smaller for higher $\eta$, a break point between $\eta=0.6$ and $\eta=2$ may not exist at which the mean drops suddenly. Instead, the mean decreases steadily but at a faster level between $0.6<\eta<2$. This is expected as the portfolio will heavily consist risk-free asset for high values of $\eta$. Another prominent impact reflected by the table concerns the guaranteed proportion $c$ and the contribution rate $\gamma$. While increasing $c$ decreases the portfolio performance, rising contribution rate $\eta$ also 
increases wealth. These findings are also supported by coefficient of variation (CV) results. Overall, random terminal wealth yields higher volatility compared to NPV. The increase in variation is also observed when the parameter values tend to rise. An unexpected spread-mean ratio is attained when the $\sigma_{S}=0.2$ in case of random terminal wealth which yields the highest volatility. Another remark is for the case when $\eta<1$ the volatility is recognizably high as the risk appetite increase.
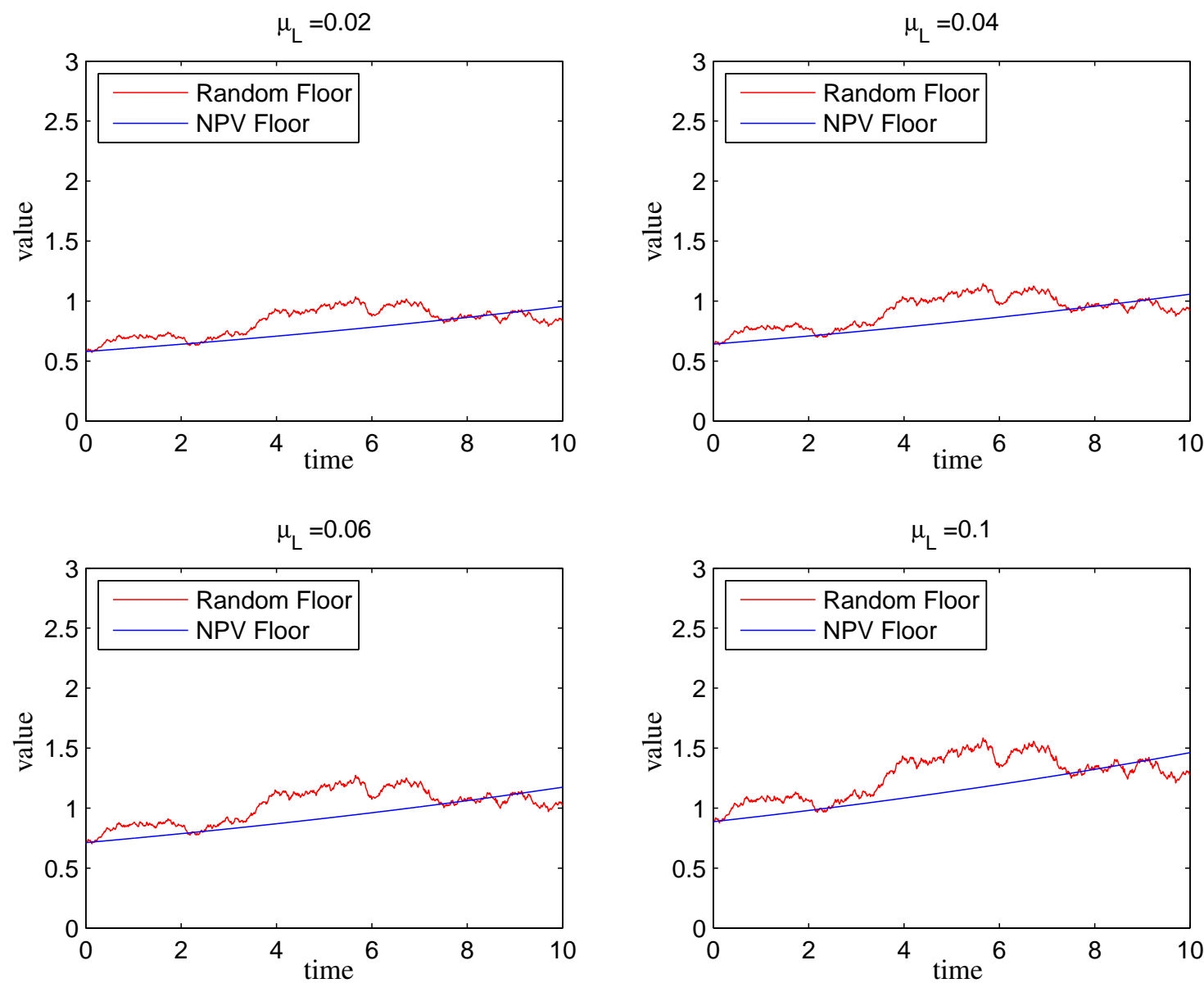

Figure 3.6: Evolution of the floors when market goes down

In Figure 3.6, floor evolutions are compared when market goes down for different values of $\mu_{L}$. From the figure, it is seen that the random floor crashes through the NPV floor after the downtrend starts and decreases steadily with the market due to its mimicking dynamics. The NPV floor, on the other hand, remains unaffected by market conditions and continues to grow with the interest rate. It should be noted that even for higher values of labor trend, $\mu_{L}$, the random floor fails to recover and ends up below the deterministic floor. Overall, when both strategies are compared, it is clear that the CPPI with random floor almost always performs better than the NPV floor CPPI in terms of higher returns. However, Figure 3.6 shows that both strategies can be considered as optimal for different investment expectations. While participants who would like to be in a hedged position should prefer CPPI with NPV floor, those who 
would like to go with the market should hold CPPI with random floor.
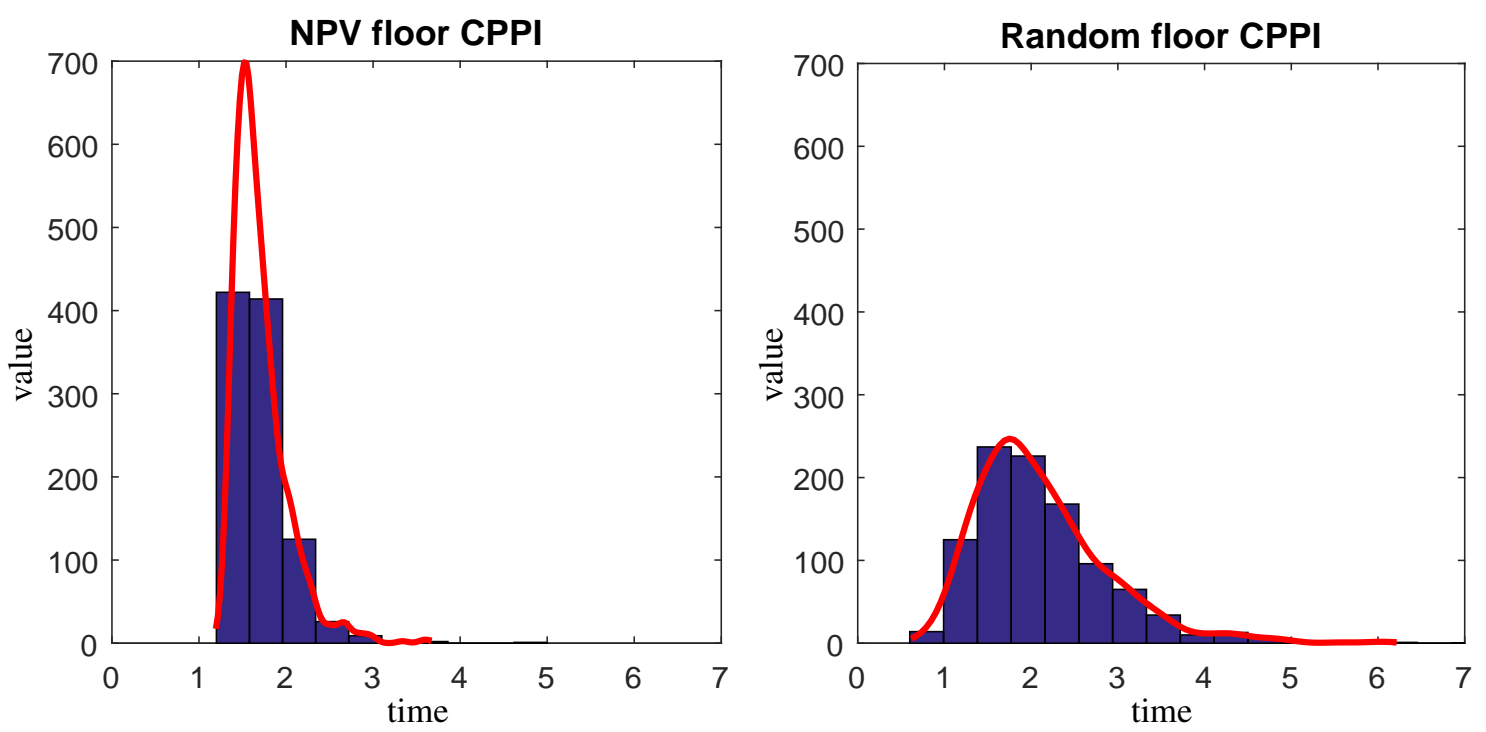

Figure 3.7: Terminal wealth densities of CPPI porfolios under certain parameter values

Finally, Figure 3.7 sharply illustrates the influence of floor choice. As the NPV floor exposes the terminal wealth to be accumulated around smaller returns with high frequency and short tail skewed to right. However, random floor extends to larger values justifying the high volatility in terminal wealth. These findings show that the random floor CPPI promises higher benefits to the participants with a larger variance in comparison to the NPV case. However, recalling that this benefit is protected by the imposed floor, the large variance only reflects the probability of having a terminal wealth equal to the level of floor at retirement time. Since this terminal floor (or wealth, for this scenario) consists of the guaranteed proportion of the contribution payments, the worst case scenario does not include any further losses. On the other hand, the NPV floor CPPI provides a more stable wealth profile with lowest wealth being yielded around a certain level. This result is due to the deterministic dynamics of the NPV floor. Since the floor grows at a constant rate, the cushion also displays a less volatile evolution while still having stochastic dynamics. In the light of these findings, it can be concluded that conservative participants can be directed to NPV floor towards more robust returns whereas less risk averse participants should prefer the other strategy. Regardless of the minimal risk aversion differences, it can be concluded that the random floor is superior to the NPV floor CPPI. 


\section{CHAPTER 4}

\section{CPPI in Pension Plans under Discrete-Time Trading}

In this chapter, the problem of portfolio insurance for DC funds is handled under discrete-time trading assumption. The market dynamics are assumed to be continuous with the same assets as given in Section 3.1.

\subsection{The market model}

Assuming that the market is comprised of a bond and a stock with the same dynamics as given in (3.1) and (3.2), one important distinction that arises for this market is incompleteness. Since perfect hedging is not possible in a discrete-time trading environment, the considered market becomes incomplete.

\subsection{Defined-Contribution modelling}

Similar to the setting given in Section 3.2, the participant is assumed to contribute a constant proportion $\gamma$ of his labor income. The dynamics of this income and the contribution rate as presented in (3.3) and (3.5), respectively. Since in this case the market is not complete, these future contributions cannot be replicated. This incompleteness problem will be handled via designing variable floors which are introduced in the next sections.

\subsection{CPPI under Discrete-Time Trading}

In this section, a discrete-time version of the classical CPPI is studied in the context of DC pension plans and describe the general discrete dynamics. The general setting is similar to that of Balder, Brandl \& Mahayni [4], however as a distinction, the problem is formulated in the presence of consecutive random contribution payments into wealth at fixed times. Since instant rebalancing is not possible under discrete-time trading, the major risks of cash-lock and gap risk are present, which are described in Section 3.6. 
Moreover, due to the inflow of regular payments into the portfolio value, the CPPI portfolio is not self-financing. After giving the discrete CPPI model, more specific CPPI strategies are introduced and study their path-dependent structures. In this discretetime framework, it is assumed that the trading is done immediately after the contribution payment $\gamma\left(t_{i}\right)$ at time $t_{i} \in[0, T]$ for $i=0,1, \ldots, n-1$. Let $\tau=\left\{t_{0}, t_{1}, \ldots, t_{n}\right\}$ be the set of fixed payment dates. Once the trading is done at time $t_{i}$, the number of shares held in the risky asset is constant until the next trading date, that is over the time period $\left(t_{i}, t_{i+1}\right]$. Instead of considering invested fractions of wealth, which may change between rebalancing times, the number of assets are taken into account at time $t$ and denote it by $\phi=(\alpha, \beta)$. Here, $\alpha$ and $\beta$ are the number of units of the stock index and the bond, respectively. Next, the discrete-time CPPI strategy is defined, as in [4].

Definition 4.1 ([4] $)$. A strategy $\phi=(\alpha, \beta)$ is called simple discrete-time CPPI if for $t \in\left(t_{k}, t_{k+1}\right]$ and $k=0, . ., n-1$

$$
\alpha_{t}=\max \left\{\frac{e\left(t_{k}\right)}{S_{t_{k}}}, 0\right\}, \beta_{t}=\frac{V_{t_{k}}-\alpha_{t} S_{t_{k}}}{B_{t_{k}}}
$$

It is important to note that due to the infeasibility of instant rebalancing, the cushion may become temporarily negative. To prevent the negative asset exposure caused by the negative cushion, a constraint on the number of risky asset is imposed as given in 4.1). Let the CPPI strategy held at time $t_{k}$ be represented by $\phi_{t_{k}}=\left(\alpha_{t_{k}}, \beta_{t_{k}}\right)$, then the value process of the DC pension portfolio under discrete-time is given by

$$
V_{t}\left(\phi_{t_{k}}\right)=\left\{\begin{array}{ll}
\alpha_{t_{k}} S_{t}+\beta_{t_{k}} B_{t}, & t \in\left(t_{k}, t_{k+1}\right) \\
\alpha_{t_{k}} S_{t_{k+1}}+\beta_{t_{k}} B_{t_{k+1}}+\gamma\left(t_{k+1}\right), & t=t_{k+1}
\end{array} .\right.
$$

The premium payment $\gamma\left(t_{k+1}\right)$ which will be invested into assets an instant later at time $t_{k+1}^{+}$, incurs a jump in the portfolio value at $t_{k+1}$. That is,

$$
\begin{aligned}
V\left(t_{k+1}\right)\left(\phi_{t_{k}}\right) & =V\left(t_{k+1}^{-}\right)\left(\phi_{t_{k}}\right)+\gamma\left(t_{k+1}\right) \\
& =V\left(t_{k+1}^{+}\right)\left(\phi_{t_{k+1}}\right)
\end{aligned}
$$

where $\phi_{t_{k+1}}$ is the portfolio held after the rebalancing at time $t_{k+1}$, for all $k=0,1, \ldots, n-$ 1. An additional assumption made is the limited borrowing. Imposing the constraint

$$
e(t)=\min \{m C(t), V(t)\}
$$

unlimited borrowing is prevented for all strategies to be introduced. Another novelty of the present study comes from the implementation the CPPI strategy, under various floor assumptions. Unlike the classical CPPI where the investor selects a certain fixed floor which he/she does not want the portfolio value fall below, different stochastic floor processes are studied along with floors with path-dependent structures. 


\subsubsection{Various CPPI strategies under Discrete-Time Trading}

This section presents floor variants under discrete-time trading and the analysis of corresponding CPPI strategies. First, two specific floor processes are introduced; net present value and random floor. After deriving their dynamics, more specific strategies are studied with path-dependent structures in following sections.

\subsubsection{CPPI with NPV floor}

The first floor introduced is the net present value (NPV) which is first described for a continuous setting in Section 4.3.1.1. In the CPPI strategy with the NPV floor, the initial floor is set to be the discounted value of the future contributions instead of fixing a constant guarantee amount for time $T$. This initial floor, denoted by $\bar{Y}$, is assumed to grow at the risk-free rate $r$ until maturity date. To understand the dynamics of this deterministic floor, the expectation of future payments are computed next. Let $Z(t)$ denote the market price at time $t$ of the stream of future contributions payable between time $t$ and $T$. Then have,

$$
Z(t):=\mathbb{E}^{\mathbb{P}^{*}}\left[\sum_{i: t_{i} \geq t} e^{-r\left(t_{i}-t\right)} \gamma\left(t_{i}\right) \mid \mathcal{F}_{t}\right]=\gamma L(t) g(t),
$$

with $g(t)=\sum_{i: t_{i} \geq t} e^{\left(\mu_{L}-r-\theta \sigma_{L}\right)\left(t_{i}-t\right)}$. Here $\mathbb{P}^{*}$ is the equivalent martingale measure used for arbitrage free pricing (for more information on the notion of arbitrage free pricing, see [31] and [32]). The dynamics of $L(t)$ under this martingale measure is given by

$$
\frac{d L(t)}{L(t)}=\left(\mu_{L}-\sigma_{L} \theta\right) d t+\sigma_{L} d \bar{W}(t)
$$

where $\theta=\frac{\mu_{s}-r}{\sigma_{S}}$ is the market price of risk and $\bar{W}$ is the Brownian motion under $\mathbb{P}^{*}$. In particular including the possible contribution exactly at time $t$ in $Z(t)$, the dynamics of $Z(t)$ is obtained as

$$
\frac{d Z(t)}{Z(t)}=r d t+\sigma_{L} d \bar{W}(t)
$$

whereas under $\mathbb{P}$ it satisfies

$$
\frac{d Z(t)}{Z(t)}=\left(r+\sigma_{L} \theta\right) d t+\sigma_{L} d W(t)
$$

Next, a remark regarding to the replication of the process $Z(t)$ is given. 
Remark. At payment times $t_{i}$, the differential does not exist and the process evolution is given by

$$
Z\left(t_{i}\right)=Z\left(t_{i}^{+}\right)+\gamma\left(t_{i}\right),
$$

for $i=0,1,2, \ldots, n . Z(t)$ is correlated with the assets in the market, it can be hedged perfectly between payment times.

By (4.4), NPV floor at time $T$ can be defined as

$$
Y:=Y(0) e^{r T}
$$

and at time $t$ as

$$
Y(t)=Y(0) e^{r t}
$$

where $Y(0)=\rho Z(0)$. Here, $\rho$ represents a constant guaranteed fraction of the total amount of contributions. In the numerical analyses, it is assumed that $0.5<\rho<1$ while testing the effectiveness and practical convenience of the portfolios with different values of $\rho$. From (4.2), the dynamics wealth process are given as follows

$$
V(t)= \begin{cases}m C\left(t_{k}\right) \frac{S_{t}}{S_{t_{k}}}+\left(V\left(t_{k}\right)-m C\left(t_{k}\right)\right) \frac{B_{t}}{B_{t_{k}}}, & C\left(t_{k}\right)>0 \\ V\left(t_{k}\right) \frac{B_{t}}{B_{t_{k}}}, & C\left(t_{k}\right) \leq 0\end{cases}
$$

for $t \in\left(t_{k}, t_{k+1}\right)$, and

$$
V(t)= \begin{cases}m C\left(t_{k}\right) \frac{S_{t_{k+1}}}{S_{t_{k}}}+\left(V\left(t_{k}\right)-m C\left(t_{k}\right)\right) \frac{B_{t_{k+1}}}{B_{t_{k}}}+\gamma\left(t_{k+1}\right), & C\left(t_{k}\right)>0 \\ V\left(t_{k}\right) \frac{B_{t_{k+1}}}{B_{t_{k}}}+\gamma\left(t_{k+1}\right), & C\left(t_{k}\right) \leq 0\end{cases}
$$

for $t=t_{k+1}$. Using (4.8) and (4.6), the cushion at time $t \in\left(t_{k}, t_{k+1}\right)$ is derived as follows:

$$
C(t)= \begin{cases}C\left(t_{k}\right)\left(m \frac{S_{t}}{S_{t_{k}}}+(1-m) e^{r\left(t-t_{k}\right)}\right), & C\left(t_{k}\right)>0 \\ C\left(t_{k}\right) e^{r\left(t-t_{k}\right)}, & C\left(t_{k}\right) \leq 0\end{cases}
$$

with

$$
C\left(t_{k+1}\right)=C\left(t_{k+1}^{-}\right)+\gamma\left(t_{k+1}\right)
$$


for all $k=0, \ldots, n-1$. One should note from the dynamics (4.7) - 4.9) that to stay always above the floor, one has to set $m \leq 1$. Otherwise, there is a non-zero probability of negative cushion in a decreasing financial market. The fact that the cushion process becomes negative only temporarily is one of the major differences between our framework and the classical CPPI. With the help of the contribution inflows, the portfolio has the chance to recover and attain a positive cushion again after a negative surplus.

\subsubsection{CPPI with random-growth floor}

In this DC pension setting, the randomness that labor income process plays an important role in the evolution of portfolio. Since the contribution payments are made into the portfolio wealth at fixed times, it is in fact logical to increase the floor process also by the same increments for insurance. Therefore, the second floor that is introduced is the random-growth floor which does not only grow at the risk-free rate between interpayment times, but also makes jumps at the consecutive payment times as the value process does. For the sake of flexibility in gains, a fraction of each contribution is guaranteed, similar to what has been done in the NPV floor case. More precisely, for each payment $\gamma\left(t_{i}\right)$ made at time $t_{i} \in[0, T], c \gamma\left(t_{i}\right)$ is included in the floor for some real constant $0<c<1$. Therefore, jumps occurring in the floor process are also fractions of the inflows made into wealth.

The present thesis defines the random-growth floor (which we will shortly address as random floor from now on) to be the summation of the time-value of paid contributions. The payments are made at fixed trading dates $t_{i} \in[0, T]$ and the accumulated amount grows at the risk-free rate $r$ between payment times. The guarantee at time $t$ is then defined as

$$
Y(t)= \begin{cases}\sum_{i=0}^{k} e^{r\left(t-t_{i}\right)} c \gamma\left(t_{i}\right), & t \in\left(t_{k}, t_{k+1}\right) \\ Y\left(t_{k+1}^{-}\right)+c \gamma\left(t_{k+1}\right), & t=t_{k+1}\end{cases}
$$

Hence, between payment dates $Y(t)$ has the dynamics

$$
d Y(t)=r Y(t) d t, \quad Y(0)=\gamma(0)
$$

and

$$
Y(t)=Y\left(t^{-}\right)+\gamma(t)
$$

for $t=t_{k}, \forall k=0,1, \ldots, n$. By (4.11) and (4.12), $Y$ can be given as 


$$
Y(t)= \begin{cases}e^{r\left(t-t_{k}\right)} Y\left(t_{k}\right), & t \in\left(t_{k}, t_{k+1}\right) \\ Y\left(t_{k+1}^{-}\right)+\gamma\left(t_{k+1}\right), & t=t_{k+1}\end{cases}
$$

From (4.2), the wealth process is given as,

$$
V(t)= \begin{cases}m C\left(t_{k}\right) \frac{S_{t}}{S_{t_{k}}}+\left(V\left(t_{k}\right)-m C\left(t_{k}\right)\right) \frac{B_{t}}{B_{t_{k}}}, & C\left(t_{k}\right)>0 \\ V\left(t_{k}\right) \frac{B_{t}}{B_{t_{k}}}, & C\left(t_{k}\right) \leq 0\end{cases}
$$

for $t \in\left(t_{k}, t_{k+1}\right)$, and

$$
V(t)= \begin{cases}m C\left(t_{k}\right) \frac{S_{t_{k+1}}}{S_{t_{k}}}+\left(V\left(t_{k}\right)-m C\left(t_{k}\right)\right) \frac{B_{t_{k+1}}}{B_{t_{k}}}+\gamma\left(t_{k+1}\right), & C\left(t_{k}\right)>0 \\ V\left(t_{k}\right) \frac{B_{t_{k+1}}}{B_{t_{k}}}+\gamma\left(t_{k+1}\right), & C\left(t_{k}\right) \leq 0\end{cases}
$$

for $t=t_{k+1}$.

As the cushion is defined by $C(t)=V(t)-Y(t)$, for all $t$, it satisfies

$$
\begin{aligned}
C\left(t_{k}\right) & =V_{t_{k}^{-}}\left(\phi_{t_{k}}\right)+\gamma\left(t_{k}\right)-Y\left(t_{k}^{-}\right)-c \gamma\left(t_{k}\right) \\
& =C\left(t_{k}^{-}\right)+(1-c) \gamma\left(t_{k}\right),
\end{aligned}
$$

for every $k=0,1, \ldots, n$. Relation 4.16 implies that for $c=1$ the cushion process has no discontinuity at payment times, i.e.

$$
C(t)=C\left(t^{-}\right), \quad \forall t \in[0, T]
$$

This is due to the fact that the floor is increased by the full contribution amount at each payment time when $c=1$. From 4.13, we derive the cushion dynamics for $t \in\left(t_{k}, t_{k+1}\right)$ as follows:

$$
C(t)= \begin{cases}C\left(t_{k}\right)\left(m \frac{S_{t}}{S_{t_{k}}}+(1-m) e^{r\left(t-t_{k}\right)}\right), & C\left(t_{k}\right)>0 \\ C\left(t_{k}\right) e^{r\left(t-t_{k}\right)}, & C\left(t_{k}\right) \leq 0\end{cases}
$$

with

$$
C\left(t_{k+1}\right)=C\left(t_{k+1}^{-}\right)+(1-c) \gamma\left(t_{k+1}\right)
$$


for all $k=0, \ldots, n-1$. Again from the dynamics (4.14), (4.15) and (4.18) one should note that it should be $m \leq 1$, for the value process to always evolve above the floor. Otherwise, the cushion may become negative when there is a sudden market drop. The CPPI strategies introduced so far possess some prominent weaknesses in real markets. One potential problem from the performance standpoint arises when market climbs. When risky asset prices rise yielding an increasing portfolio value as well, the floor might become insignificant threatening the gains. Another risk emerges when the cushion becomes so small. In this case, the total wealth faces the danger of being fully invested in the risk-free asset and staying below the floor until maturity. Furthermore, since in practice rebalancements are done at discrete times rather than continuously, there is a risk of cushion becoming negative between two rebalancement dates. To overcome these problems, some CPPI modifications are suggested by Boulier and Kanniganti in [19]. These modified strategies introduce some mechanisms which enable the floor to vary based on strong market conditions and results in a path-dependent structure. The current work extends these modified CPPI strategies to DC setting with growing floor and makes performance comparisons. Next, these path-dependent CPPI strategies are studied in DC pension plan setting.

\subsubsection{CPPI strategies with variable floors}

This section introduces a new structured CPPI for DC funds. As pension funds are long-term investments, the phenomena of floor becoming insignificant or being very close to portfolio value can both occur during the investment period. Therefore, a variant form of the classical CPPI is needed which is able to prevent these risks and but still insure the desired guarantee. The basic idea is to combine the ratchet effect and margin method in one strategy. The dynamics of the floor in the combined strategy is given as the combination of the equations (4.24) and (4.27) with the constraints 4.29) and (4.26). Based on the obtained dynamics of various CPPI strategies, a comparison their performance can be done using relevant risk measures. For all path-dependent floor cases, the plan participant makes periodical contribution payments during the time he/she stays in the plan, as described in Section 4.3 .

Constrained CPPI. In this strategy, there is a stronger constraint on the exposure compared to 4.3 . The restriction is given as $0<e(t)<p V(t)$ for some real constant $p>0$ with the exposure having the following relation

$$
e(t)=\min \{m C(t), p V(t)\}
$$

where the floor process is as given in (4.13). Here, the asset units have to be redetermined based on the exposure at each time. Therefore, instead of using the unconstrained exposure as in (4.1), it is now obtained

$$
\alpha_{t}=\max \left\{\frac{e\left(t_{k}\right)}{S_{t_{k}}}, 0\right\}, \beta_{t}=\frac{V_{t_{k}}-\alpha_{t} S_{t_{k}}}{B_{t_{k}}}
$$


with $e(t)$ as given by 4.20).

Ratchet strategy. The basic idea of the ratchet strategy is to increase the floor when market rises and floor threatens to become insignificant by adding the excess cushion. With the realistic constraint (4.20) on the exposure, the absolute value of excess cushion is given by

$$
\frac{m C(t)-p V(t)}{m}=C(t)-\frac{p}{m} V(t) .
$$

This excess cushion is put on the floor when

$$
m C(t)>p V(t),
$$

resulting the new floor and exposure,

$$
\begin{aligned}
Y^{\text {new }}(t) & =Y(t)+\left(\frac{m C(t)-p V(t)}{m}\right) \\
& =\left(1-\frac{p}{m}\right) V(t)
\end{aligned}
$$

with the new exposure being the minimum given in 4.20 . By increasing the floor and lowering the risk of a greater loss when market decreases, ratchet strategy increases the level of protection. However, the cushion might become so small in this case, causing a cash-lock position. An additional mechanism should be employed for this problem which is given next.

Margin strategy with ratchet effect. To avoid the problem where the exposure approaches to zero creating a cash-lock situation, one method is to decrease the floor when this happens. In the classical CPPI, this can be done by artificially augmenting the initial floor by some margin amount and adjusting the floor using this margin, as suggested in [19]. If it is the case that initial exposure is too high, the initial floor is then set at a higher value and the margin is used later when the floor falls too low. Thus, if $e(0)$ is too high, the initial floor is augmented by margin $M_{0}$ as follows:

$$
Y^{\text {new }}(0)=Y(0)+M_{0}
$$

The idea is to adjust the floor downward when exposure hits a predetermined lower bound $e^{*}(t)$ where $M_{0}$ grows at the risk-free rate $r$. A fraction of the remaining margin is used every time the exposure hits a fraction of the current lower bound $e^{*}(t)$. Thus, if 


$$
e(t)<e^{*}(t)=\frac{e(t)}{\epsilon}
$$

the new floor will be

$$
Y^{\text {new }}(t)=Y(t)-\frac{M_{t}}{\epsilon}
$$

with new margin being

$$
M_{t}^{\text {new }}=\frac{(\epsilon-1)}{\epsilon} M_{t},
$$

and the new exposure being

$$
e^{\text {new }}(t)=m\left(V(t)-Y^{\text {new }}(t)\right) .
$$

Here, it is a key issue to determine the lower bound $e^{*}(t)$ for increased efficiency. To be able to provide an insight on this lower bound choice problem, this thesis analyzes the effect of $\epsilon$ with a sensitivity analysis and discuss the results in Section 4.5. Another weakness of the margin strategy suggested in [19] is that; in a strongly declining market the margin might diminish the floor in time and cause a failure to meet the guaranteed amount. Apart from the diminishing floor risk, another issue is that the mechanism can not be directly applied to our framework as our initial exposure can never be high enough to make the mechanism work. The initial exposure is given by

$$
\begin{aligned}
e(0) & =m(V(0)-Y(0)) \\
& =m(1-c) \gamma(0) .
\end{aligned}
$$

Namely, the initial margin suggested for our approach would be so small that it would fail to decrease the floor low enough to keep the cushion positive. An alternative approach for us would be to use an independent deterministic process as a margin process. However, this approach would also include the risk of declining floor. Taking these facts into consideration, the margin approach is adjusted in a way that the diminishing floor problem is solved and the margin is capable of bringing the floor down, effectively. The mechanism is adopted so that every time condition $(4.23)$ is satisfied and the floor is increased with the ratchet effect, the margin is reset to a certain percentage of the exposure at that time. The new exposure thereby is redefined as

$$
e^{\text {new }}(t)=(1-h) p V(t)
$$

and the new margin is 


$$
M^{\text {new }}(t)=h p V(t)
$$

where $0<h<1$ is the percentage of exposure put in the new margin.

\subsection{Risk Measures and Comparison of Strategies}

In this section, some risk measures of the considered CPPI strategies are computed and analyzed. Besides making a comparison of different floor cases, the main result is a comparison between financial positions taken at the beginning of the pension plan. With this aim, the portfolio performance is examined when a replicating portfolio for the future contributions is short sold. In calculation of the risk measures to be presented, the probability of the sum of log-normal random variables is encountered. While closed-form expression of a log-normal sum probability density function is unknown, there exist well-known analytical approximation methods in the literature [6, 27]. The present work employs the method of Fenton-Wilkinson, approximating the log-normal sum by a single log-normal random variable, and use moments to determine the parameters of the new log-normal distribution, as often done in pricing Asian and basket options. See Appendix A for details of the method. The exact values for the pre-event probabilities are found and more complicated post-event probabilities approximated as will be explained in the subsections. After obtaining the risk measures, a numerical example is presented and the effectiveness of CPPI strategies with NPV and random floor is discussed.

\subsubsection{Cash-lock Risk}

The considered pension framework includes consecutive payments into the fund at fixed times. These inflows which change the portfolio allocation drastically in turn serves as a recoverer from a possible cash-locked position. Because of the pathdependent structure of the strategy, the cash-lock probability analysis has to be carried out for each period, i.e. for inter-payment times. Therefore, local dynamics are examined first. Next, the definition of local cash-lock probability for the interval $\left(t_{k}, t_{k+1}\right]$ is given.

Definition 4.2. (Local cash-lock probability) For the period $\left(t_{k}, t_{k+1}\right]$, the $\zeta-\xi$ cashlock probability $P_{t_{k}, t_{k+1}}^{C L_{\zeta, \xi}}$ denotes the probability that the proportion of the risky asset at $t_{k+1}$ is less than $\xi$ given that it is equal to $\zeta$ at $t_{k}$, i.e.

$$
P_{t_{k}, t_{k+1}}^{C L_{L_{k}}}:=P\left(\frac{m C\left(t_{k+1}\right)}{V\left(t_{k+1}\right)} \leq \xi \mid \frac{m C\left(t_{k}\right)}{V\left(t_{k}\right)}=\zeta\right)
$$

for any $k=0, \ldots, n-1$. 
Notice that when cushion becomes negative, the fraction of the portfolio value which is invested in the risky asset also becomes negative. This violates the general continuoustime definition of a cash-lock probability where $\zeta$ usually satisfies $0 \leq \zeta \leq 1$. The main reason of this violation is the discrete-time trading assumption. For the case $\zeta>$ 0 the portfolio includes risky asset, therefore calculation of the probability becomes complicated. Because of the inflow payments made into the wealth, the cash-lock probability is considered for two different cases. The first case is when the payment at time $t_{k+1}$ has not come in yet and and the second is when it has been paid an instant ago. Since these incoming payments include an external randomness, the derivation of cash-lock probability becomes complex for the latter case. The cash-lock probability in the first case can be considered as an upper bound for the local cash-lock probability. This upper-bound probability is defined as

$$
P_{t_{k}, t_{k+1}^{-}}^{C L_{\zeta, \xi}}:=P\left(\frac{m C\left(t_{k+1}^{-}\right)}{V\left(t_{k+1}^{-}\right)} \leq \xi \mid \frac{m C\left(t_{k}\right)}{V\left(t_{k}\right)}=\zeta\right) .
$$

Namely, assuming that the payment at the beginning has already been made and the one end of the period has not come in yet, the cash-lock probability for inter-payment times is found. It is clear that for $\zeta<0$, this upper bound is 1 as CPPI forbid any investment in risky asset for the specific period. Therefore, the probability (4.33) provides some insight only for the case $\zeta>0$. The dynamics of the strategy, as given in (4.1), does not allow investment in risky asset at time $t_{k+1}$ if $C\left(t_{k}\right)<0$. Therefore, for this case, cash-lock happens if the incoming payment fails to make the cushion positive. For this, we compute various (upper bound for the) cash-lock probabilities.

\subsubsection{Cash-lock Risk for NPV floor CPPI}

This section analyzes cash-lock risk for NPV floor CPPI.

Proposition 4.1. (Upper bound of local cash-lock probability) For $\xi \geq 0$, an upper bound for $\zeta-\xi$ cash-lock probability in NPV floor CPPI is given by

$$
P_{t_{k}, t_{k+1}^{-}}^{C L_{\zeta, \xi}}=\Phi\left(\frac{\ln \left(\frac{\xi(m-\zeta)}{m \zeta(m-\xi)}-\frac{1-m}{m}\right)-\left(\mu_{S}-r-\frac{\sigma_{S}^{2}}{2}\right) \frac{T}{n}}{\sigma_{S} \sqrt{T / n}}\right)
$$

for $\zeta>0$, and

$$
P_{t_{k}, t_{k+1}^{-}}^{C L_{\zeta, \xi}}=1
$$

for $\zeta \leq 0$ with $k=0, \ldots, n-1$. Here, $\Phi$ is the cumulative distribution function of standard normal distribution. 
Proof. First, we find the cash-lock probability for $\zeta>0$. By (4.9) and (4.8), we have the following pre-payment dynamics

$$
\begin{aligned}
& C\left(t_{k+1}^{-}\right)=C\left(t_{k}\right)\left(m \frac{S\left(t_{k+1}\right)}{S\left(t_{k}\right)}+(1-m) e^{r\left(t_{k+1}-t_{k}\right)}\right) \\
& V\left(t_{k+1}^{-}\right)=m C\left(t_{k}\right) \frac{S\left(t_{k+1}\right)}{S\left(t_{k}\right)}+\left(V\left(t_{k}\right)-m C\left(t_{k}\right)\right) e^{r\left(t_{k+1}-t_{k}\right)} .
\end{aligned}
$$

Inserting these relations into the definition of upper bound cash-lock probability, as given in (4.33), leads to following equations:

$$
\begin{aligned}
P_{t_{k}, t_{k+1}^{-}}^{C L_{\zeta, \xi}}=P\left(\frac{m C\left(t_{k}\right)\left(m \frac{S\left(t_{k+1}\right)}{S\left(t_{k}\right)}+(1-m) e^{r\left(t_{k+1}-t_{k}\right)}\right)}{m C\left(t_{k}\right) \frac{S\left(t_{k+1}\right)}{S\left(t_{k}\right)}+\left(V\left(t_{k}\right)-m C\left(t_{k}\right)\right) e^{r\left(t_{k+1}-t_{k}\right)}} \leq \xi \mid \frac{m C\left(t_{k}\right)}{V\left(t_{k}\right)}=\zeta\right) \\
=P\left(C\left(t_{k}\right)(m-\xi)\left(m \frac{S\left(t_{k+1}\right)}{S\left(t_{k}\right)}+(1-m) e^{r \frac{T}{n}}\right)\right. \\
\left.\leq Y\left(t_{k}\right) e^{r \frac{T}{n}} \xi \mid C\left(t_{k}\right)=\frac{\zeta Y\left(t_{k}\right)}{m-\zeta}\right) \\
=P\left(\frac{\zeta Y\left(t_{k}\right)}{m-\zeta}(m-\xi)\left(m \frac{S\left(t_{k+1}\right)}{S\left(t_{k}\right)}+(1-m) e^{r \frac{T}{n}}\right) \leq Y\left(t_{k}\right) e^{r \frac{T}{n}} \xi\right) \\
=P\left(\frac{S\left(t_{k+1}\right)}{S\left(t_{k}\right)} \leq \frac{\xi e^{r \frac{T}{n}}(m-\zeta)}{m \zeta(m-\xi)}-\frac{(1-m) e^{r \frac{T}{n}}}{m}\right) .
\end{aligned}
$$

Taking logarithm of both sides inside the last probability, it follows that

$$
\begin{aligned}
P_{t_{k}, t_{k+1}^{-}}^{C L_{\zeta, \xi}}=P & \left(\left(\mu_{S}-\frac{\sigma_{S}^{2}}{2}\right) \frac{T}{n}+\sigma_{S}\left(W\left(t_{k+1}\right)-W\left(t_{k}\right)\right)\right. \\
& \left.\leq r \frac{T}{n}+\ln \left(\frac{\xi(m-\zeta)}{\zeta(m-\xi) m}-\frac{1-m}{m}\right)\right) \\
=P & \left(W\left(t_{k+1}\right)-W\left(t_{k}\right) \leq \frac{1}{\sigma_{S}}\left(\ln \left(\frac{\xi(m-\zeta)}{\zeta(m-\xi) m}-\frac{1-m}{m}\right)\right.\right. \\
& \left.\left.-\left(\mu_{S}-r-\frac{\sigma_{S}^{2}}{2}\right) \frac{T}{n}\right)\right) .
\end{aligned}
$$

Since Brownian increments have normal distribution, i.e. $W\left(t_{k+1}\right)-W\left(t_{k}\right) \sim \mathcal{N}(0, T / n)$, we have 


$$
P_{t_{k}, t_{k+1}^{-}}^{C L_{\zeta,}}=\Phi\left(\frac{1}{\sigma_{S} \frac{T}{n}}\left(\ln \left(\frac{\xi(m-\zeta)}{\zeta(m-\xi) m}-\frac{1-m}{m}\right)-\left(\mu_{S}-r-\frac{\sigma_{S}^{2}}{2}\right) \frac{T}{n}\right)\right)
$$

which completes the proof for $\zeta>0$. It is clear that the upper bound for cash-lock probability is equal to 1 for $\zeta \leq 0$.

Next proposition gives the local cash-lock probability for NPV floor CPPI.

Proposition 4.2. (Local cash-lock probability) For $\xi \geq 0$, the $\zeta-\xi$ cash-lock probability in NPV floor CPPI is given by

$$
P_{t_{k}, t_{k+1}}^{C L_{\zeta, \xi}}=\Phi\left(\frac{\ln \left(\frac{Y\left(t_{k}\right) m(\xi-\zeta)}{\gamma\left(t_{k}\right)(m-\xi)(m-\zeta)}\right)-\left(\mu_{L}-r-\frac{\sigma_{L}^{2}}{2}\right) \frac{T}{n}}{\sigma_{L} \sqrt{T / n}}\right)
$$

for $\zeta \leq 0$, and

$$
P_{t_{k}, t_{k+1}}^{C L_{\zeta, \xi}} \cong \Phi\left(\frac{\ln \left(\frac{d\left(t_{k}\right) \sqrt{h\left(a\left(t_{k}\right), b\left(t_{k}\right)\right)}}{f^{2}\left(a\left(t_{k}\right), b\left(t_{k}\right)\right)}\right)}{\sqrt{\ln \left(\frac{h\left(a\left(t_{k}\right), b\left(t_{k}\right)\right)}{f^{2}\left(a\left(t_{k}\right), b\left(t_{k}\right)\right)}\right)}}\right)
$$

for $\zeta>0$ where $f$ and $g$ are functions on $\mathbb{R}^{2}$ defined as

$$
\begin{aligned}
f(x, y) & :=x e^{\frac{1}{2} \sigma_{S}^{2} \frac{T}{n}}+y e^{\frac{1}{2} \sigma_{L}^{2} \frac{T}{n}} \\
h(x, y) & :=x^{2} e^{2 \sigma_{S}^{2} \frac{T}{n}}+y^{2} e^{2 \sigma_{L}^{2} \frac{T}{n}}+2 x y e^{\frac{1}{2}\left(\sigma_{S}^{2}+\sigma_{L}^{2}\right) \frac{T}{n}}
\end{aligned}
$$

with

$$
\begin{aligned}
& a\left(t_{k}\right)=Y\left(t_{k}\right) \zeta m \frac{(m-\xi)}{m-\zeta} e^{\left(\mu_{S}-\frac{\sigma_{S}^{2}}{2}\right) \frac{T}{n}} \\
& b\left(t_{k}\right)=\gamma\left(t_{k}\right)(m-\xi) e^{\left(\mu_{L}-\frac{\sigma_{L}^{2}}{2}\right) \frac{T}{n}} \\
& d\left(t_{k}\right)=Y\left(t_{k}\right) e^{r \frac{T}{n}}\left(\xi-\frac{\zeta(m-\xi)(1-m)}{m-\zeta}\right)
\end{aligned}
$$

for $k=0, \ldots, n-1$. Here, $\Phi$ is the cumulative distribution function of standard normal distribution. 
Proof. In the first part of the proof, where we assume $\zeta>0$, we use the approximation method of Fenton and Wilkinson (see [27]). From (4.10), the post-payment dynamics are given by

$$
\begin{aligned}
& C\left(t_{k+1}\right)=C\left(t_{k}\right)\left(m \frac{S\left(t_{k+1}\right)}{S\left(t_{k}\right)}+(1-m) e^{r\left(t_{k+1}-t_{k}\right)}\right)+\gamma\left(t_{k+1}\right) \\
& V\left(t_{k+1}\right)=m C\left(t_{k}\right) \frac{S\left(t_{k+1}\right)}{S\left(t_{k}\right)}+\left(V\left(t_{k}\right)-m C\left(t_{k}\right)\right) e^{r\left(t_{k+1}-t_{k}\right)}+\gamma\left(t_{k+1}\right) .
\end{aligned}
$$

Substituting these relations into the definition (4.32), we obtain

$$
\begin{aligned}
P_{t_{k}, t_{k+1}}^{C L_{\zeta, \xi}}=P & \left(\frac{m C\left(t_{k}\right)\left(m \frac{S\left(t_{k+1}\right)}{S\left(t_{k}\right)}+(1-m) e^{r \frac{T}{n}}\right)+\gamma\left(t_{k+1}\right)}{m C\left(t_{k}\right) \frac{S\left(t_{k+1}\right)}{S\left(t_{k}\right)}+\left(V\left(t_{k}\right)-m C\left(t_{k}\right)\right) e^{r \frac{T}{n}}+\gamma\left(t_{k+1}\right)}\right. \\
& \left.\leq \xi \mid C\left(t_{k}\right)=\frac{\zeta Y\left(t_{k}\right)}{m-\zeta}\right) .
\end{aligned}
$$

The inequality inside the above probability can be rearranged as

$$
C\left(t_{k}\right)\left(m(m-\xi) \frac{S\left(t_{k+1}\right)}{S\left(t_{k}\right)}+(m-\xi)(1-m) e^{r \frac{T}{n}}\right) \leq(\xi-m) \gamma\left(t_{k+1}\right)+\xi Y\left(t_{k}\right) e^{r \frac{T}{n}}
$$

Including given information $C\left(t_{k}\right)=\frac{\zeta Y\left(t_{k}\right)}{m-\zeta}$ into the inequality yields the following probability

$$
\begin{aligned}
P_{t_{k}, t_{k+1}}^{C L_{\zeta, \xi}}=P & \left(\frac{\zeta Y\left(t_{k}\right)}{m-\zeta}\left[m(m-\xi) \frac{S\left(t_{k+1}\right)}{S\left(t_{k}\right)}+(m-\xi)(1-m) e^{r \frac{T}{n}}\right]\right. \\
& \left.-\xi Y\left(t_{k}\right) e^{r \frac{T}{n}} \leq(\xi-m) \gamma\left(t_{k}\right) e^{\left(\mu_{L}-\frac{\sigma_{L}^{2}}{2}\right) \frac{T}{n}} e^{\sigma_{L}\left(W\left(t_{k+1}\right)-W\left(t_{k}\right)\right)}\right) \\
=P & \left(\frac{\zeta m(m-\xi) Y\left(t_{k}\right)}{m-\zeta} e^{\left(\mu_{S}-\frac{\sigma_{S}^{2}}{2}\right) \frac{T}{n}} e^{\sigma_{S}\left(W\left(t_{k+1}\right)-W\left(t_{k}\right)\right)}\right. \\
& +(m-\xi) \gamma\left(t_{k}\right) e^{\left(\mu_{L}-\frac{\sigma_{L}^{2}}{2}\right) \frac{T}{n}} e^{\sigma_{L}\left(W\left(t_{k+1}\right)-W\left(t_{k}\right)\right)} \\
\leq & \left.Y\left(t_{k}\right) e^{r \frac{T}{n}}\left(\xi-\frac{(1-m)(m-\xi) \zeta}{m-\zeta}\right)\right)
\end{aligned}
$$

Here, denoting the random variables in the probability as $x_{1}=e^{\left(\mu_{S}-\frac{\sigma_{S}^{2}}{2}\right) \frac{T}{n}}$ and $x_{2}=$ $e^{\left(\mu_{L}-\frac{\sigma_{L}^{2}}{2}\right) \frac{T}{n}}$, it is clear that $x_{1} \sim \mathcal{L} \mathcal{N}\left(0, \sigma_{S}^{2} \frac{T}{n}\right)$ and $x_{2} \sim \mathcal{L N}\left(0, \sigma_{L}^{2} \frac{T}{n}\right)$, i.e. $x_{1}$ and $x_{2}$ have lognormal distribution. Making the notations 


$$
\begin{aligned}
& a\left(t_{k}\right)=Y\left(t_{k}\right) \zeta m \frac{(m-\xi)}{m-\zeta} e^{\left(\mu_{S}-\frac{\sigma_{S}^{2}}{2}\right) \frac{T}{n}} \\
& b\left(t_{k}\right)=\gamma\left(t_{k}\right)(m-\xi) e^{\left(\mu_{L}-\frac{\sigma_{L}^{2}}{2}\right) \frac{T}{n}} \\
& d\left(t_{k}\right)=Y\left(t_{k}\right) e^{r \frac{T}{n}}\left(\xi-\frac{\zeta(m-\xi)(1-m)}{m-\zeta}\right),
\end{aligned}
$$

the searched probability takes the form

$$
P\left(a\left(t_{k}\right) x_{1}+b\left(t_{k}\right) x_{2} \leq d\left(t_{k}\right)\right) .
$$

Inside the probability, is summation of two lognormal random variables. Since this sum does not have explicit distribution, to calculate this probability is approximated via using Fenton-Wilkinson method, which is described in Appendix A. Letting $\bar{X}=$ $a\left(t_{k}\right) x_{1}+b\left(t_{k}\right) x_{2}$, by FW method, it holds that

$$
\bar{X}=e^{X} \text { with } X \sim \mathcal{N}\left(\mu_{X}, \sigma_{X}^{2}\right) .
$$

Therefore, it also holds $\bar{X} \sim \mathcal{L} \mathcal{N}\left(\mu_{X}, \sigma_{X}^{2}\right)$ Using the set of equations given by A.4. the mean and variance of the approximated distribution are obtained as

$$
\begin{aligned}
& \mu_{X}^{2}=\ln \left(\frac{\left(a e^{\frac{1}{2} \sigma_{S}^{2} \frac{T}{n}}+b e^{\frac{1}{2} \sigma_{L}^{2} \frac{T}{n}}\right)^{2}}{\left(a^{2} e^{2 \sigma_{S}^{2} \frac{T}{n}}+b^{2} e^{2 \sigma_{L}^{2} \frac{T}{n}}+2 a b e^{\frac{1}{2}\left(\sigma_{S}^{2}+\sigma_{L}^{2}\right) \frac{T}{n}}\right)^{2}}\right) \\
& \sigma_{X}^{2}=\ln \left(\frac{a^{2} e^{2 \sigma_{S}^{2} \frac{T}{n}}+b^{2} e^{2 \sigma_{L}^{2} \frac{T}{n}}+2 a b e^{\frac{1}{2}\left(\sigma_{S}^{2}+\sigma_{L}^{2}\right) \frac{T}{n}}}{\left(a e^{\frac{1}{2} \sigma_{S}^{2} \frac{T}{n}}+b e^{\frac{1}{2} \sigma_{L}^{2} \frac{T}{n}}\right)^{2}}\right) .
\end{aligned}
$$

The objective probability is then approximated as follows

$$
\begin{aligned}
P\left(a\left(t_{k}\right) x_{1}+b\left(t_{k}\right) x_{2} \leq d\left(t_{k}\right)\right) & \cong P\left(\bar{X} \leq d\left(t_{k}\right)\right) \\
& =P\left(e^{X} \leq d\left(t_{k}\right)\right) \\
& =P\left(X \leq \ln \left(d\left(t_{k}\right)\right)\right) \\
& =P\left(\frac{X-\mu_{X}}{\sigma_{X}} \leq \frac{\ln \left(d\left(t_{k}\right)\right)-\mu_{X}}{\sigma_{X}}\right) \\
& =\Phi\left(\frac{\ln \left(d\left(t_{k}\right)\right)-\mu_{X}}{\sigma_{X}}\right),
\end{aligned}
$$

where $\mathcal{N}$ is the cumulative distribution function of standard normal distribution. By imposing the notation 


$$
\begin{aligned}
& f(x, y):=x e^{\frac{1}{2} \sigma_{S}^{2} \frac{T}{n}}+y e^{\frac{1}{2} \sigma_{L}^{2} \frac{T}{n}} \\
& h(x, y):=x^{2} e^{2 \sigma_{S}^{2} \frac{T}{n}}+y^{2} e^{2 \sigma_{L}^{2} \frac{T}{n}}+2 x y e^{\frac{1}{2}\left(\sigma_{S}^{2}+\sigma_{L}^{2}\right) \frac{T}{n}}
\end{aligned}
$$

it is found that

$$
P\left(a\left(t_{k}\right) x_{1}+b\left(t_{k}\right) x_{2} \leq d\left(t_{k}\right)\right) \cong \Phi\left(\frac{\ln \left(\frac{d\left(t_{k}\right) \sqrt{h\left(a\left(t_{k}\right), b\left(t_{k}\right)\right)}}{f^{2}\left(a\left(t_{k}\right), b\left(t_{k}\right)\right)}\right)}{\sqrt{\ln \left(\frac{h\left(a\left(t_{k}\right), b\left(t_{k}\right)\right)}{f^{2}\left(a\left(t_{k}\right), b\left(t_{k}\right)\right)}\right)}}\right)
$$

which concludes the first part of the proof.

Assuming $\zeta \leq 0$, the probability is given as

$$
\begin{aligned}
P_{t_{k}, t_{k+1}}^{C L_{\zeta, \xi}} & =P\left(\frac{m C\left(t_{k}\right) e^{r \frac{T}{n}}+\gamma\left(t_{k+1}\right)}{V\left(t_{k}\right) e^{r \frac{T}{n}}+\gamma\left(t_{k+1}\right)} \leq \xi \mid C\left(t_{k}\right)=\frac{\zeta Y\left(t_{k}\right)}{m-\zeta}\right) \\
= & P\left(\left(C\left(t_{k}\right)(m-\xi)-\xi Y\left(t_{k}\right)\right) e^{r \frac{T}{n}} \leq(\xi-m) \gamma\left(t_{k+1}\right) \mid C\left(t_{k}\right)=\frac{\zeta Y\left(t_{k}\right)}{m-\zeta}\right) \\
= & P\left((m-\xi) \gamma L\left(t_{k}\right) e^{\left(\mu_{L}-\frac{\sigma_{L}^{2}}{2}\right) \frac{T}{n}+\sigma_{L}\left(W\left(t_{k+1}\right)-W\left(t_{k}\right)\right)} \leq\left(\xi-\frac{\zeta(m-\xi)}{m-\zeta}\right) Y\left(t_{k}\right) e^{r \frac{T}{n}}\right) \\
= & P\left(\left(\mu_{L}-\frac{\sigma_{L}^{2}}{2}\right) \frac{T}{n}+\sigma_{L}\left(W\left(t_{k+1}\right)-W\left(t_{k}\right)\right) \leq \ln \left(\frac{\left(\xi-\frac{\zeta(m-\xi)}{m-\zeta}\right) Y\left(t_{k}\right) e^{r \frac{T}{n}}}{(m-\xi) \gamma\left(t_{k}\right)}\right)\right) \\
= & P\left(W\left(t_{k+1}\right)-W\left(t_{k}\right) \leq \frac{\ln \left(\frac{m(\xi-\zeta) Y\left(t_{k}\right)}{(m-\zeta)(m-\xi) \gamma\left(t_{k}\right)}-\left(\mu_{L}-r-\frac{\sigma_{L}^{2}}{2}\right) \frac{T}{n}\right)}{\sigma_{L}}\right) \\
= & \left(\frac{\ln \left(\frac{m(\xi-\zeta) Y\left(t_{k}\right)}{(m-\zeta)(m-\xi) \gamma\left(t_{k}\right)}-\left(\mu_{L}-r-\frac{\sigma_{L}^{2}}{2}\right) \frac{T}{n}\right)}{\sigma_{L} \sqrt{\frac{T}{n}}}\right)
\end{aligned}
$$

which completes the second part of the proof.

Notice that for the case $\zeta>0$, both the cushion and the portfolio value include the risky asset return, as is given by the Equations (4.7), (4.8) and (4.9). Since the cashlock probability does not have an explicit solution for this case due to existence of multiple randomnesses, we derive the upper bound probability which is given in the following proposition. 


\subsubsection{Cash-lock Risk for random floor CPPI}

In the next propositions cash-lock and upper bound probabilities are given for the different cases of $\zeta$ in random floor CPPI.

Proposition 4.3. (Upper bound of local cash-lock probability) For $\xi \geq 0$, an upper bound for $\zeta-\xi$ cash-lock probability in random floor CPPI is given by

$$
\bar{P}_{t_{k}, t_{k+1}^{-}}^{C L_{\zeta, \xi}}=\Phi\left(\frac{\ln \left(\frac{\xi(m-\zeta)}{m \zeta(m-\xi)}-\frac{1-m}{m}\right)-\left(\mu_{S}-r-\frac{\sigma_{S}^{2}}{2}\right) \frac{T}{n}}{\sigma_{S} \sqrt{T / n}}\right)
$$

for $\zeta>0$, and

$$
\bar{P}_{t_{k}, t_{k+1}^{-}}^{C L_{\zeta, \xi}}=1
$$

for $\zeta \leq 0$ with $k=0, \ldots, n-1$. Here, $\Phi$ is the cumulative distribution function of standard normal distribution.

Proof. First, we find the cash-lock probability for $\zeta>0$. By 4.15 and 4.16 , we have the following pre-payment dynamics

$$
\begin{aligned}
& C\left(t_{k+1}^{-}\right)=C\left(t_{k}\right)\left(m \frac{S\left(t_{k+1}\right)}{S\left(t_{k}\right)}+(1-m) e^{r\left(t_{k+1}-t_{k}\right)}\right) \\
& V\left(t_{k+1}^{-}\right)=m C\left(t_{k}\right) \frac{S\left(t_{k+1}\right)}{S\left(t_{k}\right)}+\left(V\left(t_{k}\right)-m C\left(t_{k}\right)\right) e^{r\left(t_{k+1}-t_{k}\right)}
\end{aligned}
$$

Substituting these relations into the definition of upper bound cash-lock probability, as given in 4.33 , leads to following.

$$
\begin{aligned}
\bar{P}_{t_{k}, t_{k+1}^{-}}^{C L_{, \xi}}= & \bar{P}\left(\frac{m C\left(t_{k}\right)\left(m \frac{S\left(t_{k+1}\right)}{S\left(t_{k}\right)}+(1-m) e^{r\left(t_{k+1}-t_{k}\right)}\right)}{m C\left(t_{k}\right) \frac{S\left(t_{k+1}\right)}{S\left(t_{k}\right)}+\left(V\left(t_{k}\right)-m C\left(t_{k}\right)\right) e^{r\left(t_{k+1}-t_{k}\right)}} \leq \xi \mid \frac{m C\left(t_{k}\right)}{V\left(t_{k}\right)}=\zeta\right) \\
= & \bar{P}\left(C\left(t_{k}\right)(m-\xi)\left(m \frac{S\left(t_{k+1}\right)}{S\left(t_{k}\right)}+(1-m) e^{r \frac{T}{n}}\right)\right. \\
& \left.\leq Y\left(t_{k}\right) e^{r \frac{T}{n}} \xi \mid C\left(t_{k}\right)=\frac{\zeta Y\left(t_{k}\right)}{m-\zeta}\right) \\
= & \bar{P}\left(\frac{\zeta Y\left(t_{k}\right)}{m-\zeta}(m-\xi)\left(m \frac{S\left(t_{k+1}\right)}{S\left(t_{k}\right)}+(1-m) e^{r \frac{T}{n}}\right) \leq Y\left(t_{k}\right) e^{r \frac{T}{n}} \xi\right) \\
= & \bar{P}\left(\frac{S\left(t_{k+1}\right)}{S\left(t_{k}\right)} \leq \frac{\xi e^{r \frac{T}{n}}(m-\zeta)}{m \zeta(m-\xi)}-\frac{(1-m) e^{r \frac{T}{n}}}{m}\right) .
\end{aligned}
$$


Taking logarithm of both sides inside the last probability, it follows that

$$
\begin{aligned}
& \bar{P}_{t_{k}, t_{k+1}^{-}}^{C L_{\zeta,}}=\bar{P}\left(\left(\mu_{S}-\frac{\sigma_{S}^{2}}{2}\right) \frac{T}{n}+\sigma_{S}\left(W\left(t_{k+1}\right)-W\left(t_{k}\right)\right)\right. \\
& \left.\leq r \frac{T}{n}+\ln \left(\frac{\xi(m-\zeta)}{\zeta(m-\xi) m}-\frac{1-m}{m}\right)\right) \\
& =\bar{P}\left(W\left(t_{k+1}\right)-W\left(t_{k}\right) \leq \frac{1}{\sigma_{S}}\left(\ln \left(\frac{\xi(m-\zeta)}{\zeta(m-\xi) m}-\frac{1-m}{m}\right)-\right.\right. \\
& \left.\left.\left(\mu_{S}-r-\frac{\sigma_{S}^{2}}{2}\right) \frac{T}{n}\right)\right) \text {. }
\end{aligned}
$$

Since Brownian increments have normal distribution, i.e. $W\left(t_{k+1}\right)-W\left(t_{k}\right) \sim \mathcal{N}(0, T / n)$, we have

$$
\bar{P}_{t_{k}, t_{k+1}^{-}}^{C L_{, \xi}}=\Phi\left(\frac{1}{\sigma_{S} \frac{T}{n}}\left(\ln \left(\frac{\xi(m-\zeta)}{\zeta(m-\xi) m}-\frac{1-m}{m}\right)-\left(\mu_{S}-r-\frac{\sigma_{S}^{2}}{2}\right) \frac{T}{n}\right)\right)
$$

which completes the proof for $\zeta>0$. It is clear that the upper bound for cash-lock probability is equal to 1 for $\zeta \leq 0$.

Proposition 4.4. (Local cash-lock probability) For $\xi \geq 0$, the $\zeta$ - $\xi$ cash-lock probability in random floor CPPI is given by

$$
\bar{P}_{t_{k}, t_{k+1}}^{C L_{\zeta, \xi}}=\Phi\left(\frac{\ln \left(\frac{Y\left(t_{k}\right) m(\xi-\zeta)}{\gamma\left(t_{k}\right)(m-\zeta)(m(1-c)-\xi)}\right)-\left(\mu_{L}-r-\frac{\sigma_{L}^{2}}{2}\right) \frac{T}{n}}{\sigma_{L} \sqrt{T / n}}\right)
$$

for $\zeta \leq 0$, and

$$
\bar{P}_{t_{k}, t_{k+1}}^{C L_{\zeta, \xi}} \cong \Phi\left(\frac{\ln \left(\frac{d\left(t_{k}\right) \sqrt{h\left(a\left(t_{k}\right), \bar{b}\left(t_{k}\right)\right)}}{f^{2}\left(a\left(t_{k}\right), \bar{b}\left(t_{k}\right)\right)}\right)}{\sqrt{\ln \left(\frac{h\left(a\left(t_{k}\right), \bar{b}\left(t_{k}\right)\right)}{f^{2}\left(a\left(t_{k}\right), \bar{b}\left(t_{k}\right)\right)}\right)}}\right)
$$

for $\zeta>0$ with $\bar{b}\left(t_{k}\right)=(1-c) b\left(t_{k}\right)$ and $k=0, \ldots, n-1$. Here, the functions $f, g$ and $b\left(t_{k}\right)$ are the same as in Proposition 4.2 and $\Phi$ is the cumulative distribution function of standard normal distribution.

Proof. First part of the proof is for $\zeta>0$. From 4.19, the post-payment dynamics are given by 


$$
\begin{aligned}
& C\left(t_{k+1}\right)=C\left(t_{k}\right)\left(m \frac{S\left(t_{k+1}\right)}{S\left(t_{k}\right)}+(1-m) e^{r\left(t_{k+1}-t_{k}\right)}\right)+(1-c) \gamma\left(t_{k+1}\right) \\
& V\left(t_{k+1}\right)=m C\left(t_{k}\right) \frac{S\left(t_{k+1}\right)}{S\left(t_{k}\right)}+\left(V\left(t_{k}\right)-m C\left(t_{k}\right)\right) e^{r\left(t_{k+1}-t_{k}\right)}+\gamma\left(t_{k+1}\right) .
\end{aligned}
$$

Substituting these relations into the definition 4.32 , we obtain

$$
\begin{aligned}
P_{t_{k}, t_{k+1}}^{C L_{\zeta, \xi}}=P & \left(\frac{m C\left(t_{k}\right)\left(m \frac{S\left(t_{k+1}\right)}{S\left(t_{k}\right)}+(1-m) e^{r \frac{T}{n}}\right)+(1-c) \gamma\left(t_{k+1}\right)}{m C\left(t_{k}\right) \frac{S\left(t_{k+1}\right)}{S\left(t_{k}\right)}+\left(V\left(t_{k}\right)-m C\left(t_{k}\right)\right) e^{r \frac{T}{n}}+\gamma\left(t_{k+1}\right)}\right. \\
& \left.\leq \xi \mid C\left(t_{k}\right)=\frac{\zeta Y\left(t_{k}\right)}{m-\zeta}\right) .
\end{aligned}
$$

The inequality inside the above probability can be rearranged as

$$
\begin{aligned}
C\left(t_{k}\right)\left(m(m-\xi) \frac{S\left(t_{k+1}\right)}{S\left(t_{k}\right)}+(m-\xi)(1\right. & \left.-m) e^{r \frac{T}{n}}\right) \\
& \leq(\xi-m(1-c)) \gamma\left(t_{k+1}\right)+\xi Y\left(t_{k}\right) e^{r \frac{T}{n}} .
\end{aligned}
$$

Including given information $C\left(t_{k}\right)=\frac{\zeta Y\left(t_{k}\right)}{m-\zeta}$ into the inequality yields the following probability

$$
\begin{aligned}
P_{t_{k}, t_{k+1}}^{C L_{\zeta, \xi}}=P & \left(\frac{\zeta Y\left(t_{k}\right)}{m-\zeta}\left[m(m-\xi) \frac{S\left(t_{k+1}\right)}{S\left(t_{k}\right)}+(m-\xi)(1-m) e^{r \frac{T}{n}}\right]\right. \\
& \left.-\xi Y\left(t_{k}\right) e^{r \frac{T}{n}} \leq(\xi-m(1-c)) \gamma\left(t_{k}\right) e^{\left(\mu_{L}-\frac{\sigma_{L}^{2}}{2}\right) \frac{T}{n}} e^{\sigma_{L}\left(W\left(t_{k+1}\right)-W\left(t_{k}\right)\right)}\right) \\
=P & \left(\frac{\zeta m(m-\xi) Y\left(t_{k}\right)}{m-\zeta} e^{\left(\mu_{S}-\frac{\sigma_{S}^{2}}{2}\right) \frac{T}{n}} e^{\sigma_{S}\left(W\left(t_{k+1}\right)-W\left(t_{k}\right)\right)}\right. \\
& +(m(1-c)-\xi) \gamma\left(t_{k}\right) e^{\left(\mu_{L}-\frac{\sigma_{L}^{2}}{2}\right) \frac{T}{n}} e^{\sigma_{L}\left(W\left(t_{k+1}\right)-W\left(t_{k}\right)\right)} \\
\leq & \left.Y\left(t_{k}\right) e^{r \frac{T}{n}}\left(\xi-\frac{(1-m)(m-\xi) \zeta}{m-\zeta}\right)\right)
\end{aligned}
$$

Here, denoting the random variables in the probability as $x_{1}=e^{\left(\mu_{S}-\frac{\sigma_{S}^{2}}{2}\right) \frac{T}{n}}$ and $x_{2}=$ $e^{\left(\mu_{L}-\frac{\sigma_{L}^{2}}{2}\right) \frac{T}{n}}$, it is clear that $x_{1} \sim \mathcal{L} \mathcal{N}\left(0, \sigma_{S}^{2} \frac{T}{n}\right)$ and $x_{2} \sim \mathcal{L} \mathcal{N}\left(0, \sigma_{L}^{2} \frac{T}{n}\right)$, i.e. $x_{1}$ and $x_{2}$ have lognormal distribution. Making the notations 


$$
\bar{b}\left(t_{k}\right)=(1-c) b\left(t_{k}\right)
$$

where $a\left(t_{k}\right)$ and $b\left(t_{k}\right)$ are as given in Proposition 4.2 . Then the objective probability is rewritten as

$$
P\left(a\left(t_{k}\right) x_{1}+\bar{b}\left(t_{k}\right) x_{2} \leq d\left(t_{k}\right)\right)
$$

Letting $\bar{X}=a\left(t_{k}\right) x_{1}+\bar{b}\left(t_{k}\right) x_{2}$, by FW method, it holds that

$$
\bar{X}=e^{X} \text { with } X \sim \mathcal{N}\left(\mu_{X}, \sigma_{X}^{2}\right)
$$

Therefore, it also holds $\bar{X} \sim \mathcal{L N}\left(\mu_{X}, \sigma_{X}^{2}\right)$ Using the set of equations given by (A.4), the mean and variance of the approximated distribution are obtained as

$$
\begin{aligned}
& \mu_{X}^{2}=\ln \left(\frac{\left(a e^{\frac{1}{2} \sigma_{S}^{2} \frac{T}{n}}+\bar{b} e^{\frac{1}{2} \sigma_{L}^{2} \frac{T}{n}}\right)^{2}}{\left(a^{2} e^{2 \sigma_{S}^{2} \frac{T}{n}}+\bar{b}^{2} e^{2 \sigma_{L}^{2} \frac{T}{n}}+2 a \bar{b} e^{\frac{1}{2}\left(\sigma_{S}^{2}+\sigma_{L}^{2}\right) \frac{T}{n}}\right)^{2}}\right) \\
& \sigma_{X}^{2}=\ln \left(\frac{a^{2} e^{2 \sigma_{S}^{2} \frac{T}{n}}+\bar{b}^{2} e^{2 \sigma_{L}^{2} \frac{T}{n}}+2 a \bar{b} e^{\frac{1}{2}\left(\sigma_{S}^{2}+\sigma_{L}^{2}\right) \frac{T}{n}}}{\left(a e^{\frac{1}{2} \sigma_{S}^{2} \frac{T}{n}}+\bar{b} e^{\frac{1}{2} \sigma_{L}^{2} \frac{T}{n}}\right)^{2}}\right) .
\end{aligned}
$$

In a similar way to proof of Proposition 4.2 The objective probability is then approximated as follows

$$
P\left(a\left(t_{k}\right) x_{1}+\bar{b}\left(t_{k}\right) x_{2} \leq d\left(t_{k}\right)\right) \cong \Phi\left(\frac{\ln \left(d\left(t_{k}\right)\right)-\mu_{X}}{\sigma_{X}}\right) .
$$

By imposing the notations $f(x, y)$ and $h(x, y)$ given as in Proposition 4.2 , it is found that

$$
P\left(a\left(t_{k}\right) x_{1}+\bar{b}\left(t_{k}\right) x_{2} \leq d\left(t_{k}\right)\right) \cong \Phi\left(\frac{\ln \left(\frac{d\left(t_{k}\right) \sqrt{h\left(a\left(t_{k}\right) \bar{b}\left(t_{k}\right)\right)}}{f^{2}\left(a\left(t_{k}\right), \bar{b}\left(t_{k}\right)\right)}\right)}{\sqrt{\ln \left(\frac{h\left(a\left(t_{k}\right), \bar{b}\left(t_{k}\right)\right)}{f^{2}\left(a\left(t_{k}\right), \bar{b}\left(t_{k}\right)\right)}\right)}}\right)
$$

which concludes the first part of the proof. Assuming $\zeta \leq 0$, the probability is given 


$$
\begin{aligned}
P_{t_{k}, t_{k+1}}^{C L_{\zeta, \xi}} & \left(\frac{m C\left(t_{k}\right) e^{r \frac{T}{n}}+(1-c) \gamma\left(t_{k+1}\right)}{V\left(t_{k}\right) e^{r \frac{T}{n}}+\gamma\left(t_{k+1}\right)} \leq \xi \mid C\left(t_{k}\right)=\frac{\zeta Y\left(t_{k}\right)}{m-\zeta}\right) \\
= & P\left(\left(C\left(t_{k}\right)(m-\xi)-\xi Y\left(t_{k}\right)\right) e^{r \frac{T}{n}} \leq(\xi-m(1-c)) \gamma\left(t_{k+1}\right) \mid C\left(t_{k}\right)=\frac{\zeta Y\left(t_{k}\right)}{m-\zeta}\right) \\
= & P\left((m(1-c)-\xi) \gamma L\left(t_{k}\right) e^{\left(\mu_{L}-\frac{\sigma_{L}^{2}}{2}\right) \frac{T}{n}+\sigma_{L}\left(W\left(t_{k+1}\right)-W\left(t_{k}\right)\right)}\right. \\
= & \left.\left(\xi-\frac{\zeta(m-\xi)}{m-\zeta}\right) Y\left(t_{k}\right) e^{r \frac{T}{n}}\right) \\
=P & \left.\left(\mu_{L}-\frac{\sigma_{L}^{2}}{2}\right) \frac{T}{n}+\sigma_{L}\left(W\left(t_{k+1}\right)-W\left(t_{k}\right)\right) \leq \ln \left(\frac{\left(\xi-\frac{\zeta(m-\xi)}{m-\zeta}\right) Y\left(t_{k}\right) e^{r \frac{T}{n}}}{(m(1-c)-\xi) \gamma\left(t_{k}\right)}\right)\right) \\
=P & \left(W\left(t_{k+1}\right)-W\left(t_{k}\right) \leq \frac{\ln \left(\frac{m(\xi-\zeta) Y\left(t_{k}\right)}{(m-\zeta)(m(1-c)-\xi) \gamma\left(t_{k}\right)}-\left(\mu_{L}-r-\frac{\sigma_{L}^{2}}{2}\right) \frac{T}{n}\right)}{\sigma_{L}}\right) \\
= & \left(\frac{\ln \left(\frac{m(\xi-\zeta) Y\left(t_{k}\right)}{(m-\zeta)(m(1-c)-\xi) \gamma\left(t_{k}\right)}-\left(\mu_{L}-r-\frac{\sigma_{L}^{2}}{2}\right) \frac{T}{n}\right)}{\sigma_{L} \sqrt{\frac{T}{n}}}\right),
\end{aligned}
$$

which completes the second part of the proof.

Notice that for the case $\zeta>0$, both the cushion and the portfolio value include the risky asset return, as is given by the Equations (4.7), (4.8) and (4.9). Since the cash-lock probability does not have an explicit solution for this case due to existence of multiple randomnesses, the upper bound probability is derived in the following proposition.

\subsubsection{Gap Risk}

This section analyzes the gap risk. To determine the effectiveness of each CPPI strategy discussed above, this thesis studies risk measures shortfall probability and expected shortfall alongside expected terminal wealth and its standard deviation. Basically, gap risk is the probability of a fall in the portfolio value so sharp that it falls below the floor between two re-balancing dates. In worst possible scenario, the CPPI portfolio falls below the floor before manager could re-balance and capital protection fails. The higher the value of multiplier $m$, the higher would be the gap risk. The value $1 / m$ is often referred to as the gap size which refers to the maximum loss that could be sustained between two re-balancing dates before the portfolio value crashes through the floor. 


\subsubsection{Gap risk for NPV floor CPPI}

The shortfall probability is the probability of the final wealth being less than the guaranteed amount.

Definition 4.3. (Shortfall Probability) The shortfall probability $P^{S F}$ denotes the probability that the final value of the CPPI strategy is less than the guaranteed amount $Y(T)$, i.e.

$$
P^{S F}:=P(C(T)<0) .
$$

The local shortfall probability $P^{L S F}$ is the probability that the cushion is negative after one time step, given the cushion is non-negative before, that is

$$
P^{L S F}:=P\left(C\left(t_{k+1}\right)<0 \mid C\left(t_{k}\right)>0\right)
$$

It is important to note that by local shortfall probability for period $\left(t_{k}, t_{k+1}\right)$, we describe the probability of cushion becoming negative between times $t_{k}$ and $t_{k+1}$. Thus, the case where cushion becomes negative after time $t_{k}$ and recovers back before time $t_{k+1}$ is excluded as this case does not affect the cushion dynamics that will prevail for the following period. Moreover, we carry out the analysis for two different time instants; at time $t_{k+1}$ when the contribution payment has been made and at an instant before time $t_{k+1}$ where the payment has not come in yet. Denoting the latter probability as

$$
P^{L S F}:=P\left(C\left(t_{k+1}^{-}\right)<0 \mid C\left(t_{k}\right)>0\right)
$$

the following proposition is given.

Proposition 4.5. (Local shortfall probability) The local shortfall probability at time $t_{k+1}^{-}$in NPV floor CPPI is given by

$$
P_{t_{k}, t_{k+1}^{-}}^{L S F}=\Phi(d)
$$

where $d=\frac{\ln \left(\frac{m-1}{m}\right)-\left(\mu_{S}-r-\frac{\sigma_{S}^{2}}{2}\right) \frac{T}{n}}{\sigma_{S} \sqrt{T / n}}$.

At time $t_{k+1}$, that is, after the payment has been made, the approximate probability is given as 


$$
P_{t_{k}, t_{k+1}}^{L S F} \cong \Phi\left(\frac{\ln \left(\frac{e^{r \frac{T}{n}\left(\frac{m-1}{m}\right) \sqrt{h\left(\widetilde{a}\left(t_{k}\right), \widetilde{b}\left(t_{k}\right)\right)}}}{f^{2}\left(\widetilde{a}\left(t_{k}\right), \widetilde{b}\left(t_{k}\right)\right)}\right)}{\sqrt{\ln \left(\frac{h\left(\widetilde{a}\left(t_{k}\right), \widetilde{b}\left(t_{k}\right)\right)}{f^{2}\left(\widetilde{a}\left(t_{k}\right), \widetilde{b}\left(t_{k}\right)\right)}\right)}}\right)
$$

with $\widetilde{a}\left(t_{k}\right)=e^{\left(\mu_{S}-\frac{\sigma_{S}^{2}}{2}\right) \frac{T}{n}}$ and $\widetilde{b}\left(t_{k}\right)=e^{\left(\mu_{L}-\frac{\sigma_{L}^{2}}{2}\right) \frac{T}{n}} \frac{\gamma\left(t_{k}\right)}{m C\left(t_{k}\right)}$ for $k=0, \ldots, n-1$. Here the functions $f, g$ and $b\left(t_{k}\right)$ are the same as in Proposition 4.2 and $\Phi$ is the cumulative distribution function of standard normal distribution.

Proof. In the first part of the proof, probability at time $t_{k+1}^{-}$is calculated (that is before the payment comes in).

$$
\begin{aligned}
P_{t_{k}, t_{k+1}^{-}}^{L S} & =P\left(C\left(t_{k+1}^{-}\right)<0 \mid C\left(t_{k}\right)>0\right) \\
& =P\left(C\left(t_{k}\right)\left(m \frac{S\left(t_{k+1}\right)}{S\left(t_{k}\right)}+(1-m) e^{r\left(t_{k+1}-t_{k}\right)}\right)\right) \\
& =P\left(\frac{S\left(t_{k+1}\right)}{S\left(t_{k}\right)}<\frac{m-1}{m} e^{r \frac{T}{n}}\right) \\
& =P\left(e^{\left(\mu_{S}-r-\sigma_{S}^{2} / 2\right) \frac{T}{n}+\sigma_{S}\left(W\left(t_{k+1}-W\left(t_{k}\right)\right)\right.}<\frac{m-1}{m}\right) \\
& =P\left(W(T / n)<\frac{1}{\sigma_{S}}\left(\ln \left(\frac{m-1}{m}\right)-\left(\mu_{S}-r-\sigma_{S}^{2} / 2\right)\right)\right)
\end{aligned}
$$

where $W(T / n) \sim \mathcal{N}(0, T / n)$. Therefore the probability is obtained as

$$
\begin{aligned}
P_{t_{k}, t_{k+1}^{-}}^{L S} & =P\left(\frac{W(T / n)}{\sqrt{T / n}}<\frac{1}{\sigma_{S} \sqrt{T / n}}\left(\ln \left(\frac{m-1}{m}\right)-\left(\mu_{S}-r-\sigma_{S}^{2} / 2\right)\right)\right) \\
& =\Phi\left(\frac{1}{\sigma_{S} \sqrt{T / n}}\left(\ln \left(\frac{m-1}{m}\right)-\left(\mu_{S}-r-\sigma_{S}^{2} / 2\right)\right)\right) .
\end{aligned}
$$

For the second part of the proof, probability at time $t_{k+1}$, i.e. after-payment probability will be obtained. Using the cushion dynamics at payment date, the probability is given as 


$$
\begin{aligned}
P_{t_{k}, t_{k+1}}^{L S F}= & P\left(C\left(t_{k}\right)\left(m \frac{S\left(t_{k+1}\right)}{S\left(t_{k}\right)}+(1-m) e^{r\left(t_{k+1}-t_{k}\right)}+\gamma\left(t_{k+1}\right)\right)<0 \mid C\left(t_{k}\right)>0\right) \\
= & P\left(\frac{S\left(t_{k+1}\right)}{S\left(t_{k}\right)}+\frac{\gamma\left(t_{k+1}\right)}{m C\left(t_{k}\right)}<\frac{m-1}{m} e^{r \frac{T}{n}} \mid C\left(t_{k}\right)>0\right) \\
= & P\left(e^{\left(\mu_{S}-\sigma_{S}^{2} / 2\right) \frac{T}{n}} e^{\sigma_{S}\left(W\left(t_{k+1}\right)-W\left(t_{k}\right)\right)}+e^{\left(\mu_{L}-\sigma_{L}^{2} / 2\right) \frac{T}{n}+\ln \left(\frac{\gamma\left(t_{k}\right)}{m C\left(t_{k}\right)}\right)}\right. \\
& \left.e^{\sigma_{L}\left(W\left(t_{k+1}\right)-W\left(t_{k}\right)\right)}<\frac{m-1}{m} e^{r \frac{T}{n}}\right) .
\end{aligned}
$$

With the notation $\widetilde{a}\left(t_{k}\right)=e^{\left(\mu_{S}-\frac{\sigma_{S}^{2}}{2}\right) \frac{T}{n}}$ and $\widetilde{b}\left(t_{k}\right)=e^{\left(\mu_{L}-\frac{\sigma_{L}^{2}}{2}\right) \frac{T}{n}} \frac{\gamma\left(t_{k}\right)}{m C\left(t_{k}\right)}$, and assuming random variables $x_{1} \sim \mathcal{N}\left(0, \sigma_{S}^{2} \frac{T}{n}\right)$ and $x_{2} \sim \mathcal{N}\left(0, \sigma_{L}^{2} \frac{T}{n}\right)$, the probability is represented as

$$
P\left(\widetilde{a}\left(t_{k}\right) e^{x_{1}}+\widetilde{b}\left(t_{k}\right) e^{x_{2}}<\frac{m-1}{m} e^{r \frac{T}{n}}\right)
$$

Approximating the summation inside the probability with another lognormal random variable $\bar{X}$ based on Fenton-Wilkinson method, it holds that $\bar{X}=e^{X}$ with $X \sim$ $\mathcal{N}\left(\mu_{X}, \sigma_{X}^{2}\right)$. Then by FW method, the distributional properties are found as

$$
\begin{gathered}
\mu_{X}=\ln \left(\frac{f^{2}\left(\widetilde{a}\left(t_{k}\right), \widetilde{b}\left(t_{k}\right)\right)}{\sqrt{h\left(\widetilde{a}\left(t_{k}\right), \widetilde{b}\left(t_{k}\right)\right)}}\right) \\
\sigma_{X}^{2}=\ln \left(\frac{h\left(\widetilde{a}\left(t_{k}\right), \widetilde{b}\left(t_{k}\right)\right)}{f^{2}\left(\widetilde{a}\left(t_{k}\right), \widetilde{b}\left(t_{k}\right)\right)}\right) .
\end{gathered}
$$

where $f(x, y)$ and $h(x, y)$ are as defined in Proposition 4.2. The probability is then calculated as follows

$$
\begin{aligned}
P\left(\widetilde{a}\left(t_{k}\right) e^{x_{1}}+\widetilde{b}\left(t_{k}\right) e^{x_{2}}<\frac{m-1}{m} e^{r \frac{T}{n}}\right) & \cong \Phi\left(\frac{\ln \left(\frac{m-1}{m}\right) e^{r \frac{T}{n}}-\mu_{X}}{\sigma_{X}^{2}}\right) \\
& =\Phi\left(\frac{\ln \left(\frac{e^{r \frac{T}{n}}\left(\frac{m-1}{m}\right) \sqrt{h\left(\widetilde{a}\left(t_{k}\right), \widetilde{b}\left(t_{k}\right)\right)}}{f^{2}\left(\widetilde{a}\left(t_{k}\right), \widetilde{b}\left(t_{k}\right)\right)}\right)}{\sqrt{\ln \left(\frac{h\left(\widetilde{a}\left(t_{k}\right), \widetilde{b}\left(t_{k}\right)\right)}{f^{2}\left(\widetilde{a}\left(t_{k}\right), \tilde{b}\left(t_{k}\right)\right)}\right)}}\right) .
\end{aligned}
$$

This completes the proof. 
Proposition 4.6. The shortfall probability is given as

$$
P^{S F}=1-\prod_{k=0}^{n-1}\left(1-P_{t_{k}, t_{k+1}}^{L S F}\right)
$$

for $k=0, \ldots, n-1$.

Proof. The proof follows from the definitions of shortfall and local shortfall probabilities.

The expected shortfall, on the other hand, measures the amount that is lost if a shortfall occurs.

Definition 4.4. (Expected Shortfall) The expected shortfall (ESF) is the amount which is lost if a shortfall occurs, i.e.

$$
E S F:=\mathbb{E}(-C(T) \mid C(T)<0)
$$

Considering the path-dependent structure of the proposed strategies, localized version of $E S F$ is defined and denoted by $E S F^{L}$.

Definition 4.5. (Local Expected Shortfall) The local expected shortfall at time $t_{k+1}^{-}$is given as

$$
E S F_{t_{k+1}^{-}}^{L}=\mathbb{E}\left(-C\left(t_{k+1}^{-}\right) \mid C\left(t_{k+1}^{-}\right)<0\right)
$$

Next, $E S F^{L}$ for NPV floor CPPI is given for the period $\left(t_{k}, t_{k+1}\right)$.

Proposition 4.7. (Local Expected shortfall) The local expected shortfall at time $t_{k+1}^{-}$ in NPV floor CPPI is given by

$$
E S F_{t_{k+1}^{-}}^{L}= \begin{cases}\frac{-C\left(t_{k}\right) F_{1}}{P_{t_{k}, t_{k+1}^{-}}^{L S F}}, & C\left(t_{k}\right)>0 \\ -C\left(t_{k}\right) e^{r \frac{T}{n}}, & C\left(t_{k}\right) \leq 0\end{cases}
$$

At time $t_{k+1}$, that is, taking the end of period payment into account, we find the approximate $E S F^{L}$ is as follows

$$
E S F_{t_{k+1}}^{L} \cong \begin{cases}\frac{-C\left(t_{k}\right) F_{2}-e^{\mu_{L} \frac{T}{n}} \Phi\left(\tilde{d}-\sigma_{L} \sqrt{\frac{T}{n}}\right)}{P_{t_{k}, t_{k+1}}^{L S}}, & C\left(t_{k}\right)>0 \\ -C\left(t_{k}\right) e^{r \frac{T}{n}}-\frac{\gamma\left(t_{k}\right) e^{\mu_{L} \frac{T}{n}} \Phi\left(\bar{d}-\sigma_{L} \sqrt{\frac{T}{n}}\right)}{\Phi(\bar{d})}, & C\left(t_{k}\right) \leq 0\end{cases}
$$


where

$$
\begin{aligned}
& F_{1}=m e^{\mu_{S} \frac{T}{n}} \Phi\left(d-\sigma_{S} \sqrt{\frac{T}{n}}\right)+(1-m) e^{r \frac{T}{n}} P_{t_{k}, t_{k+1}^{-}}^{L S F} \\
& F_{2}=m e^{\mu_{S} \frac{T}{n}} \Phi\left(\tilde{d}-\sigma_{S} \sqrt{\frac{T}{n}}\right)+(1-m) e^{r \frac{T}{n}} P_{t_{k}, t_{k+1}}^{L S F}
\end{aligned}
$$

with

$$
\begin{aligned}
& \bar{d}=\frac{\ln \left(-\frac{C\left(t_{k}\right)}{\gamma\left(t_{k}\right)}\right)-\left(\mu_{L}-r-\frac{\sigma_{L}^{2}}{2}\right) \frac{T}{n}}{\sigma_{L} \sqrt{\frac{T}{n}}} \\
& \tilde{d}=\frac{\ln \left(\frac{e^{r \frac{T}{n}\left(\frac{m-1}{m}\right) \sqrt{h(\widetilde{a} \widetilde{b})}}}{f^{2}(\widetilde{a}, \tilde{b})}\right)}{\sqrt{\ln \left(\frac{h(\widetilde{a}, \tilde{b})}{f^{2}(\widetilde{a}, \tilde{b})}\right)}},
\end{aligned}
$$

and $d$ is given as in Proposition 4.5 for $k=0,1, . ., n-1$. Here, $\Phi$ is the cumulative distribution function of standard normal distribution.

Proof. The proof will be done in four steps. First, the following event is defined to be used in the further steps:

$$
A_{k}:=\left\{\frac{S\left(t_{k}\right)}{S\left(t_{k-1}\right)} \geq\left(\frac{m-1}{m}\right) e^{r \frac{T}{n}}\right\} .
$$

It is clear that $A_{k}$ is the event of shortfall probability during the period $\left(t_{k-1}, t_{k}\right)$ being zero and the complement event is defined as

$$
A_{k}^{c}:=\left\{\frac{S\left(t_{k}\right)}{S\left(t_{k-1}\right)}<\left(\frac{m-1}{m}\right) e^{r \frac{T}{n}}\right\} .
$$

In the first step, pre-payment ESF will be calculated for $C\left(t_{k}\right)>0$. By definition of ESF, it holds 


$$
\begin{aligned}
E S F_{t_{k+1}^{-}}^{L} & =\mathbb{E}\left(-C\left(t_{k+1}^{-}\right) \mid C\left(t_{k+1}^{-}\right)<0\right) \\
& =\frac{\mathbb{E}\left(-C\left(t_{k+1}^{-}\right) \mathbb{1}_{A_{k+1}^{c}}\right)}{P\left(A_{k+1}\right)} \\
& =-C\left(t_{k}^{-}\right) \frac{\mathbb{E}\left(\left(m \frac{S\left(t_{k+1}\right)}{S\left(t_{k}\right)}+(1-m) e^{r\left(t_{k+1}-t_{k}\right)}\right) \mathbb{1}_{A_{k+1}^{c}}\right)}{P\left(A_{k+1^{c}}\right)}
\end{aligned}
$$

Denote the expectation in the numerator as $F_{1}$ and compute it as follows:

$$
\begin{aligned}
F_{1} & =\mathbb{E}\left(\left(m \frac{S\left(t_{k+1}\right)}{S\left(t_{k}\right)}+(1-m) e^{r\left(t_{k+1}-t_{k}\right)}\right) \mathbb{1}_{A_{k+1}^{c}}\right) \\
& =m \mathbb{E}\left(\frac{S\left(t_{k+1}\right)}{S\left(t_{k}\right)} \mathbb{1}_{A_{k+1}^{c}}\right)+(1-m) e^{r \frac{T}{n}} \mathbb{E}\left(\mathbb{1}_{A_{k+1}^{c}}\right) \\
& =m e^{\left(\mu_{S}-\sigma_{S}^{2} / 2\right) \frac{T}{n}} \mathbb{E}\left(e^{\sigma_{S}\left(W\left(t_{k+1}\right)-W\left(t_{k}\right)\right)}\right)+(1-m) e^{r \frac{T}{n}} P_{t_{k}, t_{k+1}}^{L F}
\end{aligned}
$$

The last equation is obtained by the relation

$$
P_{t_{k}, t_{k+1}}^{L S}=\mathbb{E}\left(\mathbb{1}_{A_{k+1}^{c}}\right)
$$

which is clear once the definition of the event $A_{k+1}$ is considered. Since it holds that $W\left(t_{k+1}\right)-W\left(t_{k}\right) \sim \mathcal{N}(0, T / n)$, it can be written that $W\left(t_{k+1}\right)-W\left(t_{k}\right)=\sqrt{T / n} Z$ for $Z \sim \mathcal{N}(0,1)$.

Then the expectation in the last equation satisfies,

$$
\begin{aligned}
\mathbb{E}\left(e^{\sigma_{S} \sqrt{T / n} Z_{1}} \mathbb{1}_{A_{k+1}^{c}}\right) & =\int_{\mathbb{1}_{A_{k+1}^{c}}} e^{\sigma_{S} x \sqrt{T / n}} \frac{1}{2 \pi} e^{-\frac{x^{2}}{2}} \\
& =\int_{-\infty}^{d} e^{\sigma_{S} x \sqrt{T / n}} \frac{1}{2 \pi} e^{-\frac{x^{2}}{2}}
\end{aligned}
$$

where $d=\frac{\ln \left(\frac{m-1}{m}\right)-\left(\mu_{S}-r-\frac{\sigma_{S}^{2}}{2}\right) \frac{T}{n}}{\sigma_{S} \sqrt{T / n}}$. Computing the integral, the following is obtained

$$
\mathbb{E}\left(e^{\sigma_{S} \sqrt{T / n} Z_{\mathbb{1}^{c}}}\right)=e^{\frac{1}{2} \sigma_{S} T / n} \Phi\left(d-\sigma_{S} \sqrt{T / n}\right)
$$

Substituting this relation in $F_{1}$, the expected shortfall is found as 


$$
E S F_{t_{k+1}^{-}}^{L}=\frac{-C\left(t_{k}\right) F_{1}}{P_{t_{k}, t_{k+1}}^{L S F}}
$$

where

$$
F_{1}=m e^{\mu_{s} \frac{T}{n}} \Phi\left(d-\sigma_{S} \sqrt{T / n}\right)+(1-m) e^{r \frac{T}{n}} P_{t_{k}, t_{k+1}}^{L S F} .
$$

In the second part of the proof it is assumed that $C\left(t_{k}\right) \leq 0$. The computation of ESF for case is much simpler since the cushion $C\left(t_{k}\right)$ is only invested in risk-free asset after time $t_{k}$. Therefore, it holds that

$$
\begin{aligned}
E S F_{t_{k+1}^{-}}^{L} & =\mathbb{E}\left(-C\left(t_{k}\right) e^{r \frac{T}{n}} \mid C\left(t_{k+1}^{-}\right)<0\right) \\
& =\mathbb{E}\left(-C\left(t_{k}\right) e^{r \frac{T}{n}}\right) \\
& =-C\left(t_{k}\right) e^{r \frac{T}{n}}
\end{aligned}
$$

In the next parts, post-payment ESFs will be calculated for cases of $C\left(t_{k}\right)$. For this, again new notation is introduced. First, the following events are defined

$$
\begin{aligned}
B_{k}:= & \left\{e^{\left(\mu_{S}-\frac{\sigma_{S}^{2}}{2}\right) \frac{T}{n}+\sigma_{S}\left(W\left(t_{k+1}\right)-W\left(t_{k}\right)\right)}+\frac{\gamma\left(t_{k}\right)}{m C\left(t_{k}\right)} e^{\left(\mu_{L}-\frac{\sigma_{L}^{2}}{2}\right) \frac{T}{n}+\sigma_{L}\left(W\left(t_{k+1}\right)-W\left(t_{k}\right)\right)}\right. \\
& \left.<\frac{(m-1) e^{r \frac{T}{n}}}{m}\right\}
\end{aligned}
$$

Assuming $C\left(t_{k}\right)>0$, the ESF is computed as

$$
E S F_{t_{k+1}}^{L}=\frac{\mathbb{E}\left(-C\left(t_{k+1}\right) \mathbb{1}_{B_{k}}\right)}{P\left(B_{k}\right)}
$$

The expectation in the numerator is equal to

$$
\begin{aligned}
\mathbb{E}\left(-C\left(t_{k+1}\right) \mathbb{1}_{B_{k}}\right) & =\mathbb{E}\left(-\left(C\left(t_{k}\right)\left(\frac{S\left(t_{k+1}\right)}{S\left(t_{k}\right)}+(1-m) e^{r \frac{T}{n}}\right)+\gamma\left(t_{k+1}\right)\right) \mathbb{1}_{B_{k}}\right) \\
& =-C\left(t_{k}\right)\left(m \mathbb{E}\left(\frac{S\left(t_{k+1}\right)}{S\left(t_{k}\right)} \mathbb{1}_{B_{k}}\right)+(1-m) e^{r \frac{T}{n}} P\left(B_{k}\right)\right) \\
& -\mathbb{E}\left(\gamma\left(t_{k+1}\right) \mathbb{1}_{B_{k}}\right) .
\end{aligned}
$$


Here, by definition

$$
P_{t_{k}, t_{k+1}}^{L S F}=\mathbb{E}\left(\mathbb{1}_{B_{k}}\right)
$$

To compute the expectations in $E S F_{t_{k+1}}^{L}$, we again approximate the sum of lognormal random variables by $\mathrm{FW}$ method and obtain

$$
\mathbb{E}\left(\gamma\left(t_{k+1}\right) \mathbb{1}_{B_{k}}\right)=e^{\mu_{L} \frac{T}{n}} \Phi\left(\tilde{d}-\sigma_{S} \sqrt{T / n}\right)
$$

where

$$
\tilde{d}=\frac{\ln \left(\frac{e^{r \frac{T}{n}}\left(\frac{m-1}{m}\right) \sqrt{h(\widetilde{a}, \widetilde{b})}}{f^{2}(\widetilde{a}, \widetilde{b})}\right)}{\sqrt{\ln \left(\frac{h(\widetilde{a}, \widetilde{b})}{f^{2}(\widetilde{a}, \widetilde{b})}\right)}} .
$$

Then, by further computations similar the first part of the proof, it is obtained that

$$
\mathbb{E}\left(\frac{S\left(t_{k+1}\right)}{S\left(t_{k}\right)} \mathbb{1}_{B_{k}}\right)=e^{\mu_{S} \frac{T}{n}} \Phi\left(\tilde{d}-\sigma_{S} \sqrt{T / n}\right)
$$

and ESF is found as

$$
E S F_{t_{k+1}}^{L}=\frac{-C\left(t_{k}\right) F_{2}-e^{\mu_{L} \frac{T}{n}} \Phi\left(\tilde{d}-\sigma_{L} \sqrt{\frac{T}{n}}\right)}{P_{t_{k}, t_{k+1}}^{L S F}}
$$

where

$$
F_{2}=m e^{\mu_{S} \frac{T}{n}} \Phi\left(\tilde{d}-\sigma_{S} \sqrt{\frac{T}{n}}\right)+(1-m) e^{r \frac{T}{n}} P_{t_{k}, t_{k+1}}^{L S} .
$$

Finally, post-payment EFS for the case $C\left(t_{k}\right) \leq 0$ is found as

$$
E S F_{t_{k+1}}^{L}=\frac{\mathbb{E}\left(\left(-C\left(t_{k}\right) e^{r \frac{T}{n}}-\gamma\left(t_{k+1}\right)\right) \mathbb{1}_{B_{k}}\right)}{P\left(B_{k}\right)} .
$$

Similarly, the expectation is obtained follows by computing the integral and ESF is calculated as 


$$
E S F_{t_{k+1}}^{L}=-C\left(t_{k}\right) e^{r \frac{T}{n}}-\frac{\gamma\left(t_{k}\right) e^{\mu_{L} \frac{T}{n}} \Phi\left(\bar{d}-\sigma_{L} \sqrt{\frac{T}{n}}\right)}{\Phi(\bar{d})}
$$

where

$$
\bar{d}=\frac{\ln \left(-\frac{C\left(t_{k}\right)}{\gamma\left(t_{k}\right)}\right)-\left(\mu_{L}-r-\frac{\sigma_{L}^{2}}{2}\right) \frac{T}{n}}{\sigma_{L} \sqrt{\frac{T}{n}}} .
$$

\subsubsection{Gap Risk for Random floor CPPI}

Note that, as the next payment is not included in the calculations, the local shortfall probability at time $t_{k+1}^{-}$for random floor case is the same as in NPV floor case.

Proposition 4.8. (Local shortfall probability) The local shortfall probability at time $t_{k+1}^{-}$in random floor CPPI is the same as in NPV case

$$
\bar{P}_{t_{k}^{-}, t_{k+1}}^{L F}=\Phi\left(\frac{\ln \left(\frac{m-1}{m}\right)-\left(\mu_{S}-r-\frac{\sigma_{S}^{2}}{2}\right) \frac{T}{n}}{\sigma_{S} \sqrt{T / n}}\right)
$$

At time $t_{k+1}$, that is, after the payment has been made, the approximate probability is given as

$$
\bar{P}_{t_{k}, t_{k+1}}^{L S F} \cong \Phi\left(\frac{\ln \left(\frac{e^{r \frac{T}{n}\left(\frac{m-1}{m}\right) \sqrt{h\left(\widetilde{a}\left(t_{k}\right), \hat{b}\left(t_{k}\right)\right)}}}{f^{2}\left(\widetilde{a}\left(t_{k}\right), \hat{b}\left(t_{k}\right)\right)}\right)}{\sqrt{\ln \left(\frac{h\left(\widetilde{a}\left(t_{k}\right), \hat{b}\left(t_{k}\right)\right)}{f^{2}\left(\widetilde{a}\left(t_{k}\right), \hat{b}\left(t_{k}\right)\right)}\right)}}\right)
$$

with $\hat{b}\left(t_{k}\right)=(1-c) \widetilde{b}\left(t_{k}\right)$. Here the functions $f, g$ and $b\left(t_{k}\right)$ are the same as in Proposition 4.2 and $\Phi$ is the cumulative distribution function of standard normal distribution..

Proof. The first part of the proof can be done the same way as in Proposition 4.5. For the after payment probability $\bar{P}_{t_{k}, t_{k+1}}^{L S F}$, it holds 


$$
\begin{aligned}
\bar{P}_{t_{k}, t_{k+1}}^{L S F}= & P\left(C\left(t_{k}\right)\left(m \frac{S\left(t_{k+1}\right)}{S\left(t_{k}\right)}+(1-m) e^{r\left(t_{k+1}-t_{k}\right)}+(1-c) \gamma\left(t_{k+1}\right)\right)<0 \mid C\left(t_{k}\right)>0\right) \\
= & P\left(\frac{S\left(t_{k+1}\right)}{S\left(t_{k}\right)}+\frac{(1-c) \gamma\left(t_{k+1}\right)}{m C\left(t_{k}\right)}<\frac{m-1}{m} e^{r \frac{T}{n}} \mid C\left(t_{k}\right)>0\right) \\
= & P\left(e^{\left(\mu_{S}-\sigma_{S}^{2} / 2\right) \frac{T}{n}} e^{\sigma_{S}\left(W\left(t_{k+1}\right)-W\left(t_{k}\right)\right)}+e^{\left(\mu_{L}-\sigma_{L}^{2} / 2\right) \frac{T}{n}+\ln \left(\frac{(1-c) \gamma\left(t_{k}\right)}{m C\left(t_{k}\right)}\right)}\right. \\
& \left.\times e^{\sigma_{L}\left(W\left(t_{k+1}\right)-W\left(t_{k}\right)\right)}<\frac{m-1}{m} e^{r \frac{T}{n}}\right) .
\end{aligned}
$$

Therefore, using the notation $\hat{b}\left(t_{k}\right)=(1-c) \widetilde{b}\left(t_{k}\right)$ for any $k=1,2, . ., n-1$ and applying Fenton-Wilkinson approximation as in Proposition 4.5 , it is obtained that

$$
\bar{P}_{t_{k}, t_{k+1}}^{L S F} \cong \Phi\left(\frac{\ln \left(\frac{e^{r \frac{T}{n}\left(\frac{m-1}{m}\right) \sqrt{h\left(\widetilde{a}\left(t_{k}\right), \hat{b}\left(t_{k}\right)\right)}}}{f^{2}\left(\widetilde{a}\left(t_{k}\right), \hat{b}\left(t_{k}\right)\right)}\right)}{\sqrt{\ln \left(\frac{h\left(\widetilde{a}\left(t_{k}\right), \hat{b}\left(t_{k}\right)\right)}{f^{2}\left(\widetilde{a}\left(t_{k}\right), \hat{b}\left(t_{k}\right)\right)}\right)}}\right) .
$$

Following proposition gives $E S F^{L}$ in random floor case for the period $\left(t_{k}, t_{k+1}\right)$.

Proposition 4.9. (Local Expected shortfall) The local expected shortfall at time $t_{k+1}^{-}$ in random floor CPPI is given by

$$
\overline{E S F}_{t_{k+1}^{-}}^{L}= \begin{cases}\frac{-C\left(t_{k}\right) F_{1}}{\bar{P}_{t_{k}, t_{k+1}^{-}}^{L F}}, & C\left(t_{k}\right)>0 \\ -C\left(t_{k}\right) e^{r \frac{T}{n}}, & C\left(t_{k}\right) \leq 0\end{cases}
$$

At time $t_{k+1}$, that is, taking the end of period payment into account, we find the approximate $E S F^{L}$ is as follows

$$
\overline{E S F}_{t_{k+1}}^{L} \cong \begin{cases}\frac{-C\left(t_{k}\right) F_{2}-(1-c) e^{\mu_{L} \frac{T}{n}} \Phi\left(\tilde{d}-\sigma_{L} \sqrt{\frac{T}{n}}\right)}{\bar{P}_{t_{k}, t_{k+1}}^{L S F}}, & C\left(t_{k}\right)>0 \\ -C\left(t_{k}\right) e^{r \frac{T}{n}}-\frac{(1-c) \gamma\left(t_{k}\right) e^{\mu_{L} \frac{T}{n}} \Phi\left(\bar{d}-\sigma_{L} \sqrt{\frac{T}{n}}\right)}{\Phi(\bar{d})}, & C\left(t_{k}\right) \leq 0\end{cases}
$$

where 


$$
\begin{aligned}
& F_{1}=m e^{\mu_{S} \frac{T}{n}} \Phi\left(d-\sigma_{S} \sqrt{\frac{T}{n}}\right)+(1-m) e^{r \frac{T}{n}} \bar{P}_{t_{k}, t_{k+1}^{-}}^{L S F} \\
& F_{2}=m e^{\mu_{S} \frac{T}{n}} \Phi\left(\tilde{d}-\sigma_{S} \sqrt{\frac{T}{n}}\right)+(1-m) e^{r \frac{T}{n}} \bar{P}_{t_{k}, t_{k+1}}^{L S F}
\end{aligned}
$$

with

$$
\tilde{d}=\frac{\ln \left(\frac{e^{r \frac{T}{n}}\left(\frac{m-1}{m}\right) \sqrt{h(\widetilde{a}, \hat{b})}}{f^{2}(\widetilde{a}, \hat{b})}\right)}{\sqrt{\ln \left(\frac{h(\widetilde{a}, \hat{b})}{f^{2}(\widetilde{a}, \hat{b})}\right)}}
$$

and $\bar{d}, \hat{b}\left(t_{k}\right)$ are as defined in Propositions 4.7 and 4.8 . Here, $\Phi$ is the cumulative distribution function of standard normal distribution.

Proof. Proof is obtained in a similar way to Proposition 4.7. Here, as a distinction, one needs to define the events in accordance to random floor CPPI dynamics as follows:

$$
\begin{aligned}
\overline{A_{k}}:= & \left\{\frac{S\left(t_{k}\right)}{S\left(t_{k-1}\right)}+\gamma\left(t_{k}\right) \geq\left(\frac{m-1}{m}\right) e^{r \frac{T}{n}}\right\} \\
\overline{B_{k}}:= & \left\{e^{\left(\mu_{S}-\frac{\sigma_{S}^{2}}{2}\right) \frac{T}{n}+\sigma_{S}\left(W\left(t_{k+1}\right)-W\left(t_{k}\right)\right)}+\frac{(1-c) \gamma\left(t_{k}\right)}{m C\left(t_{k}\right)} e^{\left(\mu_{L}-\frac{\sigma_{L}^{2}}{2}\right) \frac{T}{n}+\sigma_{L}\left(W\left(t_{k+1}\right)-W\left(t_{k}\right)\right)}\right. \\
& \left.<\frac{(m-1) e^{r \frac{T}{n}}}{m}\right\}
\end{aligned}
$$

Then, using the before and after payment shortfall probabilities given Proposition 4.8 and carrying out the same calculations of Proposition 4.7, it can be shown that

$$
\overline{E S F}_{t_{k+1}^{-}}^{L}= \begin{cases}\frac{-C\left(t_{k}\right) F_{1}}{\bar{P}_{t_{k}, t_{k+1}^{-}}^{L S F}}, & C\left(t_{k}\right)>0 \\ -C\left(t_{k}\right) e^{r \frac{T}{n}}, & C\left(t_{k}\right) \leq 0\end{cases}
$$

and 


$$
\overline{E S F}_{t_{k+1}}^{L} \cong \begin{cases}\frac{-C\left(t_{k}\right) F_{2}-(1-c) e^{\mu_{L} \frac{T}{n}} \Phi\left(\tilde{d}-\sigma_{L} \sqrt{\frac{T}{n}}\right)}{\bar{P}_{t_{k}, t_{k+1}}^{L S F}}, & C\left(t_{k}\right)>0 \\ -C\left(t_{k}\right) e^{r \frac{T}{n}}-\frac{(1-c) \gamma\left(t_{k}\right) e^{\mu_{L} \frac{T}{n}} \Phi\left(\bar{d}-\sigma_{L} \sqrt{\frac{T}{n}}\right)}{\Phi(\bar{d})}, & C\left(t_{k}\right) \leq 0\end{cases}
$$

for any $k=0,1, \ldots n-1$.

As mentioned in Section 4.3.1, the CPPI strategies considered in the present thesis are path-dependent. Since this dependent structure prevents tractability, the only possible computable risk measures represent local dynamics. Therefore, the best way to study the evolution of calculated measures is to illustrate them through trajectories. The specific considered trajectory is presented in Figure 4.1 .
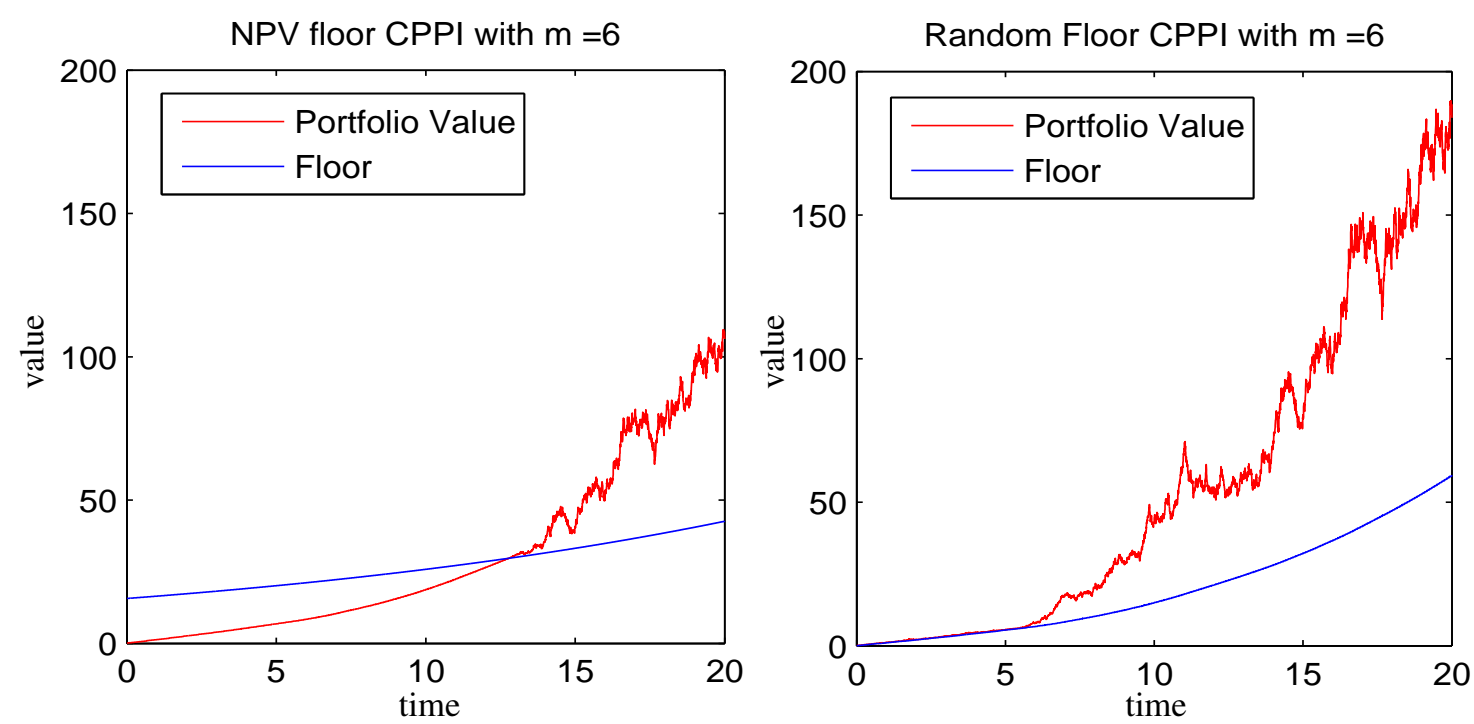

Figure 4.1: A trajectory for the parameters under a certain parameter set

Figures 4.2 - 4.4 reflect realizations of cash-lock probability, shortfall probability and expected shortfall for the same trajectory and for differing multiplier values. 

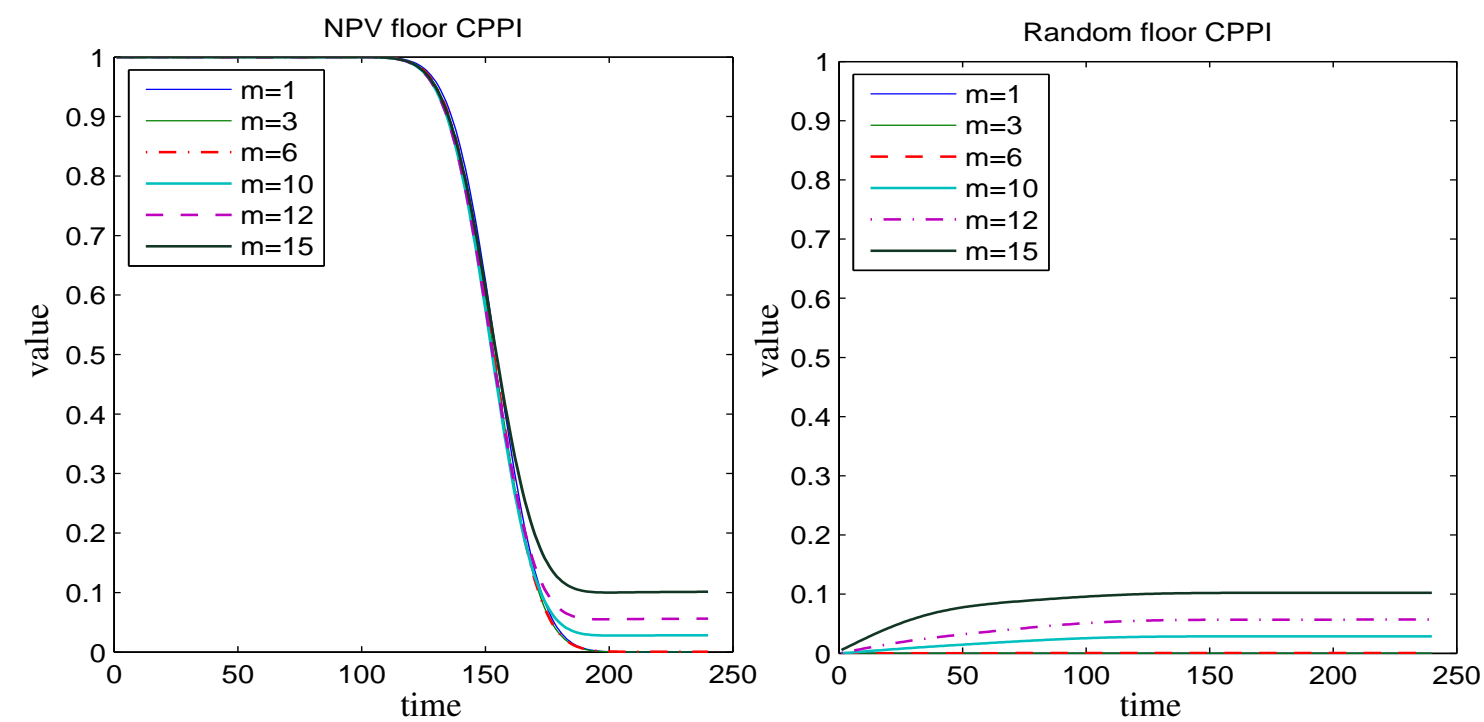

Figure 4.2: Local cash-lock probabilities for a given trajectory

The regular inflows provide a great protection against cash-lock and this effect can be clearly seen in Figure 4.2. Even for a very high multiplier value of 15, the maximum probability is bounded above. For the NPV floor CPPI, the probabilities are equal to 1 for the period when the cushion is negative indicating a high risk of being close to the floor and decrease drastically as the portfolio value recovers.
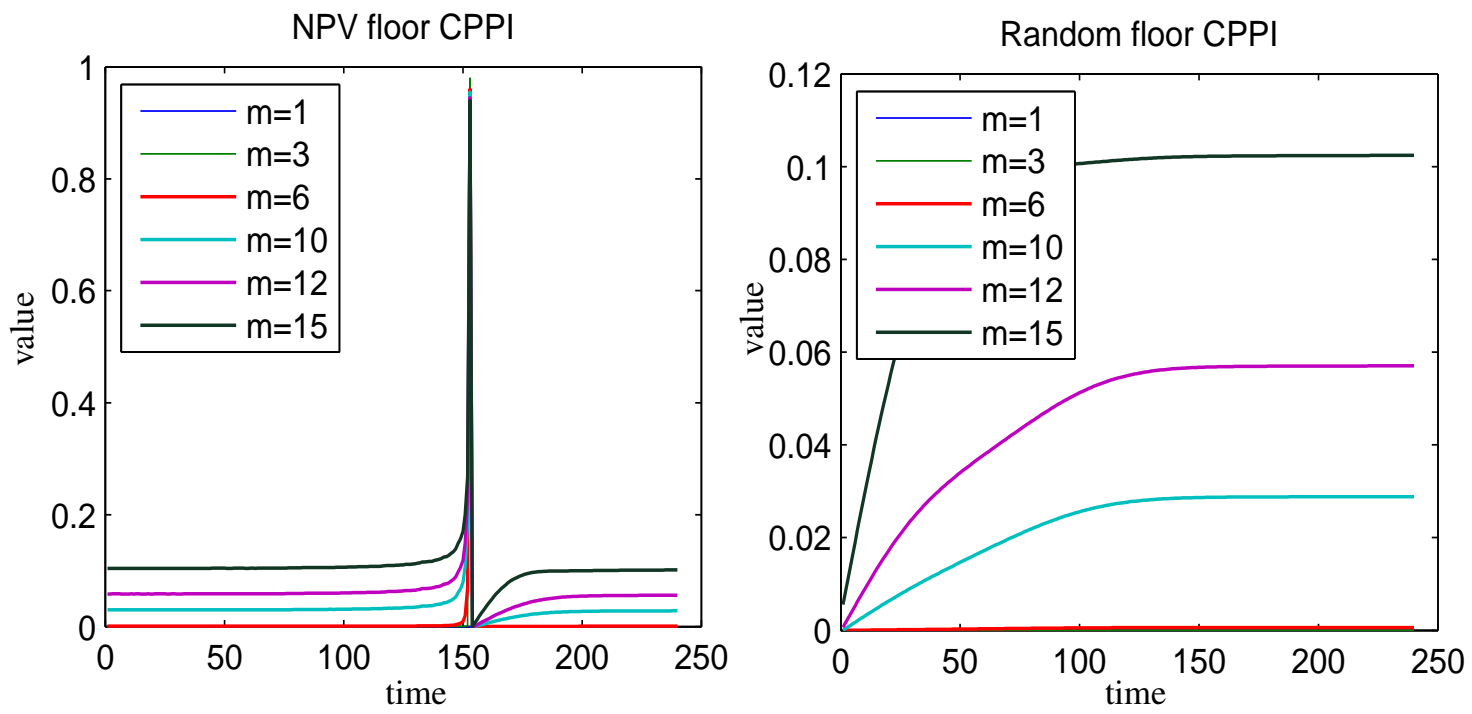

Figure 4.3: Local shortfall probabilities for a given trajectory

The behavior of increasing shortfall probability for higher multipliers is reflected in Figure 4.3. The displayed irregularity is again a result of the transition of the portfolio from being in loss to recovery. As shortfall probability quantifies risk based on the distance of portfolio value and the floor through trajectory, as the portfolio touches the floor and cushion becomes zero, the probability suddenly jumps to unity. This touching 
time can also be observed from the Figure 4.1 where the timeline consists of the fixed payment dates. It is important to note that once the portfolio begins to evolve above the floor, the shortfall probabilities resemble to those of random floor CPPI as their dynamics are the same for $C(t)>0$.
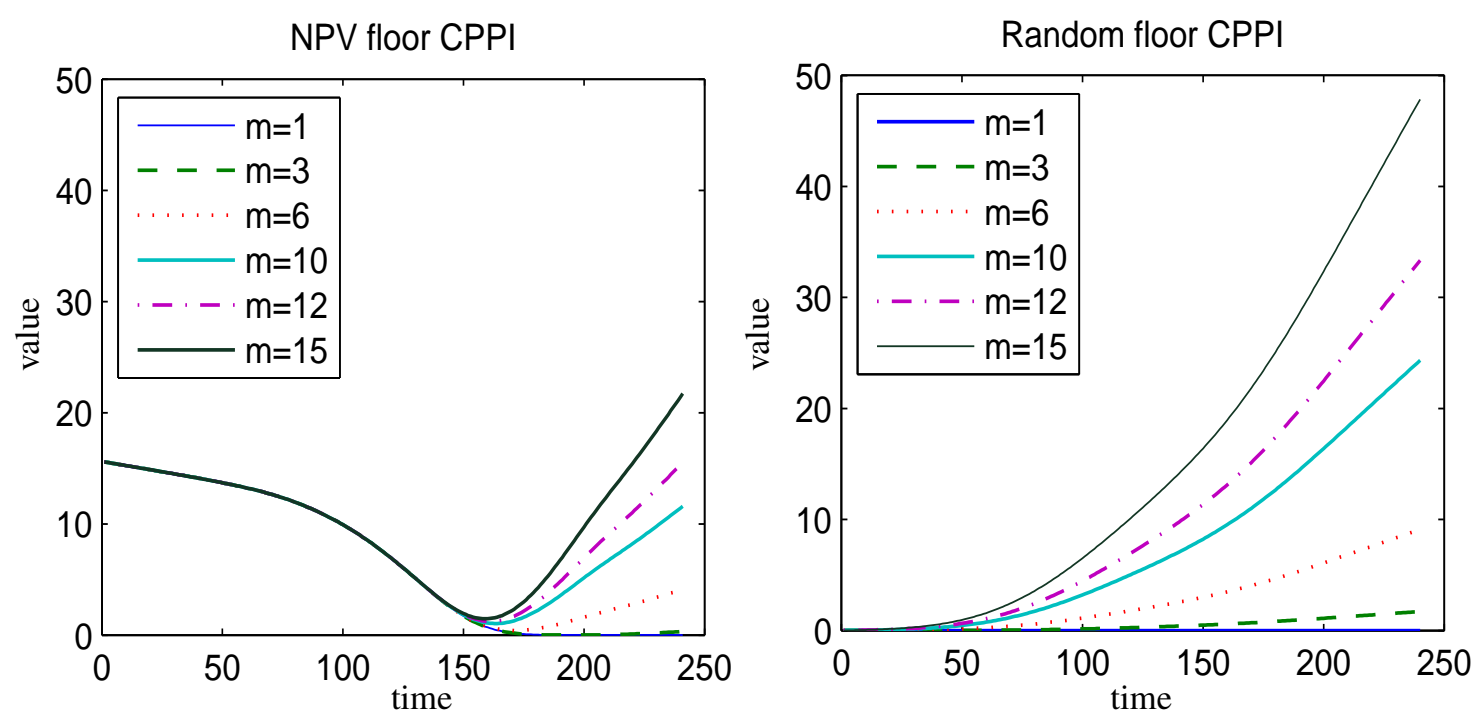

Figure 4.4: Local expected shortfall values for a given trajectory

Lastly, Figure 4.4 displays the direct relation between the multiplier and the expected shortfall supporting the result of shortfall probability. Note that, at the time when NPV portfolio touches the floor and cushion becomes zero, the ESF also becomes zero. Another important point is that in all cases presented above, the probabilities are bounded above. This happens because of the assumption which prevents unlimited borrowing. Even in a bullish market as ours, the maximum exposure is limited to $V$ which also puts an upper bound on the shortfall risk.

\subsection{Numerical Results}

To illustrate the behavior of various CPPI strategies discussed throughout the thesis, some numerical examples are given in this section. The set of input parameters is given in Table 4.1. Throughout this section the given parameter set will be used in numerical calculations, unless stated otherwise. All numerical computations are carried out via MATLAB. 
Table 4.1: Assumed values for the parameters under discrete-time trading model

\begin{tabular}{lc}
\hline Interest rate, $r$ & 0.05 \\
Stock parameters & \\
$\quad$ Drift, $\mu_{S}$ & 0.12 \\
$\quad$ Volatility, $\sigma_{S}$ & 0.2 \\
Labor income parameters & \\
$\quad$ Drift, $\mu_{L}$ & 0.06 \\
$\quad$ Volatility, $\sigma_{L}$ & 0.09 \\
Guarantee rate, $c$ & 0.8 \\
Risk aversion parameter, $\eta$ & 2 \\
Contribution rate, $\gamma$ & 0.1 \\
Lower bound coefficient, $\epsilon$ & 0.25 \\
Multiplier, $m$ & 2 \\
Margin parameter, $h$ & 0.05 \\
Constraint parameter, $p$ & 0.5 \\
Time horizon of pension plan, $T$ & 20 \\
\hline
\end{tabular}

Table 4.2 and 4.3 present the sensitivities of the moments of terminal wealth to under varying parameters for different CPPI schemes. When the values in Table 4.2 are compared horizontally, it is seen that there is a rough ordering between the means of the five strategies. The random floor always gives the highest terminal wealth as well as highest coefficient of variation (CV), as expected. This is a result of the less strict constraint defined on the exposure. Since the whole wealth is allowed to be invested in risky asset, the portfolio with the random floor climbs up in rising markets and takes advantage of the increase in the stock. This investment freedom comes with a widely dispersed sample of terminal wealths whose $\mathrm{CV}$ is the most sensitive to the increase in its value. Even though such a high deviation is normally considered as a negative indicator of performance, this is not the case for our framework. Since the guarantee is always satisfied (except for the case of a very large $m$ coupled with a sudden decrease in the market close to maturity), this upside risk is a sign of potential excessive gains. The second highest wealth is provided by the Ratchet CPPI portfolio. As a nice advantage of the ratchetings performed during the investment horizon which decrease the cushion and the proportion of wealth at risk, the gains are protected throughout the investment period. This is also supported by the lower standard deviation compared to random and NPV floor strategies. The next best strategy in terms of high terminal wealth is NPV floor CPPI. While yielding higher returns than margin and constrained CPPI strategies, it has a very volatile profile. This is another expected result, as NPV floor CPPI also has a weaker control mechanism on the exposure. 


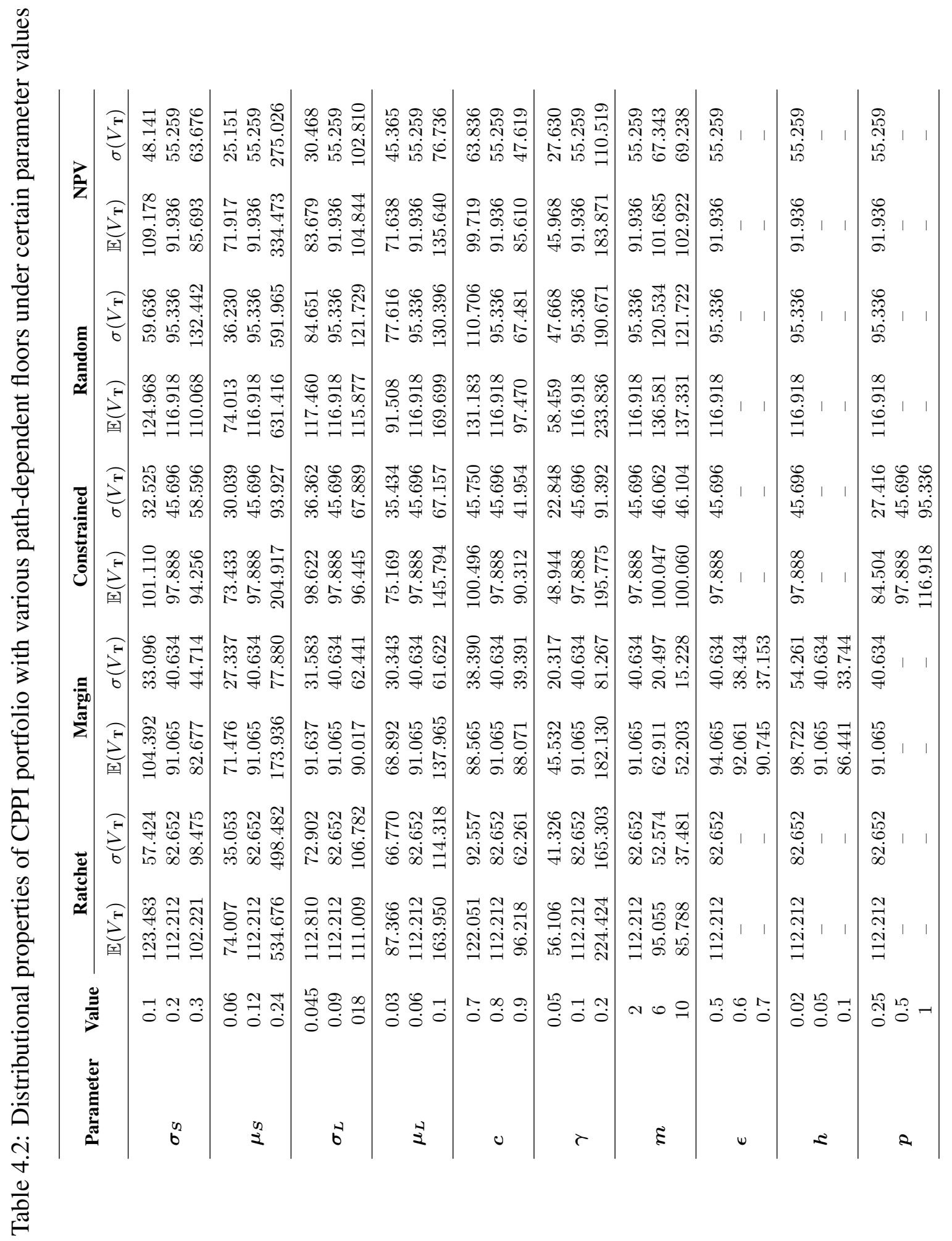


Table 4.3: Coefficients of variation of CPPI portfolio with various path-dependent floors under certain parameter values

\begin{tabular}{|c|c|c|c|c|c|c|}
\hline \multirow{2}{*}{ Parameter } & \multirow{2}{*}{ Value } & \multirow{2}{*}{$\begin{array}{l}\text { Ratchet } \\
C V V\left(V_{\mathrm{T}}\right) \\
\end{array}$} & \multirow{2}{*}{$\begin{array}{c}\text { Margin } \\
C C V\left(V_{\mathrm{T}}\right)\end{array}$} & \multirow{2}{*}{$\begin{array}{c}\text { Constrained } \\
C V\left(V_{\mathrm{T}}\right) \\
\end{array}$} & \multirow{2}{*}{$\begin{array}{l}\text { Random } \\
C V\left(V_{\mathrm{T}}\right)\end{array}$} & \multirow{2}{*}{$\begin{array}{c}\text { NPV } \\
C V\left(V_{\mathrm{T}}\right)\end{array}$} \\
\hline & & & & & & \\
\hline \multirow{3}{*}{$\sigma_{S}$} & 0.1 & 0.465 & 0.317 & 0.322 & 0.477 & 0.441 \\
\hline & 0.2 & 0.737 & 0.446 & 0.467 & 0.815 & 0.601 \\
\hline & 0.3 & 0.963 & 0.541 & 0.622 & 1.203 & 0.743 \\
\hline \multirow{3}{*}{$\mu_{S}$} & 0.06 & 0.474 & 0.382 & 0.409 & 0.490 & 0.350 \\
\hline & 0.12 & 0.737 & 0.446 & 0.467 & 0.815 & 0.601 \\
\hline & 0.24 & 0.932 & 0.448 & 0.458 & 0.938 & 0.822 \\
\hline \multirow{3}{*}{$\sigma_{L}$} & 0.05 & 0.646 & 0.345 & 0.369 & 0.721 & 0.364 \\
\hline & 0.09 & 0.737 & 0.446 & 0.467 & 0.815 & 0.601 \\
\hline & 0.18 & 0.962 & 0.694 & 0.704 & 1.051 & 0.981 \\
\hline \multirow{3}{*}{$\mu_{L}$} & 0.03 & 0.764 & 0.440 & 0.471 & 0.848 & 0.633 \\
\hline & 0.06 & 0.737 & 0.446 & 0.467 & 0.815 & 0.601 \\
\hline & 0.1 & 0.697 & 0.447 & 0.461 & 0.768 & 0.566 \\
\hline \multirow{3}{*}{$c$} & 0.70 & 0.758 & 0.433 & 0.455 & 0.844 & 0.640 \\
\hline & 0.80 & 0.737 & 0.446 & 0.467 & 0.815 & 0.601 \\
\hline & 0.90 & 0.647 & 0.447 & 0.465 & 0.692 & 0.556 \\
\hline \multirow{3}{*}{$\gamma$} & 0.05 & 0.737 & 0.446 & 0.467 & 0.815 & 0.601 \\
\hline & 0.1 & 0.737 & 0.446 & 0.467 & 0.815 & 0.601 \\
\hline & 0.20 & 0.737 & 0.446 & 0.467 & 0.815 & 0.601 \\
\hline \multirow{3}{*}{$m$} & 2 & 0.737 & 0.446 & 0.467 & 0.815 & 0.601 \\
\hline & 6 & 0.553 & 0.326 & 0.460 & 0.883 & 0.662 \\
\hline & 10 & 0.437 & 0.292 & 0.461 & 0.886 & 0.673 \\
\hline \multirow{3}{*}{$\epsilon$} & 0.5 & 0.737 & 0.432 & 0.467 & 0.815 & 0.601 \\
\hline & 0.6 & - & 0.417 & - & - & - \\
\hline & 0.7 & - & 0.409 & - & - & - \\
\hline \multirow{3}{*}{$h$} & 0.02 & 0.737 & 0.550 & 0.467 & 0.815 & 0.601 \\
\hline & 0.05 & - & 0.446 & - & - & - \\
\hline & 0.1 & - & 0.390 & - & - & - \\
\hline \multirow{3}{*}{$p$} & 0.25 & 0.737 & 0.446 & 0.324 & 0.815 & 0.601 \\
\hline & 0.5 & - & - & 0.467 & - & - \\
\hline & 1 & - & - & 0.815 & - & - \\
\hline
\end{tabular}

The reason that it is able to provide high returns is because the initial NPV floor, which is the time zero value of the future contributions, grows deterministically being independent from the incoming payments. Therefore, the floor starts at a much higher value than the other floors which eventually pulls the portfolio above itself. A prominent risk in this scenario is the probability of the participant withdrawing from the system. Since the strategy needs some time to recover and provide gains by investing in the risky asset, early withdrawals is will bring loss. Considering this result with the risky structure of the strategy, we can conclude that the NPV floor CPPI is profitable for those who wish to stay in the system for a long time and can bear a possibly wide range for the wealth at the end. As for constrained CPPI, the mean wealth values are lower than the ones considered above and they come with a low dispersion. The outcome of the low wealth and risk is due to the constrained mechanism which limits the exposure being 
invested in the risky asset and eventually prevents portfolio from taking advantage of a possible rise in the market. While being very convenient for the risk averse investors the constrained CPPI is also able to yield a reasonable return. Among those constrained CPPI yields the less reaction to increase in the parameters as the CV for each case does not significantly increase. The last strategy is the margin strategy with the ratchet effect. This strategy has the lowest risk because it possesses the most protective and varying floor. At times when the floor decreases to reduce the cash-lock risk, the portfolio temporarily follows a downward trend. This indeed affects the profits in the overall, resulting in a relatively lower wealth. However, the successive ratchetings performed during the investment horizon guarantees the gains at each step decreasing the volatility and providing more protection. While being in a competitive level with the other floors, margin strategy offers a really small risk. Therefore, it is preferable for the most conservative investors. It is also interesting to see the sensitivities on a strategy basis. An increase in stock volatility decreases the terminal wealth while an increase in the stock drift $\mu_{S}$ enhances the wealth for all strategies. As expected, higher stock volatility $\sigma_{S}$ increases final wealth's standard deviation and increasing $\mu_{S}$ also contributes the riskiness of the portfolio. Looking at the labor income parameters, it is seen that while being a small change, a rise in the drift $\sigma_{L}$ increases the mean and standard deviation of the terminal wealth. The labor drift $\mu_{L}$ also has a positive effect on the moments. The guarantee parameter $c$ is negatively proportional with the mean and standard deviation, as it increases the floor resulting in smaller investment in risky asset and promising lower profits. Since the money inflow into the fund enhances with a high contribution parameter, this causes the moments to increase. A change in multiplier has various effects on different strategies based on the dependency of their constraints on multiplier $m$. The margin parameters $\epsilon$ and $h$ only positively impact on the margin strategy as they are not input parameters for other strategies. Lastly, for an increase in the constraint parameter $p$, the moments also increase displaying a strong positive sensitivity. It is also noted that the $\mathrm{CV}$ of all the strategies are insensitive to the change in contribution rate $\gamma$ and the CV decrease when the values of $m$ and margin parameters $\epsilon, h$ and $p$ increase. Overall, the high standard deviations that Table 4.2 presents for each parameter set and strategy can seem very large. However, it should be noted that these are upside standard deviations which only represent the upside risk. This situation is not necessarily undesirable especially when we take into account the fact that the guarantee is almost always satisfied. Another reason for this relatively high deviation is the lengthiness of the investment horizon. Since DC pension plans are long-term products, we conducted our numerical examples for $T=20$ years which gives the stock process enough time to climb very high in bullish markets as we assume with $\mu_{S} \in\{0.06,0.12,0.24\}$. To further investigate the standard deviations, we look at the worst $10 \%$ of the terminal wealths from the sample of random floor strategy which displays the highest deviation with the parameter set as given in Table 4.1. A much lower mean of 45.94 with a small standard deviation 3.8824 suggests that the deviation of the strategy is enhanced more due to some exceptionally large wealths rather than an overall dispersion in the terminal wealths. 

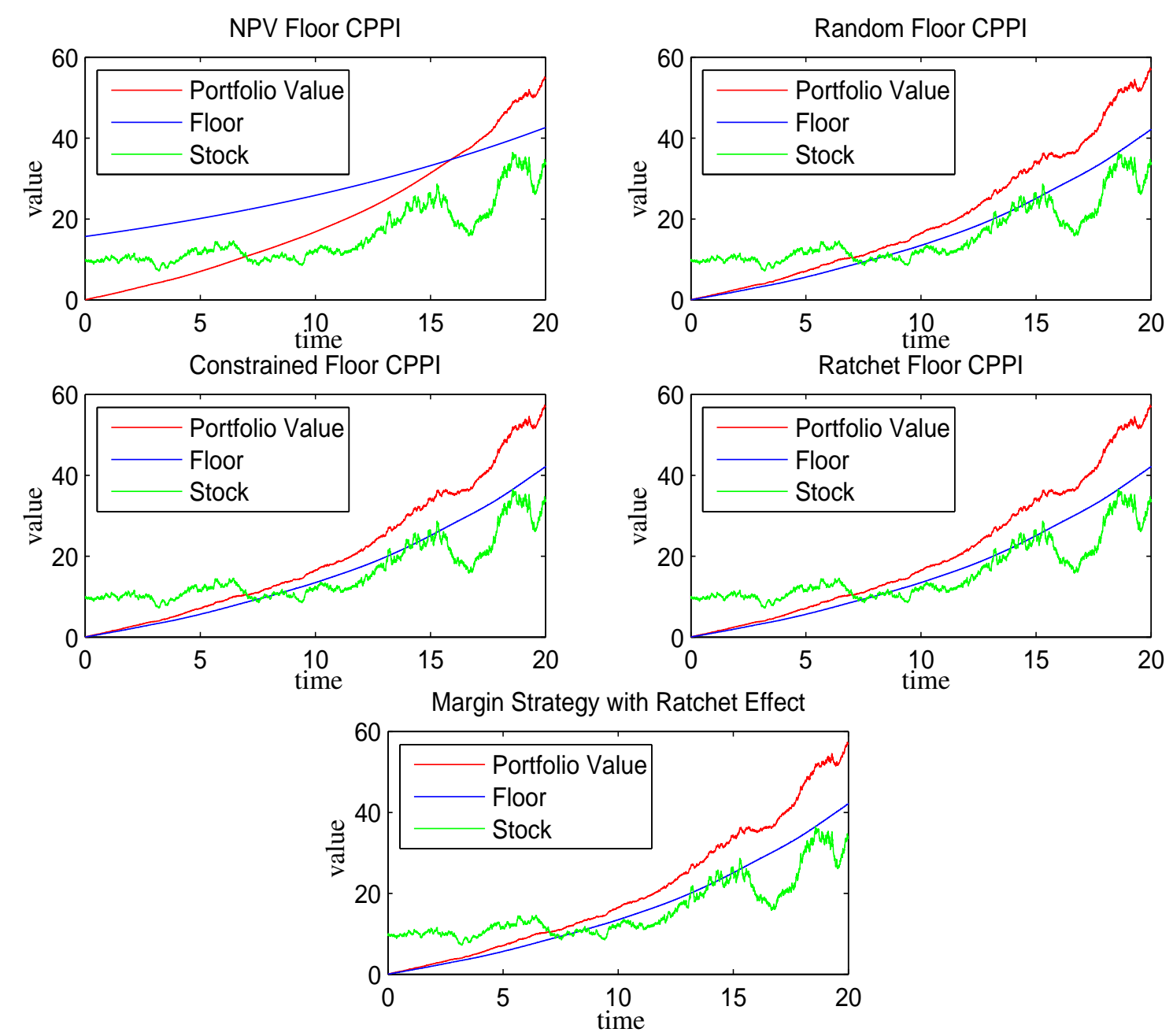

Figure 4.5: A trajectory for $m=1$ 

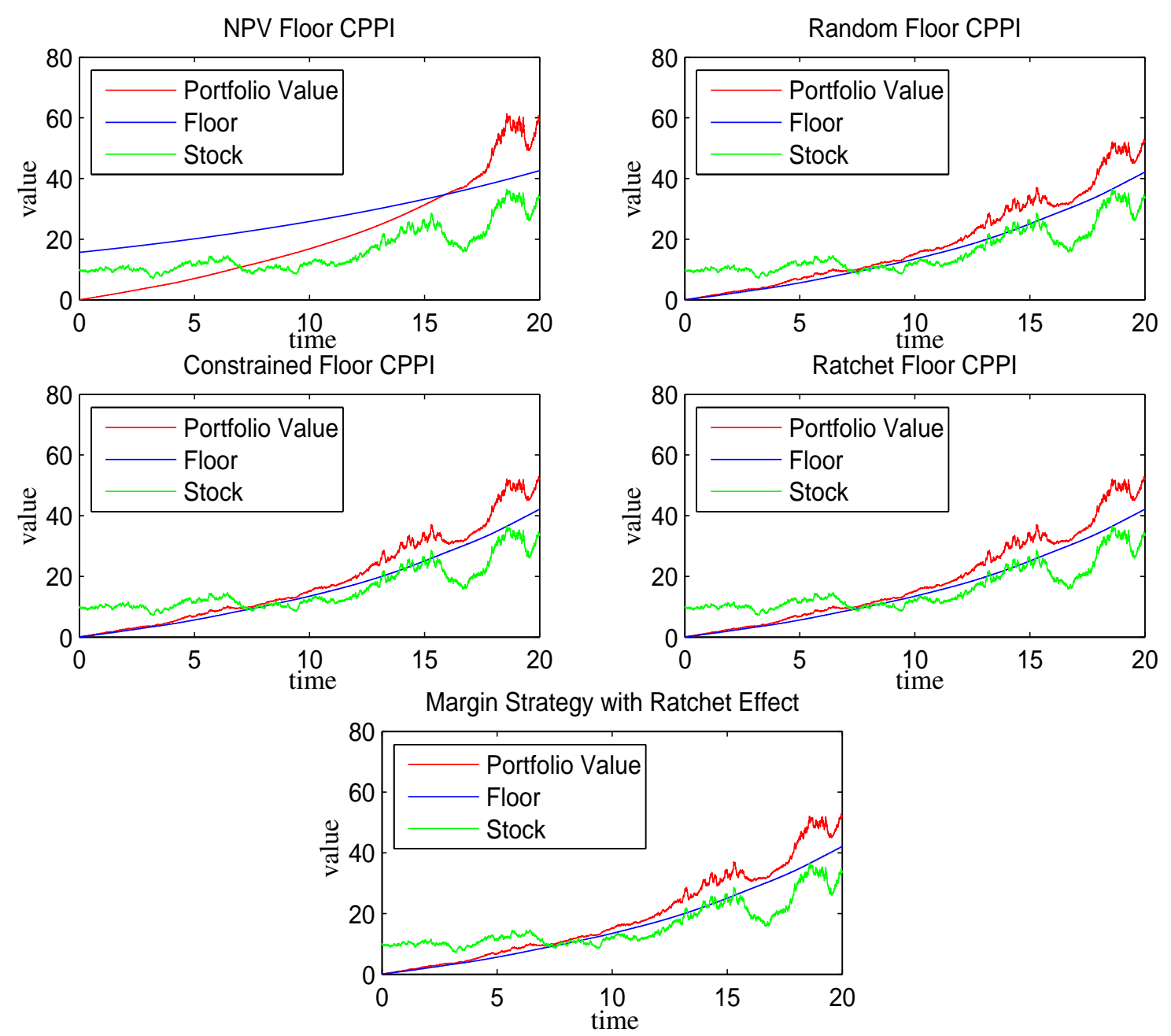

Figure 4.6: A trajectory for $m=3$

Figures 4.5-4.7 shows a particular trajectory of each strategy to illustrate the evolution of the portfolio under different strategies. As it can be clearly seen, the NPV portfolio recovers after sometime and begins to evolve above the floor requiring a certain amount of time to be spent in the pension system. From the ratchet strategy, the floor follows the portfolio value at the desired distance with help of artificial increases. In plot which displays margin strategy the ratcheting and margin effects are observed which are used to manipulate the floor to avoid cash-lock position while keeping the final guarantee as intact as possible. This variability in floor is especially important when the investment horizon is very long as in our case. Lastly, one can observe that while the random floor strategy has a volatile profile, constrained strategy is more stable due to limited exposure. 
NPV Floor CPPI
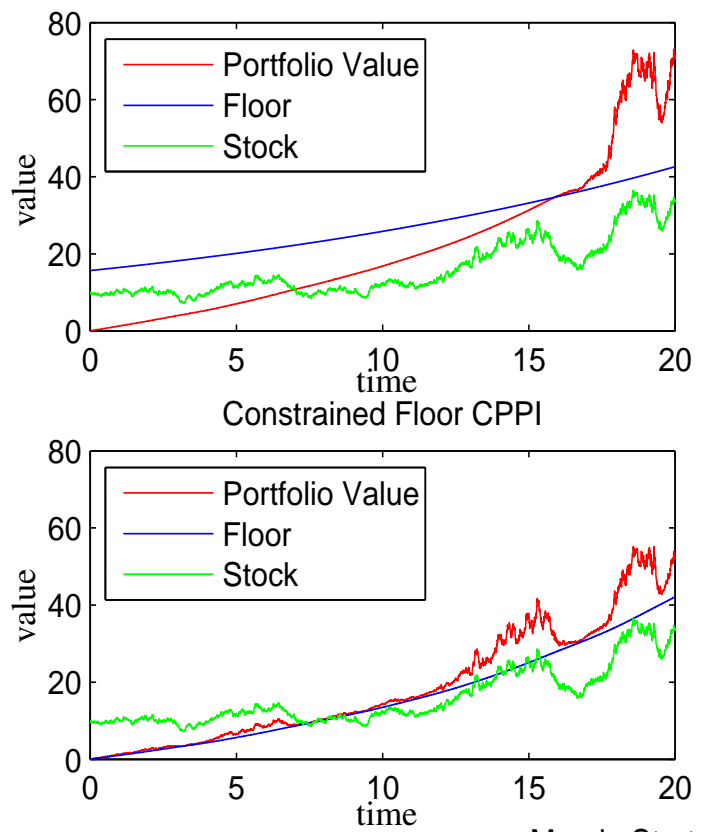

Random Floor CPPI
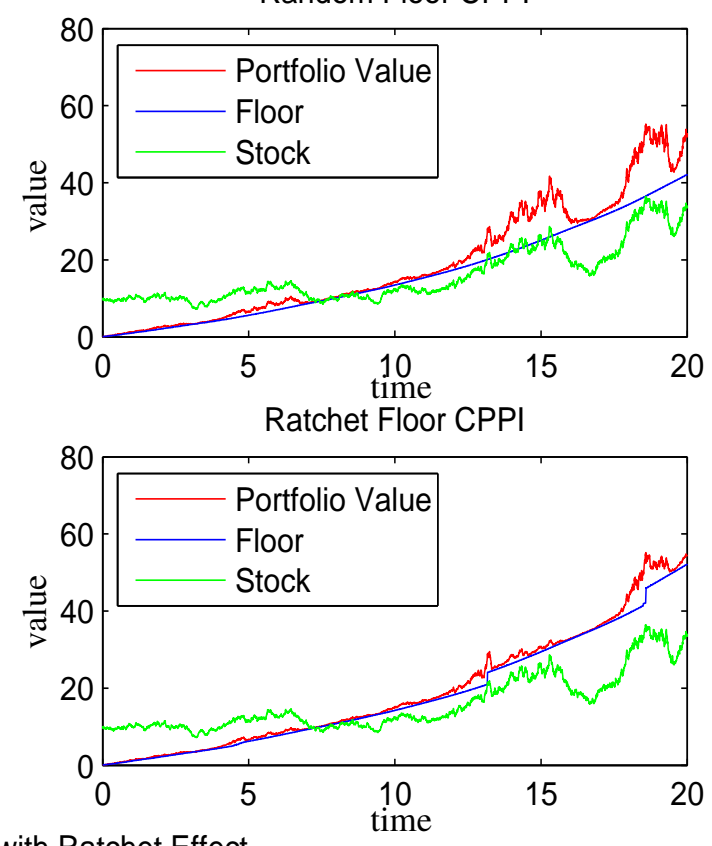

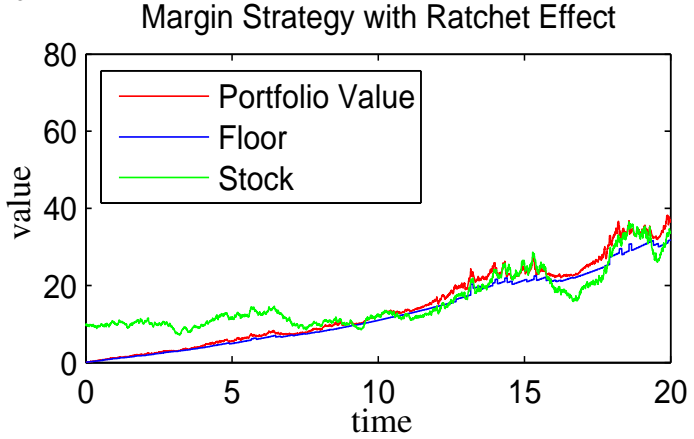

Figure 4.7: A trajectory for $m=6$ 

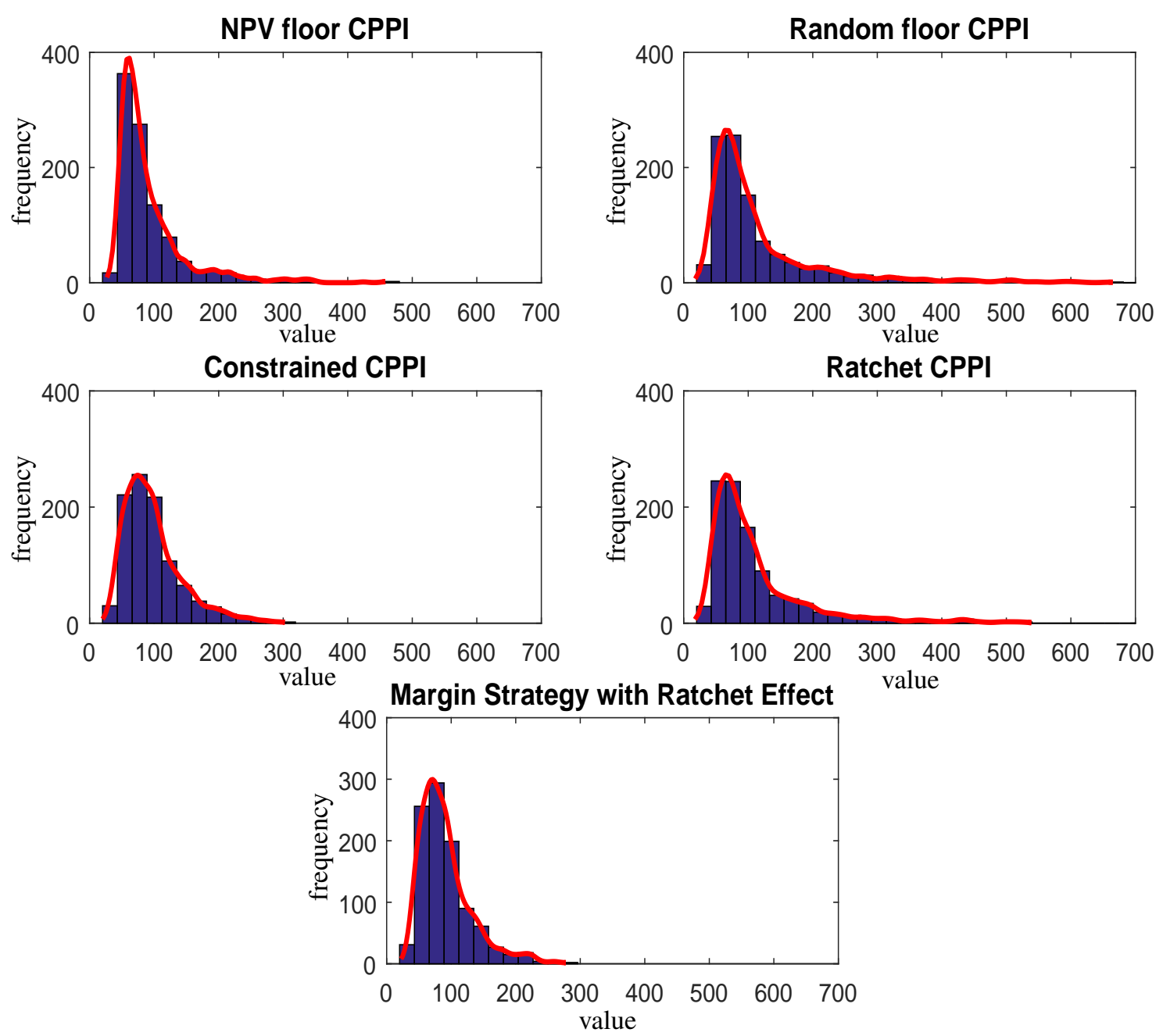

Figure 4.8: Terminal wealth densities for the parameters under a certain parameter set

Tail properties and the distributional behavior of terminal wealth for each strategy illustrated in Figure 4.8 verify the conclusions made for Table 4.2. Random floor and ratchet resemble the same behavior and extend to higher values of wealth. Constrained CPPI is the most conservative among others and short right tail indicates less volatility. The strategy offers poorer performance compared to others as a result of not being able to benefit from rising markets. Margin strategy with ratchet effect follows constrained as second less risky one. Among all strategies NPV floor which resembles the same variation pattern as the random floor yields the highest peak on moderate terminal wealth values, yet pertaining the long right tail. Therefore, NPV floor CPPI can be considered as a tolerable choice with a medium tail and moderately high profits for participants who commit to stay in the pension plan long enough to let the portfolio recover from initial negative status. 


\title{
CHAPTER 5
}

\author{
Conclusion
}

As defined-contribution type pension plans are becoming an essential part of the compulsory pension systems in many countries, in this thesis various constant proportion portfolio insurance (CPPI) strategies with different structures are introduced to defined-contribution pension plans where each investor makes consecutive stochastic payments based on their incomes. The labor income is modeled as stochastic process and contributions assumed to be a proportion of this income. The discontinuity coming from the incoming contribution payments is eliminated via pricing and shortselling the claim of future premiums. Considering two different floor processes; one being directly dependent on the stochastic contributions and the other being time zero value of the future payments, the optimal portfolio problem is formulated and solved under continuous-time trading. To ensure that there is no bias in the comparison, the optimal CPPI-multiplier is obtained for each guarantee framework. Through terminal wealth distributions and sensitivity analyses, performances of both strategies are compared portfolio efficiencies are discussed. Performances of each strategy are compared based on analytically computed risk measures and also through sensitivity analyses based on Monte-Carlo simulations. Moreover, kernel densities are estimated for terminal wealths which support the results of the sensitivity analysis. To further analyze the prominent risks which are ignored under continuous-trading and to study the appropriate hedging methods, the same problem is considered under discrete-time trading. Redefining the NPV and random floors in a way that they preserve their discrete structure and considering a new path-dependent set of floors, cash-lock and gap-risks are addressed and the relevant risk measures are computed. Specific variable CPPI strategies such as constrained CPPI, Ratchet CPPI and Margin CPPI with Ratchet effect are studied. With a detailed sensitivity analysis the effectiveness of each strategy is discussed and comparisons are made. Risks of the proposed CPPIs are analyzed and quantified through risk measures and sensitivity analyses. This thesis have theoretical and practical contributions, summarized below.

- By numerical illustrations, it is concluded that both strategies proposed for the continuous-time trading market can be preferred according to participants' expectations. While participants who would like to be in a hedged position should prefer the CPPI with net present value (NPV) floor, those who would like to go with the market should hold CPPI with random floor. Specifically, it is shown that the terminal wealth of the random floor CPPI has a higher mean than the 


\section{NPV floor strategy.}

- For the analytically tractable strategies that are considered under the assumption of discrete-time trading (NPV and random floor CPPI), it is found that random floor performs better by providing not only higher terminal wealths with positive upside deviation but also having lower local cash-lock and gap risks. This means that the portfolio will evolve above the guarantee level with a low probability of crashing through the floor. Also, with a lower cash-lock risk the portfolio has a small probability of being locked in the riskless asset and a potential excess gain at the retirement date.

- For the second set of variable floor CPPI strategies which includes also the first two floors a detailed sensitivity analysis is conducted through Monte-Carlo simulations. The analysis shows that ratchet floor is superior to the other variable floors due to the protection provided by the successive upwards adjustments performed on the floor.

- For the constrained CPPI, which is the case of a realistic constraint on exposure, the strategy loses the ability of taking advantage of increasing stock process and reflects lower probabilities of high gains.

- The margin strategy offers little positive effect on the performance and inhibits the effectiveness of ratchetings. The main issue is the very small initial margin amount that we encounter. To solve this problem, the margin process is modified and a new mechanism is proposed which creates small margins to be used later out of the ratcheted values. Although this mechanism solves the diminishing floor problem, it needs some ratchetings to be performed before any margin can be played.

- The behavior of random and ratchet strategies resemble each other which promises higher values of wealth. Constrained CPPI is the most conservative among others as its short right tail indicates low volatility. Hence, the strategy offers poorer performance as a result of not being able to benefit from rising markets. Margin strategy with ratchet effect follows constrained as second less risky one. Among all strategies NPV floor which resembles the same variation pattern as random floor yields the highest peak on moderate terminal wealth values, yet pertaining the long right tail. Therefore, NPV floor CPPI can be considered as a tolerable choice with a medium tail and moderately high profits for participants who commit to stay in the pension plan long enough to let the portfolio recover from initial negative status.

As future study, an effective margin mechanism independent from the guaranteed amount can be constructed. Moreover, jump dynamics can be introduced into the modelling to successfully mimic possible drops between re-balancement times; corresponding protection strategies can then be investigated. More general pension schemes such as hybrid pension plans including both defined-contribution and defined-benefit characteristics can be modeled with the approach presented in this thesis and are subjects of further research. Two possible candidates are CPPI portfolios with variable 
floors depending on the market conditions and analysis of strategies under discretetime trading. Application of the methodology to Turkish Individual Pension System to determine how accurate the model captures the pattern and growth of the fund under emerging financial markets. 


\section{REFERENCES}

[1] P. Albrecht and R. Maurer, Self-annuitization, consumption shortfall in retirement and asset allocation: the annuity benchmark, Journal of Pension Economics and Finance, 1, pp. 269-288, 2002.

[2] H. Ameur and P. J-L., CPPI method with a conditional floor, International Journal of Business, 16(3), pp. 218-230, 2011.

[3] A. Anderson, Pension mathematics for actuaries, Actex Publications, 2006.

[4] S. Balder, M. Brandl, and A. Mahayni, Effectiveness of CPPI strategies under discrete-time trading, Journal of Economic Dynamics \& Control, 33, pp. 204220, 2009.

[5] S. Balder and A. Mahayni, Cash-lock comparison of portfolio insurance strategies, Univ. Duisburg-Essen, 2010.

[6] R. Barakat, Sums of independent lognormally distributed random variables, The Journal of the Optical Society of America, 66, pp. 211-216, 1976.

[7] P. Battocchio and F. Menoncin, Optimal pension management in a stochastic framework, Insurance: Mathematics and Economics, 34(1), pp. 79-95, 2004.

[8] P. Battocchio, F. Menoncin, and O. Scaillet, Optimal asset allocation for pension funds under mortality risk during the accumulation and decumulation phases, Annals of Operations Research, 152(1), pp. 141-165, 2007.

[9] N. Beaulieu, A. Abu-Dayya, and P. McLane, Estimating the distribution of a sum of independent log-normal random variables, IEEE Transactions on Communications, 73(12), pp. 2869-2873, 1995.

[10] P. Bertrand and J.-L. Prigent, Portfolio insurance strategies: OBPI versus CPPI, Finance, 26(1), pp. 5-32, 2005.

[11] F. Black and R. Jones, Simplifying portfolio insurance, The Journal of Portfolio Management, pp. 48-51, 1987.

[12] D. Blake, Pension economics, John Wiley \& Sons, 2006.

[13] D. Blake, A. Cairns, and K. Dowd, Pensionmetrics: stochastic pension plan design and value-at-risk during the accumulation phase, Insurance: Mathematics and Economics, 29, pp. 187-215, 2001.

[14] D. Blake, A. Cairns, and K. Dowd, Pensionmetrics 2: stochastic pension plan design during the distribution phase, Insurance: Mathematics and Economics, 33, pp. 29-47, 2003. 
[15] P. Booth and Y. Yakoubov, Investment policy for defined contribution pension scheme members close to retirement: an analysis of the lifestyle concept, North American Actuarial Journal, 4(2), pp. 1-19, 2000.

[16] J. Boulier, S. Michel, and V. Wisnia, Optimizing investment and contribution policies of a defined benefit pension fund, Proceedings of the 6th AFIR International Colloquim, 1, pp. 593-607, 1996.

[17] J. Boulier, E. Trussant, and F. D., A dynamic model for pension funds management, Proceedings of the 5th AFIR International Colloquim, 1, pp. 361-384, 1995.

[18] J.-F. Boulier, S. Huang, and G. Taillard, Optimal management under stochastic interest rates: the case of a protected defined contribution pension fund, Insurance: Mathematics and Economics, 28, pp. 172-189, 2001.

[19] J.-F. Boulier and A. Kanniganti, Expected performance and risk of various portfolio insurance strategies, Proceedings of the 5th AFIR International Colloquium, 2005.

[20] A. Cairns, D. Blake, and K. Dowd, Optimal dynamic asset allocation for definedcontribution pension plans, Proceedings of the 10th AFIR International Colloquium, pp. 131-154, 2000.

[21] A. Cairns, D. Blake, and K. Dowd, Stochastic lifestyling: Optimal dynamic asset allocation for defined contribution pension plans, Journal of Economic Dynamics and Control, 30(5), pp. 843-877, 2006.

[22] N. Charupat and M. Milevsky, Optimal asset allocation in life annuities: a note, Insurance: Mathematics and Economics, 30, pp. 199-209, 2002.

[23] E. Davis, Pension funds: retirement-income security and capital markets: an international perspective, Oxford University Press, 1995.

[24] G. Deelstra, M. Grasselli, and P. Koehl, Optimal investment strategies in the presence of a minimum guarantee, Insurance: Mathematics and Economics, 33(1), pp. 189-207, 2003.

[25] G. Deelstra, M. Grasselli, and P. Koehl, Optimal design of a guarantee for defined contribution funds, Journal of Economic Dynamics and Control, 28(11), pp. 2239-2260, 2004.

[26] P. Devolder, M. Bosch-Princep, and I. Dominguez-Fabian, Stochastic optimal control of annuity contract, Insurance: Mathematics and Economics, 33, pp. 227238,2003

[27] L. Fenton, The sum of log-normal probability distibutions in scattered transmission systems, IEEE Trans. Commun. Systems, 8, pp. 57-67, 1960.

[28] J. Gao, Stochastic optimal control of DC pension funds, Insurance: Mathematics and Economics, 42, pp. 1159-1164, 2008. 
[29] S. Haberman and E. Vigna, Optimal investment strategy for defined contribution pension schemes, Insurance: Mathematics and Economics, 28(2), pp. 233-262, 2001.

[30] S. Haberman and E. Vigna, Optimal investment strategies and risk measures in defined contribution pension schemes, Insurance: Mathematics and Economics, 31(1), pp. 35-69, 2002.

[31] J. Harrison and D. Kreps, Martingales and arbitrage in multiperiod securities markets, Journal of Economic Theory, 20, pp. 381-408, 1979.

[32] J. Harrison and S. Pliska, Martingales and stochastic integrals in the theory of continuous trading, Stochastic Processes and their Applications, 11, pp. 215-260, 1981.

[33] R. Horsky, Barrier option pricing and CPPI-optimization, $\mathrm{PhD}$ Thesis, TU Kaiserslautern, 2012.

[34] M. Khorasanee, Deterministic modelling of defined-contributions pension funds, North American Actuarial Journal, 1(4), pp. 83-103, 1998.

[35] D. Knox, A critique of defined contribution plans using a simulation approach, Journal of Actuarial Practice, 1(2), pp. 49-66, 1993.

[36] R. Korn and E. Korn, Option Pricing and Portfolio Optimization, Vieweg Verlag, 2001 .

[37] R. Korn and H. Kraft, A stochastic control approach to portfolio problems with stochastic interest rates, SIAM Journal on Control and Optimization, 40(4), pp. 1250-1269, 2002.

[38] R. Korn and M. Krekel, Optimal portfolios with fixed consumption or income streams, Berichte des Fraunhofer ITWM, 31, 2002.

[39] P. Ludvik, Investment strategy for defined contribution plans, 4th AFIR International Colloquium, 3, pp. 1389-1400, 1994.

[40] T. O'Brien, A stochastic dynamic approach to pension funding, Insurance: Mathematics and Economics, 5, pp. 141-146, 1986.

[41] A. Perold and W. Sharpe, Dynamic strategies for asset allocation, Financial Analyst Journal, pp. 16-27, January-February 1995.

[42] S. Sbaraglia, M. Papi, M. Briani, M. Bernaschi, and F. Gozzi, A model for the optimal asset-liability management for insurance companies, International Journal of Theoretical and Applied Finance, 6(3), pp. 277-299, 2003.

[43] S. Schwartz and Y. Yeh, On the distribution function and moments of power sums with log-normal components, Bell System Technical Journal, 61(7), pp. 1441-1462, 1982.

[44] S. Shreve, Stochastic calculus for finance II: Continuous-time models, Springer, 2004. 
[45] H. Soner, Stochastic optimal control in finance, Cattedra Galileiana, Pisa: Scuola Normale Superiore, 2004.

[46] P. Tankov, Pricing and hedging gap risk, The Journal of Computational Finance, 3, pp. 33-59, 2010. 


\section{APPENDIX A}

\section{Fenton-Wilkinson Approximation Method.}

Fenton and Wilkinson [27] estimate the probability density function of a sum of lognormal random variables again using a log-normal distribution with the same mean and variance. The Fenton-Wilkinson approximation (often referred to as the FW method) is based on the assumption that the sum of independent log-normal random variables also has log-normal distribution. The method is often used in pricing Asian and basket options, and for a wide range of parameters has been shown to yield sufficiently accurate results compared to another pioneer method given in the literature, the Schwartz-Yeh (SY) method [43], (see [9]).

Let $X_{1}, X_{2}, \ldots, X_{N}$ be $N$ independent log-normally distributed random variables, i.e. $X_{i} \sim \mathcal{L N} \mathcal{N}\left(\mu_{i}, \sigma_{i}\right)$ for $i=1,2, \ldots, N$. Then, each $X_{i}$ can be written as $X_{i}=\exp \left(Y_{i}\right)$ where $Y_{i} \sim \mathcal{N}\left(\mu_{i}, \sigma_{i}\right)$. The general closed form expressions of the probability densitiy function and the cumulative densitiy function of the sum

$$
\sum_{i=1}^{N} X_{i}
$$

are not available. However, FW method suggests that this sum can be approximated by a new log-normal random variable $X \sim \mathcal{L N}(\mu, \sigma)$, and the new distribution can be specified by matching the moments of $X$ and the sum. While computing the risk measures presented in Section 4.4, we encounter the sum of two log-normal random variables. To specify this approximation method for our case and to introduce some further notation, we next present a simple special case.

Consider the summation $a X_{1}+b X_{2}$ where $X_{i} \sim \mathcal{L N}\left(\mu_{i}, \sigma_{i}\right)$ for $i=1,2$, and $a, b$ are real constants. By FW method, we approximate this sum with a log-normal random variable $X=\exp \{Y\}$ with $Y \sim \mathcal{N}(\mu, \sigma)$. Then, we have

$$
\begin{aligned}
\mathbb{E}(X) & =e^{\mu+\frac{1}{2} \sigma^{2}} \\
\mathbb{E}\left(X^{2}\right) & =e^{2 \mu+2 \sigma^{2}}
\end{aligned}
$$


On the other hand, matching the moments yields

$$
\begin{aligned}
\mathbb{E}(X) & =a \mu_{1}+b \mu_{2} \\
\mathbb{E}\left(X^{2}\right) & =a^{2} \mathbb{E}\left(X_{1}^{2}\right)+b^{2} \mathbb{E}\left(X_{2}^{2}\right)+2 a b \mu_{1} \mu_{2}
\end{aligned}
$$

Equations (A.2) and (A.3) leads to

$$
\begin{aligned}
\mu & =\ln \left(\frac{\left(a \mu_{1}+b \mu_{2}\right)^{2}}{\left(a^{2} \mathbb{E}\left(X_{1}^{2}\right)+b^{2} \mathbb{E}\left(X_{2}^{2}\right)+2 a b \mu_{1} \mu_{2}\right)^{\frac{1}{2}}}\right) \\
\sigma^{2} & =\ln \left(\frac{a^{2} \mathbb{E}\left(X_{1}^{2}\right)+b^{2} \mathbb{E}\left(X_{2}^{2}\right)+2 a b \mu_{1} \mu_{2}}{\left(a \mu_{1}+b \mu_{2}\right)^{2}}\right) .
\end{aligned}
$$




\section{CURRICULUM VITAE}

\section{PERSONAL INFORMATION}

Surname, Name: Temoçin, Büşra Zeynep

Nationality: Turkish

Date and Place of Birth: 07.09.1986, Adapazarı

Phone: +903122102987

Fax: +903122102985

\section{EDUCATION}

$\begin{array}{lll}\text { Degree } & \text { Institution } & \text { Year of Graduation } \\ \text { M.S. } & \text { Middle East Technical University } & 2010 \\ \text { B.S. } & \text { Ankara Gazi University } & 2008 \\ \text { High School } & \text { Ankara Gazi Anatolian High School } & 2004\end{array}$

\section{PROFESSIONAL EXPERIENCE}

$\begin{array}{lll}\text { Year } & \text { Place } & \text { Enrollment } \\ \text { 2009-2010 } & \text { Middle East Technical University } & \text { Research Project Assistant } \\ \text { 2010-2011 } & \text { Ankara University } & \text { Research Assistant } \\ \text { 2011-2014 } & \text { Middle East Technical University } & \text { Research Assistant } \\ \text { 2014-2015 } & \text { Fraunhofer ITWM } & \text { Visiting Researcher }\end{array}$

\section{PUBLICATIONS}

- Y. Yolcu Okur, B. Z. Temocin, A. Hayfavi, Pricing and completion in a Lévy market model with Teugel martingales, Hacettepe Journal of Mathematics and Statistics, 41(5), 767 - 783.

- B. Z. Temocin, G. Weber, Optimal control of stochastic hybrid system with jumps: A numerical approximation, Journal of Computational and Applied Mathematics, $259443-451$. 
- B. Z. Temocin, R. Korn, S. Selcuk-Kestel Constant Proportion Portfolio Insurance in Defined Contribution Pension Plan Management (submitted to Insurance: Mathematics and Economics, 2015)

- B. Z. Temocin, R. Korn, S. Selcuk-Kestel Constant Proportion Portfolio Insurance in Defined Contribution Pension Plan Management under Discrete-Time Trading (submitted to Annals of Operations Research, 2015)

\section{Abstracts in International Conferences}

- B.Z. Temocin, N. Azevedo, D. Pinheiro and G.-W. Weber, Stochastic hybrid systems and applications in finance, New Developments in Theory and Applications of Statistics: An International Conference Dedicated to the Memory of Moti Lal Tiku, Ankara, Turkey, May 2-4, 2011.

- B. Z. Temocin, S. Kestel, Premium effciency on the compulsory earthquake insurance in Turkey, International Congress on Insurance: Mathematics and Economics, Trieste, Italy, June 14-17, 2011.

- B. Z. Temocin, G.-W. Weber, Optimal control of stochastic hybrid system with jumps: a numerical approximation, International Conference on Applied and Computational Mathematics, Ankara, Turkey, Oct 3-6, 2012.

- B. Z. Temocin, S. Kestel, Pension fund management for Turkish individual retirement system, 26th European Conference on Operational Research Rome, Italy, July 1-4, 2013.

- B. Z. Temocin, R. Korn, S. Kestel, Constant Proportion Portfolio Insurance in Defined-Contribution Pension Plan Management, SIAM Conference on Financial Mathematics \& Engineering, Chicago, USA, Nov 13-15, 2014. 